\title{
THE INFLUENCE OF MOSQUITO PREDATORS ON POPULATION DYNAMICS OF ENDEMIC AND EXOTIC MOSQUITOES
}

By

Wan Fatma Zuharah Wan Musthapa

\author{
A thesis \\ Submitted to the Victoria University of Wellington \\ In fulfillment of the requirements for the degree of \\ Doctor of Philosophy \\ In Ecology \& Biodiversity
}

Victoria University of Wellington

2010 


\begin{abstract}
The presence of predators can shape the population dynamics of prey. Here, I evaluated the influence of predators on mosquito populations by direct effects through predation, and indirect effects through sub-lethal responses. The predator under investigation was the backswimmer Anisops wakefieldi.

I first quantified the relationship between mosquito and predator populations in animal drinking water troughs, and correlated their abundance with water volume and environmental factors. Logistic regression indicated that the presence of mosquitoes was primarily affected by three factors; predator numbers, week of observation, and water volume. A translocation experiment was established to understand the pre- and post-treatment effects on mosquito survival after exposure to the predator Anisops wakefieldi. The presence of these predators in water troughs significantly decreased subsequent survival of mosquito prey within two days posttranslocation.
\end{abstract}

A major hypothesis in invasion ecology suggests that native predators have less impact on exotic species relative to native prey species, enabling exotic species to establish and thrive in novel environments. This is the "escape from natural enemies" hypothesis. Contrary to this hypothesis $A$. wakefieldi, a native New Zealand predator, showed a greater preference, and consumed more of the exotic mosquito Aedes (Ochleratatus) notoscriptus compared to the native (Culex pervigilans) mosquito larvae. 
Anisops wakefieldi exhibited a decelerating Type II functional response for both prey species, but consumed more exotic mosquito species at high prey densities and displayed higher attack rates. The effects of the preference of this predator on mosquito behaviour were examined. In the presence of predators the exotic species, Ae. notoscriptus, demonstrated significantly higher levels of "thrashing" behaviours, apparently making itself more obvious to the predators. In contrast $C x$. pervigilans fulfilled the "threat sensitivity" hypothesis by altering its behaviour towards "resting", known to be the best strategy for avoiding predators.

In addition to lethal effects, predators can substantially alter prey populations by means of sub-lethal influences. To further our understanding of how predators limit mosquito abundance, I developed an experiment based on adult mosquito oviposition. I predicted that the New Zealand native mosquito, Cx. pervigilans would likely avoid containers with $A$. wakefieldi or their kairomones. Contrary to our predictions, Cx. pervigilans appeared to ignore the presence of predators and their kairomones when choosing oviposition habitats and the number of egg rafts was not significantly affected by the density of predators.

Culex pervigilans eggs from the oviposition experiment were reared in two different laboratory conditions: $(A)$ in clean water without any traces of predators, or $(B)$ in water with the same treatments as in field. This experiment was established in order to have better understand on what happens to the next generation after exposure to $A$. wakefieldi predators or their kairomones. Sub-lethal effects were still apparent in the developing 
larvae. I observed a significant reduction in the survival rate of $C x$. pervigilans in the presence of predators and their kairomones, even when the eggs were only exposed briefly to water containing either predators or kairomones in the field, and were then reared in clean water without any traces of the predator. No effect was observed on the sex ratio of $C x$. pervigilans, or the development times of each life stage.

Overall, this thesis has highlighted the importance of predators in influencing mosquito populations, not only through direct predation, but also in indirect and sub-lethal ways. This study may have implications for the dynamics of other predator-prey systems. Despite this, we are only beginning to understand the complex interactions between predators and prey. 


\section{ACKNOWLEDGEMENTS}

My sincere thanks to all the people who have contributed to and worked on this dissertation during the past three years.

My special thanks to my supervisor, Associate Professor Phil Lester for the guidance, support, encouragement, inspiration and patience throughout my Ph.D. journey. I would also like to express my gratitude to my second supervisor, Dr. Nicole Phillips for the idea and guidance for my project.

Thanks for the tremendous support, advice and warm friendship from all friends and staffs within the School of Biological Sciences at Victoria University of Wellington. Also to the member of "Bug Club" for sharing the ideas and knowledge. Thanks to Catherine Duthie for the thesis editing and comments.

My project would not have been possible without the permission for conducting experiment received from Rewi Elliot (Otari-Wilton's Bush) and Nikki LaMonica (Queens Elizabeth Park II). Thanks for the equipment assistance provided by Vector Control Research Unit, Universiti Sains Malaysia. Three anonymous reviewer provided comments which greatly strengthened the Chapter 2 (In press in Journal of Vector Ecology), Chapter 3 (In press in Population Ecology) Chapter 4 (published in Journal of Vector Ecology), Chapter 5 (In press in Population Ecology) and all that have provided critical review of this work in manuscripts and in seminars. 
I am also grateful for the financial support given to me by various funding bodies: the Ministry of Higher Education Malaysia, Universiti Sains Malaysia, Victoria University of Wellington, Faculty Strategic Research Grant, and PhD Submission Scholarship; without which this project would have not been possible.

Finally, I wish my sincere grateful to my husband, Nik Fadzly and my blessing son, Nik Adam Farees for the unwavering support, understanding and assistance till the end of my Ph.D. journey. Also my parents, sisters and brothers for their encouragement and support. I'm forever grateful and thankful to all of you! 


\section{TABLE OF CONTENTS}

Page

Abstract........................................................... i

Acknowledgements.......................................... iv

Table of content................................................... vi

List of figure..................................................... $\quad x$

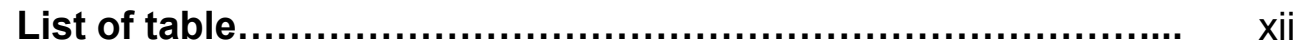

1 General Introduction........................................... 1

1.1 Introduction to mosquitoes............................. 2

1.1.1 Mosquito lifecycle............................. 3

1.2 Mosquitoes in New Zealand.............................. 6

1.3 Successful factors of mosquito invasions in New Zealand...... 8

1.4 Risks of mosquito borne diseases for New Zealand............ 8

1.5 Mosquito predators in New Zealand......................... 11

1.6 Predator-prey interaction in shaping population dynamics..... 11

1.7 Lethal effects of predators on mosquitoes.................. 13

1.8 Sub-lethal effects of predators on mosquitoes................ 14

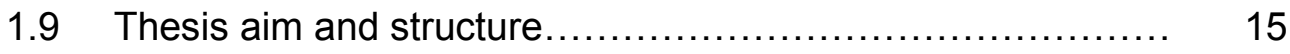

2 The influences of aquatic predators on mosquito abundance in 19 animal-drinking troughs in New Zealand...........................

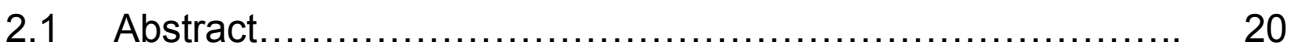

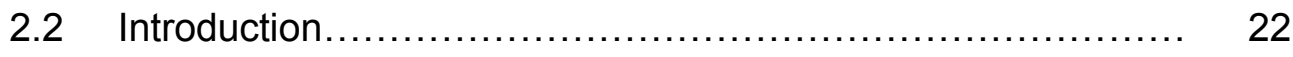

2.3 Materials and methods.................................. 24 


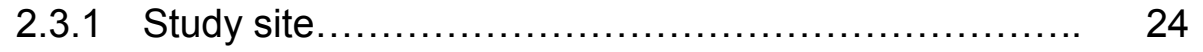

2.3.2 The relationship between predator and mosquito $\quad 25$ populations.

2.3.3 Predator translocation experiment....................... 26

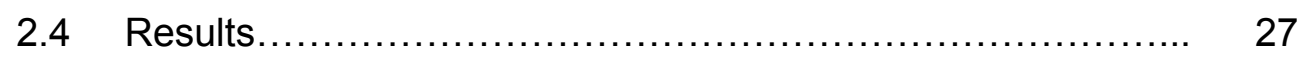

2.4.1 The relationship between predator and mosquito $\quad 27$ populations ...............................................

2.4.2 Predator translocation experiment........................ 33

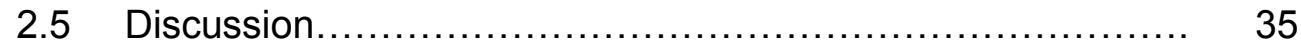

3 Are exotic invaders less susceptible to native predators? A $\quad 39$ test using native and exotic mosquito species in New Zealand.

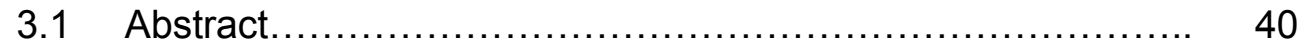

3.2 Introduction..................................................... 42

3.3 Materials and methods ..................................... 46

3.3.1 Predator and prey colonies............................ 46

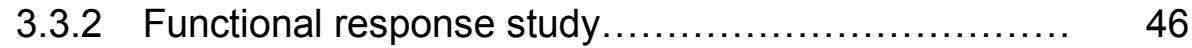

3.3.3 Attack rate and handling time using two methods........ 50

3.3.4 Prey preferences and prey switching........................... 50

3.3.5 Predator avoidance behavior............................ 52

$3.4 \quad$ Results........................................................ 54

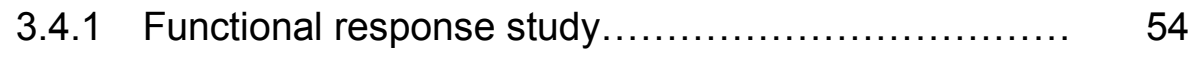

3.4.2 Prey preferences and prey switching study ............. 59

3.4.3 Predator avoidance behavior............................ 62

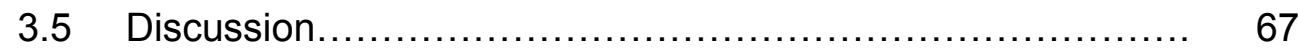


4 Can adults of the New Zealand mosquito Culex pervigilans

(Bergorth) detect the presence of a key predator in larval

habitats?

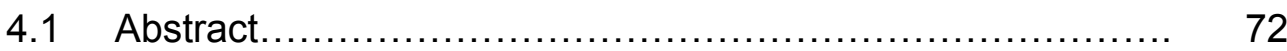

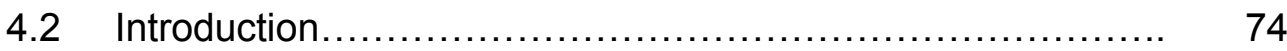

4.3 Materials and methods $\ldots \ldots \ldots \ldots \ldots \ldots \ldots \ldots \ldots \ldots \ldots \ldots \ldots, 77$

4.3.1 Study sites........................................ 77

4.3.2 Predator colonies.................................. 77

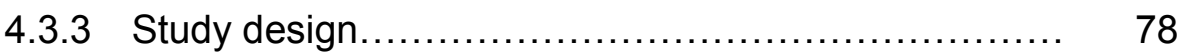

4.3.4 Statistical analysis .................................. 80

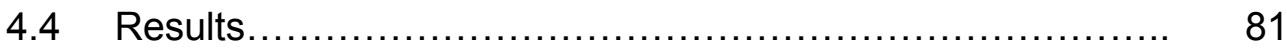

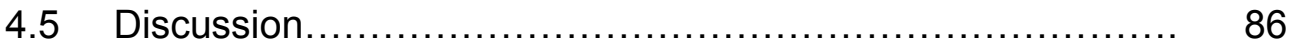

5 Sub-lethal exposure of prey to predators substantially 90 influences the survival rate and life history traits of a mosquito

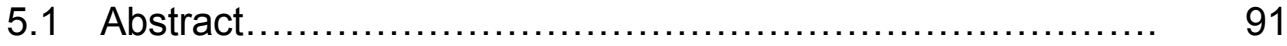

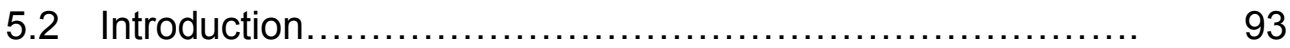

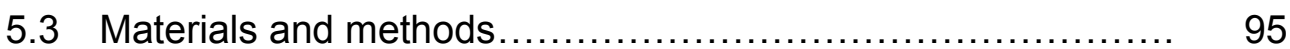

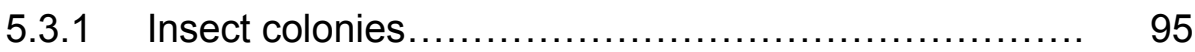

5.3.2 Life-history influence of predators at the time of 97

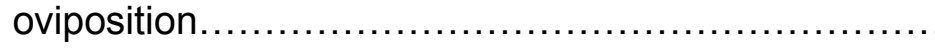

5.3.3 Life-history influence of predators throughout 99

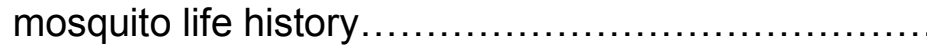


5.4.1 Life-history influence of predators at the time of oviposition.

5.4.2 Life-history influence of predators throughout mosquito life history.

5.5 Discussion

6 General Discussion

6.1 Do predators influence mosquito population?

6.2 What are the major mechanisms by which predator influence

122 mosquito population?

6.3 The variable role of sub-lethal effects of predators on mosquito populations.

6.4 Future research.

Appendices

A Abstract from The $25^{\text {th }}$ Annual Meeting of The Society of Population Ecology

B Abstract from The $58^{\text {th }}$ Annual Conference of the Entomological Society of New Zealand

C Zuharah WF and Lester PJ (2010) Can adult of New Zealand mosquito Culex pervigilans (Bergorth) detect the presence of a key predator in larval habitat? Journal of Vector Ecology. 35(1): 100-105

D Zuharah WF and Lester PJ (2010) The influence of aquatic predators on mosquito abundance in animal drinking troughs in New Zealand. Journal of Vector Ecology. 35(2): (In Press).

References. 


\section{LiST OF FIGURES}

\section{Figure Abbreviated Caption $\quad$ Page}

\section{Chapter One}

$1.1 \quad$ Four distinct stages of the mosquito life

cycle

\section{Chapter two}

2.1 Example of the relationship between predators and mosquitoes in water troughs

2.2 Logistic regression between mosquito in association with predator abundance.

2.3 Abundance of mosquito larvae, predators and association to water volume

2.4 Effects of predator on mosquito survival in translocation experiment after 2 days of post-treatment

\section{Chapter Three}

3.1 Type II functional response displayed by $A$. wakefieldi on two mosquito species

3.2 The preferences of $A$. wakefieldi for exotic species in compared to native species

3.3 Switching behavior by $A$. wakefieldi when two mosquito species were offered

$3.4 \quad$ Behavior displayed by Cx. pervigilans in $200 \mathrm{ml}$ and $500 \mathrm{ml}$ of seasoned water

\section{Chapter Four}

4.1 Effects of predator treatments and densities on number of Cx. pervigilans egg rafts. 


\section{Chapter Five}

5.1 Egg hatching rates in the absence or presence of the 102 predator $A$. wakefieldi...................................

5.2 The development time needed by eggs that were 105 exposed to the predators or kairomones in the field

5.3 The influence of the presence of predators at the time of 106 oviposition by adult mosquitoes on the survival rate of developing mosquitoes

$5.4 \quad$ The influence of direct exposure to the presence of predators or kairomones on development time of stagespecific progeny....

5.5 Survival rate of developing Cx. pervigilans mosquito progeny until adult death after eggs were hatched and larvae were reared in the water with the presence of predators or kairomones 


\section{LIST OF TABLES}

Table Abbreviated Title

Page

\section{Chapter Two}

2.1 Logistic regression analysis that effects mosquito population in water trough.

2.2 Pearson correlation between mosquito, predator, environmental factors and water volume

\section{Chapter Three}

3.1 Maximum likehood estimates of the logistic regression of mosquito proportion eaten by $A$. wakefieldi predator............

3.2 Comparison between the attack rate and handling

time

3.3 Results for multinomial logistic regression model for mosquito species, types of treatment, activities and positions in two different water volumes.

\section{Chapter Four}

4.1 Results from repeated measures ANOVA on Cx. pervigilans egg rafts in response to various treatments and predator densities.

4.2 Pearson correlation analysis between environmental factors and $C x$. pervigilans egg rafts

\section{Chapter Five}

5.1 Results from Chi-square test for mosquito adult sex ratio. 
5.2 Pairwise comparison using log-rank test in order to test the differences between survival rates of treatments at

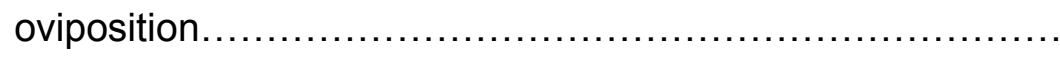

5.3 Log-rank test results to test the differences of survival rates after eggs were collected from field experiments and reared in same condition as in field 


\section{CHAPTER ONE:}

\section{General Introduction}


There is concern that the establishment of exotic and invasive mosquito species may increase the risk of infectious disease to humans occurring in New Zealand. The overall goal of this thesis is to investigate the influence of predators on mosquito population dynamics. To achieve this aim, I focused my study on the lethal and sub-lethal effects of the native predator, Anisops wakefieldi, on the endemic mosquito, Culex pervigilans. I also examined the interaction between this predator and the exotic mosquito, Aedes notoscriptus.

\subsection{Introduction to mosquitoes}

Mosquitoes are known as the most important disease vectors in the world because of their ability to carry various pathogenic agents such as viruses, protozoa and helminthes. Mosquitoes have a worldwide distribution; they occur throughout tropical and temperate regions, and their range extends northwards into the Arctic Circle, they are only absent from Antarctica. Anopheles, Culex, Aedes, Ochlerotatus, Psorophora, Haemagogus, Mansonia and Sabethes are a few of the most important genera that can be vectors for a variety of diseases. There are a total of 41 genera in the family Culicidae, containing 3450 known species and subspecies of mosquitoes. Culicidae can be divided into three subfamilies; Toxorhynchitinae, Anophelinae and Culicinae (Service 1996, Service 2004).

Anopheles species are well known vectors for malaria, Filariasis (Wuchereria bancrofti, Brugia malayi and Brugia timori) and other arboviruses. Certain Culex species can transmit Wuchereria bancrofti and a variety of arboviruses. Arboviruses are a class of virus transmitted to humans 
or animals by arthropods such as mosquitoes and ticks. The first two letters of the words arthropod and borne, make up the 'arbo' that now designates this group of viruses as arthropod-borne. Aedes species are important vectors of yellow fever, dengue, encephalitis viruses and many other arboviruses, and they are also vectors of Wuchereria bancrofti and Brugia malayi. Filariasis and encephalitis viruses are also transmitted by mosquitoes that are closely related to Aedes (Ochlerotatus) species. Mansonia species transmit Brugia malayi and sometimes Wuchereria bancrofti and a few arboviruses. Haemagogus and Sabethes mosquitoes are vectors of yellow fever and other arboviruses in Central and South America, while the genus Psorophora contains some troublesome pest species in North and South America. However, many species of mosquito do not carry disease but are a biting nuisance and pose other problems to humans and animals (Service 1996, Service 2004).

\subsubsection{Mosquito lifecycle}

Mosquito pass through four distinct stages in their lifecycle; eggs, larva, pupa and adult (Figure 1.1). Eggs are laid either singly or in rafts, within 2 to 3 centimeterson the water surface or undersides floating vegetation (Service 2000; 2004). Some mosquitoes may lay their eggs on vegetation in the water. Within 1 or 2 hours after the eggs are laid, the endochorion of the shell changes from a soft white layer to a hard dark one (Fay 1964). According to Weissman-Strum and Kindler (1963), it is possible to divide the process of hatching into two distinct stages. The first stage is the breakdown of the water impermeable barrier which is most likely due to 
the action of the pro larvae and the second stage is the influx of water to the larvae with concomitant swelling and emergence from the shell.

There are four stages, or instars, in the mosquito larvae. Normally, the third and fourth instar larvae are used in efficacy studies because of their stable biology and susceptibility (Busvine 1971). The pupae have commashaped bodies divisible into two distinct regions. The front region consists of the head and thorax (cephalothorax) and is greatly enlarged. It bears a pair of respiratory trumpets to take in oxygen. The second region is the abdomen which has freely-movable segments with a pair of paddle like appendages at the tip. Feeding does not take place during the pupal stage (Blackmore and Lord 2000).

When maintained on a carbohydrate restricted diet, most adult female mosquitoes are likely to produce eggs after ingesting a blood meal (Klowden 1993). Adult mosquitoes emerging from habitats with insufficient nutrients may lay eggs that are programmed to go into early diapause. Oogenesis is initiated in about $20 \%$ of the mated population even when as little as $0.1 \mu$ of blood was ingested (Pumpuni et al. 1992). Large females ingest more than twice the blood volume of small females and their fecundity quadruples (Briegel 1990). 


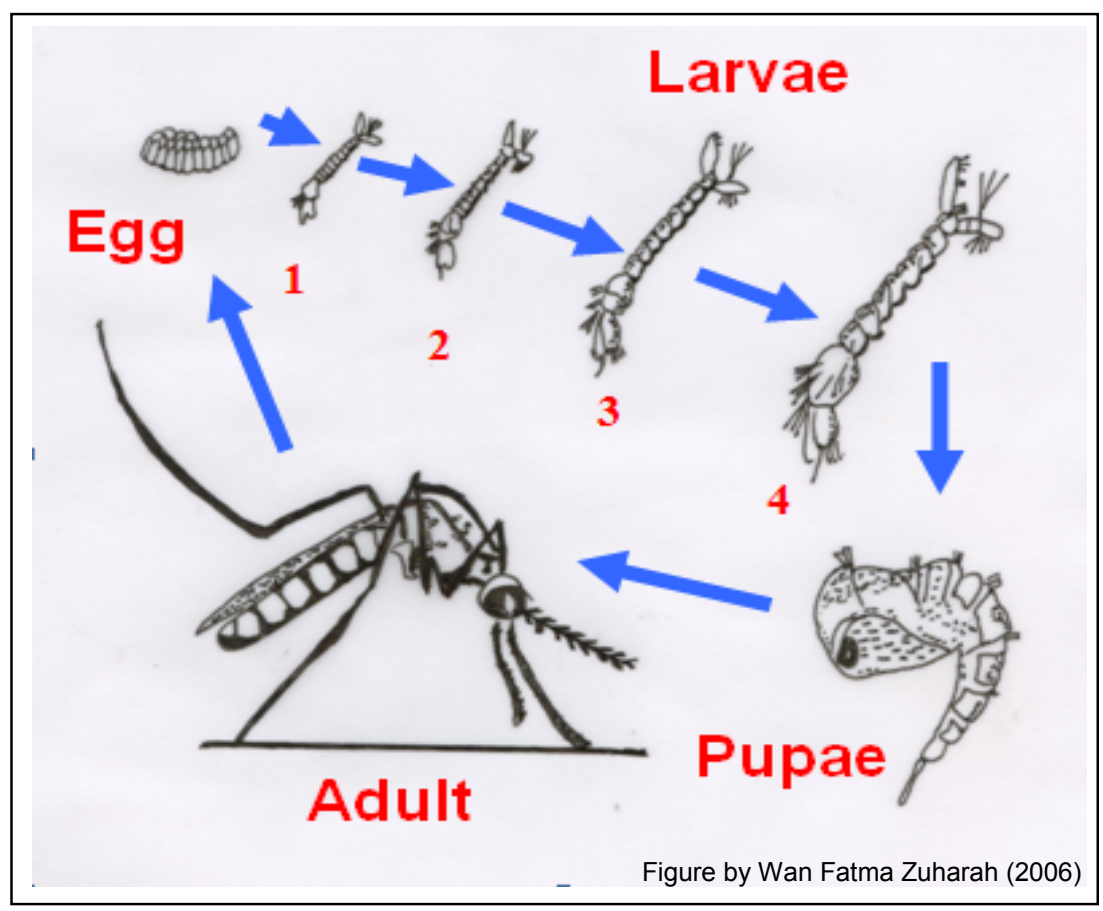

Figure 1.1: Four distinct stages of the mosquito life cycle. There are four instars of larval development in mosquitoes and one non-feeding stage in the pupa.

Most mosquito species survive winter, or overwinter, in the egg stage, awaiting the spring thaw, when waters warm and the eggs hatch. A few important species spend the winter as adult, mated females, resting in protected, cool locations, such as cellars, sewers, crawl spaces, and well pits. With warm spring days, these females will seek blood sustenance and begin the cycle again. Only a few species can survive overwinter as larvae (Service 2004). 


\subsection{Mosquitoes in New Zealand}

Before the arrival of humans, New Zealand had only 12 indigenous species. Since the arrival of humans in New Zealand, approximately 800 years ago, the abundance of exotic species has increased rapidly. The invasion rates have increased since European settlement and the arrival of goods and passengers (Derraik 2004a). As of 2004, it has been estimated that New Zealand has 12 endemic and 4 exotic mosquito species (Russell 1995, Snell 2005). The endemic mosquito species in New Zealand are Coquillettidia (Austromansonia) tenuipalpis, Coquillettidia (Coquillettidia) iracunda, Culex (Culex) asteliae, Culex (Culex) pervigilans, Culex (Culex) rotoruae, Culiseta (Climacura) novaezealandiae, Culiseta (Climacura) tonnoiri, Maorigoeldia argyropus, Ochleratatus (Nothoskusae) chatamicus, Ochleratatus (Ochleratatus) antipodues, Ochleratatus (Ochleratatus) subalbirostris and Opifex fuscus. The four exotic species are Culex (Culex) quinquefasciatus, Aedes (Ochleratatus) (Finlaya) notoscriptus, Ochleratatus (Halades) australis and Ochleratatus (Ochleratatus) camptorhynchus (Derraik 2004a).

Since European settlement, 3 out of the 4 exotic mosquito species are believed to have established in New Zealand. Culex quinquefasciatus Say, native to the warmer parts of Africa, was first collected in New Zealand in 1848. Aedes (Ochleratatus) notoscriptus was first collected in Auckland in 1916 during World War I. The third exotic mosquito species, Ochleratatus (Halades) australis was discovered only three decades ago in 1962. These mosquitoes were accidentally transported aboard sailing vessels and dispersed along the North Island's east coast and the South Island. Aedes 
(Ochleratatus) notoscriptus was more successful than Culex quinquefasciatus in colonizing New Zealand, probably because it can adapt to low temperatures and has radiated into varied and widely dispersed larval niches. The latest exotic mosquito found in New Zealand is Ochleratatus (Ochleratatus) camptorhynchus, originating from Australia, it was discovered on the east coast of the North Island in 1998 (Derraik 2004a; 2004b, Laird 1990, Laird 1995, Weinstein et al. 2007).

There is a possibility of new mosquito species entering New Zealand by accidental introduction. At least 30 other exotic culicid species have been intercepted at national entry posts, including the Asian tiger mosquito, Aedes albopictus, which is a vector of dengue fever (Derraik 2006). In May and September 1929, a new mosquito species Anopheles maculipennis, was reported to have reached Auckland from Indonesia aboard a shipping vessel. The possible introduction of Anopheles species, a malaria vector, represents a real danger in temperate country such as New Zealand (Laird 1990). However, no cases of malaria transmission have yet been reported in New Zealand as Anopheles maculipennis is not yet been established in New Zealand. MAF Biosecurity New Zealand has carried out over 11 years of the eradication programs involved helicopter and ground treatment, sampling and trapping using using S-methoprene granules and Bacillus thuringiensis. Due to these eradication programs, that the later exotic mosquito species may soon be declared. 


\subsection{Successful factors of mosquito invasions in New Zealand}

Human activities have been causing dramatic and unpredictable changes for the Earth's ecosystem. As a result, a growing number of disease outbreaks have occurred, including mosquito borne disease. The New Zealand landscape has suffered dramatic changes since the arrival of humans, leading to extensive habitat destruction, extinction of native species and the introduction of exotic species (Cook et al. 2002, Derraik and Slaney 2007). Williams et al. (2005) predicted that climate changes in Australia and New Zealand will lead to the presence of new mosquito species such as Culex gelidus.

There are several other characteristics of exotic mosquito species that contribute to their success in non-native habitats. For example; rapid growth, short lifespan, high fecundity, the ability to utilize a broad range of habitats, association with human activity and fewer natural enemies are several factors that will determine their likelihood of establishment (Griswold and Lounibos 2005). New Zealand's species poor mosquito fauna and high level of anthropogenic environmental disturbance make it particularly vulnerable to invasion by exotic mosquitoes (Derraik 2004a). The apparent underutilization of larval breeding habitats may also encourage exotic mosquitoes to establish in New Zealand (Crump et al. 2001, Laird 1990, Laird et al. 1994).

\subsection{Risks of mosquito borne diseases for New Zealand}

The human population in New Zealand has not yet experienced any outbreaks of mosquito borne diseases. However, their potential involvement in local disease transmission has been recently highlighted. Exotic mosquito 
species have demonstrated vector competence for human arboviruses (Derraik and Slaney 2007, Weinstein et al. 1997, Weinstein et al. 2007). The rapid modern movement of people, the consequent routine arrival of infected people, exotic arthropods, and increasing international trade and commerce are likely to increase New Zealanders chances of contracting mosquito borne disease (Derraik 2004a, Derraik 2004b, Derraik and Calisher 2003, Laird 1990, Spurr and Sandlatt 2004, Weinstein et al. 1997).

All of the four exotic species of mosquitoes in New Zealand are known as vectors for mosquito borne diseases in other parts of the world. Culex (Culex) quinquefasciatus is known to be a West Nile Virus vector overseas (Derraik 2004a). This mosquito is believed to have originated in America. As of 2004, Spurr and Sandlatt (2004) reported that at least 30 bird and 16 mammals, especially introduced species in New Zealand, are susceptible to the West Nile Virus. This mosquito can cause irritation and discomfort because they feed on mammals (including humans). Given that New Zealand has many proven avian and mammalian hosts of the West Nile Virus, the risk of infection in this country is quite high, provided that this virus can overwinter here. Culex (Culex) quinquefasciatus has also been proven to be a vector for Murray Valley encephalitis virus in the laboratory and Ross River Virus (Lindsay et al. 1993, McLean 1953, Weinstein et al. 2007).

The natural Australian habitats of larval Ae. notoscriptus are tree hole and rock pool environments. However, after they became established in New Zealand, this mosquito has made the shift from natural to artificial containers. The establishment of Ae. notoscriptus was likely facilitated by a lack of competition from native species, and mosquito larval habitats that were 
considerably underutilized (Laird 1990). Because of their establishment, infection by the avian Whataroa virus has a possibility of occurring in humans. However, no human cases of infection with Whatoroa virus has been recorded even though this mosquito is capable of harboring the virus under laboratory conditions (Lee et al. 1982, Weinstein et al. 2007). This mosquito is also known to be a vector for Yellow fever, Dengue fever, Murray Valley encephalitis, Ross River Virus, Japanese encephalitis and Barmah Forest virus (Derraik and Calisher 2003, van der Hurk et al. 2003, Watson and Kay 1998, Weinstein et al. 2007).

Due to high number of viraemic people entering New Zealand, the abundance of possums, and the presence of Oc. camptorhynchus, the transmission of River Ross Virus within New Zealand is possible. In 2001, annual infection rates of Ross River Virus and Barmah Forest virus in Queensland ranged between 48.4- 423.5 and 3.8- 40.4/ 100,000 respectively. It has been estimated that more than 100 viraemic travelers may enter New Zealand from Queensland each year (Kelly-Hope et al. 2001). Ross River virus is the most common mosquito-borne pathogen affecting humans in Australia and seems likely to occur sooner rather than later in New Zealand (Derraik and Calisher 2003).

One of the exotic mosquitoes, Oc. australis, has not been considered a significant threat, in the public health context, other than as a potential vector of Ross River virus. This is because they do not have a sufficiently close relationship with humans. As an adult, it is autogenous and capable of oviposition without a blood meal (Weinstein et al. 2007). Very little research 
has been done on New Zealand's endemic mosquito species, thus their vector capability is largely unknown.

\subsection{Mosquito predators in New Zealand}

Mosquito larvae are prey for a wide variety of aquatic organisms. Invertebrate predators directly or indirectly influence mosquito population dynamics. Backswimmers and Dysticid beetles are the most common and abundant predators (Graham 1939). Predators in the family Corixidae are occasionally found in water bodies. Backswimmers, Notonecta spp., are highly predaceous and can consume large numbers of mosquito larvae (Gilbert and Burns 1999). Their presence in water bodies can significantly reduce oviposition by adult mosquitoes (Blaustein et al. 1995). Diving beetle and damselfly larvae are often observed in water bodies and have been known as aquatic predators of mosquitoes in New Zealand. However, their effects on mosquito population dynamics have not been studied previously (Lester and Pike 2003).

Flightless predator morphs are well-suited to keep stock-trough water containers relatively or totally free from mosquito larvae (Laird 1990). Young (1970) stated that flightlessness and polymorphism might have considerable practical value in limiting mosquito populations.

\subsection{Predator-prey interaction in shaping population dynamics}

Ecological communities are collections of species that co-occur in space and time and interact with one another. The main objective of studies 
of ecological communities is to better understand the pattern within and among these collections of species and the processes that generate those patterns. Many metrics have been used to search for patterns in community 'structure', including the number of species, absolute and relative abundances, the type of species present (e.g. guilds, trophic levels) and their phenotypic properties (e.g. body size, morphological attributes, physical tolerances, behavioral responses). Many processes can shape patterns in these metrics of community structure, including the supply of energy and materials, environmental tolerances (e.g. abiotic limits, disturbance), direct interactions among species (e.g. interference competition, predation, mutualism, disease, parasitism), indirect effects of direct interactions transmitted through intermediate species (e.g. exploitative competition), migration and dispersal and historical contingencies (McPeek and Miller 1996).

More recently, community ecologists have recognized the way in which controphic species can indirectly interact with each other when embedded in complex communities. Interference competition, exploitive competition, apparent competition or mutualism, indirect mutualism, intraguild predation and keystone predation are six mechanisms that illustrate the rich diversity of effects in shaping communities (Blaustein 1998, Blaustein and Chase 2007).

Apparent competition occurs when two (or more) prey species share a common predator, and the predator's numbers are limited by prey availability. The second prey species enables the abundance of the predator to increase by becoming an additional food source, and as a result reduces 
the density of the target species (Holt 1977). This situation also occurs when there is competition for enemy free space, in which the prey are confined to using certain sources (e.g. refuges, food type) in the presence of predators. The species can limit each others' numbers if more than one prey is present and both utilize enemy-free resources (Blaustein and Chase 2007). This interaction occurs when predator and prey share the same trophic level. However, the roles of controphic species of mosquito larvae in affecting mosquito populations have received little attention.

\subsection{Lethal effects of predators on mosquitoes}

The functional response has been utilized extensively as a tool to assess the potential of natural enemies to control prey or pest species (Lester et al. 1999). This is the relationship between the density of prey in a certain area and the average number of prey consumed by each predator in that area. The functional response of the target prey is dependent on the predator, life-stage and species of an alternative prey. Prey factors that influence prey selection are suggested to include size, mobility, defense or avoidance characteristics, palatability, abundance, and the extent of overlapping prey and predator habitats.

The presence of alternative prey in same water body can affect the number of target prey eaten by predators. One obvious effect is that the pursuit, capture and consumption of alternative prey reduce the encounter time available for predators towards the target prey (Chesson 1989). But if an alternative prey species is more abundant, predators may develop a 
search pattern resulting in a preference for the more common species (Murdoch and Oaten 1975, Tschanz et al. 2007).

\subsection{Sub-lethal effects of predators on mosquitoes}

Prey behavioral responses to predators may have important effects at the community level. For example, predators often have important impacts on prey activity rates, such as influencing feeding, growth rates, competitive abilities and changing the local prey density and community structure. In the presence of predators, prey communities may increase, decrease or not alter their movement rates (Wooster and Sih 1995). These are all 'sub-lethal' effects of predators that can have a major role in structuring communities.

Aquatic arthropods can respond to the presence of predators by changing their behavior and life history traits. Behaviors by aquatic arthropods can be assigned to specific anti-predation responses, such as non-aggressive behavior, by reducing the time spent foraging, and increasing their use of water currents to drift away (Stibor 1992). In other words, the prey will seek refuge and focus more on their own productivity rather than fighting against the predator. Predators can dramatically reduce prey population growth and fecundity rates, resulting in a significant reduction of fitness beyond the direct mortality effects usually considered in studies of predator-prey interactions (Peckarsky et al. 1993). Higher activity levels are associated with a higher predation rate, since the probability of encounter between prey and predators increases. Lower activity levels may also result in fewer encounters with food which in turn reduces energy gain to the prey 
species (Mikolajewski et al. 2005). Thus, investigations of the sub-lethal consequences of behavioral responses of prey to predators are essential to further understanding of the total impact of predators on prey populations and communities.

Mosquito adult fecundity is a function of the amount of food eaten, but their potential fitness is determined by the number of offspring that survive to adulthood. Therefore, in situations where juvenile mortality is high, the adult oviposition strategy becomes very important (Kindlmann and Dixon 2001). For example, females of the mosquito species Culiseta longiareolata avoid ovipositing in pools that contain the backswimmer, Notonecta maculata, which preys on its larvae (Kiflawi et al. 2003). Faced with a choice between an equal number of pools with and without predators, about $90 \%$ of females oviposit in the pools that have no predators.

\subsection{Thesis aim and structure}

The aim of this thesis is to understand the mechanisms of how a common native predator influences mosquito populations in New Zealand. I examined lethal and sub-lethal affects that may directly or indirectly influence mosquito population abundance in the presence of the mosquito predator, Anisops wakefieldi. Functional response studies reflect lethal effects. To examine sub-lethal effects, I tested oviposition habitat selection, life history changes and predator avoidance behavior. I also investigated the effects of predators on mosquito populations in the field. The field sampling survey was conducted in water troughs in Queen Elizabeth II 
Park, Waikanae, to observe the relationship between predators, mosquito larvae and other associated variables (such as water volume, temperature, wind speed etc.). My thesis consists of six main chapters. Each chapter is written as a stand-alone manuscript, and some repetition may occur in the information contained in the introduction and discussion.

In Chapter Two, the aim in this study was to examine the relationship and interactions between predators and mosquito populations in animal drinking troughs. This study was conducted every week during the southern hemisphere summer for two consecutive years. I sought to understand the relationship between mosquito predators and immature mosquitoes in natural conditions. I also considered associated water volume and environmental factors to include in the model. In order to examine the effectiveness of $A$. wakefieldi in controlling the Cx. pervigilans community, I ran a separate experiment where I transferred this predator between troughs with different densities of mosquito larvae.

Based on 'the escape from natural enemies' hypothesis, I tested this hypothesis by examining the New Zealand native predator $A$. wakefieldi consuming native (Cx. pervigilans) and exotic (Ae. notoscriptus) mosquito larvae in chapter three. First, I established the experiment by offering $A$. wakefieldi predators Cx. pervigilans (native) and Ae. notoscriptus (exotic) prey and estimated their functional responses. I also examined the predator's preferences and prey switching behavior when these two mosquito species persisted together in the water body. The avoidance behavior of mosquitoes when facing the predator was also investigated in order to understand the strategies that may help mosquitoes successfully establish. 
In Chapter Four, the aim of this experiment was to assess the influence of the notonectid predator $A$. wakefieldi on $C x$. pervigilans mosquitoes when choosing their oviposition habitat under the field. Here, I established a number of artificial container habitats with four treatments of varying predator densities; control (without $A$. wakefieldi), free-roaming $A$. wakefieldi, $A$. wakefieldi in cages and $A$. wakefieldi kairomones (with a kairomone concentration of varying numbers of $A$. wakefieldi that were present in the water for $24 \mathrm{~h}$ prior to the experiment, but removed at the start of each trial). The purpose of this experiment was to assess the influence of predators on mosquitoes when choosing their oviposition habitat. Oviposition habitat selections by adult mosquitoes can play a very important role in determining the success rate of their progeny.

Culex pervigilans eggs that were successfully oviposited in the containers used in experiments in chapter four were brought back to laboratory in order to establish an experiment for Chapter Five. The aim of this study is to investigate the survival rate and subsequent life history of the mosquito $C x$. pervigilans (Bergorth) under the influence of its major predator $A$. wakefieldi (White). In this chapter, I also examined the mosquitoes' life history including the successful rate of egg hatching, survival rate, and development time in two different water conditions; (1) eggs which were reared in the same treatments used in chapter four and, (2) eggs which were reared in clean water without any traces of predators or their kairomones. The purpose of these experiments is to investigate the subsequent and indirect effects of $A$. wakefieldi predators on mosquito progeny. 
Lastly, in Chapter Six, I integrated all the findings from the previous chapters and combine all the current results to come out with into a general discussion. Overall, this thesis suggested that the successful establishment of mosquito communities can be explained by a complex synthesis of two different components; (1) lethal effects- by direct predation, prey preferences and prey switching behavior, (2) sub-lethal effects- by life history changes and avoidance behavior in mosquito larvae after exposure to predators or their kairomones. I did not find any evidence for a change in oviposition behavior. I hope this entire thesis will provide good baseline knowledge and add new information as to how predators influence the mosquito population dynamics in New Zealand. 


\section{Chapter TWO:}

The influences of aquatic predators on mosquito abundance in animal-drinking troughs in New Zealand

In part published as: Zuharah WF and Lester PJ. The influence of predators on the mosquito community structure. Journal of Vector Ecology. 35(2): (In Press, See appendix D)

(In Press in Journal of Vector Ecology, accepted on 10 May 2010) 


\subsection{ABSTRACT}

The occurrence and abundance of mosquito populations may be associated with the abundance of predators. My aim in this manuscript was to examined the relationship between aquatic predators and populations of mosquitoes in animal-drinking water troughs in Waikanae, New Zealand. I also investigated the effects of water volume and environmental factors (temperature, rainfall, wind speed, humidity and pressure) in order to further understand factors influencing mosquito and predator populations. Logistic regression indicated that the presence or absence of mosquitoes was primarily affected by three factors; predator abundance, week of observation, and water volume. Pearson's correlation indicated the presence of predators had a positive correlation with water volume $\left(r^{2}=0.176, p<0.05\right)$. Otherwise, the presence of mosquito larvae in water troughs was negatively correlated with water volume $\left(r^{2}=-0.159, p=0.022\right)$ and wind speed $\left(r^{2}=0.142, p=0.041\right)$. I established a translocation experiment in which predators or mosquitoes were moved between troughs in order to examine the prey survival rate after the exposure to $A$. wakefieldi predators. The survival rate of mosquitoes was statistically similar, between $0-0.1 \%$, irrespective of the number of predators translocated (1-9) or the initial mosquito density (20- 70 larvae). My results suggested that $A$. wakefieldi predators may have the potential to become one of the most promising biological control tools for the control of mosquito populations by means of altering mosquito population dynamics. 
CHAPTER 2: THE INFLUENCES OF AQUATIC PREDATORS ON MOSQUITO ABUNDANCE

Keywords: Environmental factors · Mosquito population · Predator . Translocation · Water trough · Water volume. 


\subsection{INTRODUCTION}

Artificial containers such as bottles, cans, tires, pots and animal drinking troughs are major sources of habitat for mosquito populations. However, aquatic predators also occur in many of these habitats including animal drinking troughs and have been suggested to have a major influence on the abundance of mosquitoes (Laird 1990). Mosquito species may coexist and share the same habitat with predators, with some predators appearing to have little influence on mosquito populations (Lundkvist et al. 2003). Different mosquito species may be differently affected by predators (Griswold and Lounibos 2006), with the differential consumption of various mosquito species by predators resulting in the coexistence of some mosquito species (Griswold and Lounibos 2005).

A variety of aquatic insects in the orders Coleoptera, Hemiptera, Odonata and Diptera are known to attack and eat mosquito larvae. In general, most predators are polyphagous and consume a broad range of prey species (Shaalan et al. 2007). In New Zealand the common mosquito predators seen in natural and anthropogenic water bodies are the notonectid backswimmer Anisops spp. (Hemiptera), diving beetles in the genus Rhantus (Coleoptera), and damselfly larvae (Odonata) (Graham 1939). Several studies have focused on notonectid predators because of their effectiveness in controlling mosquito populations (Scott and Murdoch 1983, Murdoch and Scott 1984, Murdoch et al. 1984, Koivisto et al. 1997). Notonectid predators clearly have the potential to alter mosquito communities via direct or indirect effects (Gilbert and Burns 1999). 
The indirect effects of the presence of notonectid predators in water bodies can include a reduction in oviposition by adult mosquitoes (Chesson 1984, Blaustein et al. 1995), while direct effects occur primarily through predation.

New Zealand currently has only 16 mosquito species, with 12 indigenous species and four exotic species (Derraik 2004a, 2004b, Laird 1990, Laird 1995). No outbreaks of mosquito-borne disease have been recorded. However, out of 12 indigenous mosquito species, Culex pervigilans and Culiseta tonnoiri have been identified as vectors of the avian arbovirus (Whataroa Virus) (Maguire et al. 1967). Culex pervigilans is New Zealand's most abundant and widespread species, and has the potential to be a vector of human pathogens. Culex pervigilans is often found in artificial containers including animal drinking troughs (Graham 1929, Graham 1939, Belkin 1968, Laird 1990, Laird 1995). There are other species which are of much greater concern such as Aedes notoscriptus and Coquilletidia iracunda, with the former also being found in drinking water troughs in New Zealand (Laird 1995).

Environmental factors may affect the abundance of predator and mosquito populations. A backtrack simulation study of wind speeds sufficient for mosquito transport from Papua New Guinea to Australia was research by Ritchie and Rochester (2001). Winds at 36 and $72 \mathrm{~km} / \mathrm{h}$ were capable of carrying mosquitoes from New Guinea to the Northern Peninsula of Australia. Slow velocity winds are also important as they allow female mosquitoes to place their eggs calmly without disturbance in water containers (Service 2000). Temperatures can also strongly influenced predation rates. For example, Anderson et al. (2001) showed that tadpoles raised in warmer water experienced 
a higher probability of capture by notonectids predators than those reared in cooler conditions.

My aim in this study was to examine the relationship and interactions between predators and mosquito populations in animal drinking troughs. I translocated predators between troughs in order to better understand their influence on mosquito populations. I also examined the effects of water volume and environmental factors on predator and mosquito populations.

\subsection{MATERIALS AND METHODS}

\subsubsection{Study site}

My study was undertaken at Queen Elizabeth II Park, Waikanae, New Zealand (41"06'31.43 S, 175"13'12.91 E). This area contains a variety of habitats, including coastal and inland sand dunes as well as pastoral areas for animal farming. A total of 13 water troughs within an area of $4.8 \mathrm{~km}^{2}$ were sampled. Troughs ranged in volume from $0.32-0.84 \mathrm{~m}^{3}$ were sampled at weekly intervals. Sampling continued for two southern hemisphere summers from December to February of 2007/2008 and 2008/ 2009. 


\subsubsection{The relationship between predator and mosquito populations}

During each sampling occasion predators such as Anisops wakefieldi (backswimmers), Rhantus rhantus larvae (diving beetles) and Onychohydrus hookeri (water beetles) were visually observed and counted. Predators were inspected and identified in situ, as they were easily identified to genus level. To estimate mosquito densities I used a conventional dipping technique (Russell 1993, Service 1995). The water surface was stirred using a stick before the sample was taken. A total of ten litres of water was sampled by dipping at equal intervals around the water trough. The water samples were strained through 0.10 $\mathrm{mm}$ mesh and the filtered water was then returned to the trough. Mosquitoes collected in the strainer were placed separately in containers with $500 \mathrm{ml}$ of water and brought back to laboratory for identification. If any predators were caught in the strainer, they were released back into the trough. Mosquito larvae were identified using a key by Snell (2005). The dipper and strainer were thoroughly rinsed with distilled water before sampling the next water trough.

The water volume for each trough was recorded. Water volume was used rather that water depth because there were different shapes of water trough located in the field. Environmental data (temperature, wind speed, rainfall, pressure, and humidity) were provided by New Zealand National Institute for Water and Atmospheric Research from Paraparaumu Aero Station, which is approximately $4.5 \mathrm{~km}$ from my study site.

I analyzed the data with logistic regression using R version 2.10.1 (Ihaka and Gentleman 1996). The presence and absence of mosquitoes served as the 
response variable. The predictor variables were predator, water volume, week of observation, temperature, rainfall, wind speed, and humidity. This logistic regression approach was used because prior work has suggested that solely the presence of a predators or kairomones (chemical cues that are released by the predator) can influence mosquito communities through altering mosquito behaviours such as adult oviposition (Blaustein et al. 2004, Blaustein et al. 2005). I then used Pearson's correlation tests in SPSS 15.0 (2006) to examine the relationship between the environmental factors and water volume, and the number of predators and mosquito in water troughs. If, as in my study system, the presence or absence of predators do not influence mosquito behaviour, such as oviposition, an analysis of the influence of predator abundance is more appropriate.

\subsubsection{Predator translocation experiment}

In order to examine the effectiveness of the predator $A$. wakefieldi in altering mosquito populations, I transferred these predators between troughs. Anisops wakefieldi was used in this study because it was the most common predator species at my study site. I transferred between one and nine predators, and third instar Cx. pervigilans mosquito larvae, in each water trough as follows; (A) zero predators (control) with 20,40 , or 70 mosquito larvae, (B) one predator with 10,15 , or 20 mosquito larvae (C) three predators with 20,30 , or 40 mosquito larvae (D) nine predators with 30,50 , or 70 mosquito larvae. 
Experiments were replicated four times. Data were recorded two days after each transfer.

In order to test the effects of predator density and prey number on mosquito survival rates in the translocation experiments, I ran a two-way ANOVA in SPSS 15.0 (2006). The percentage of surviving prey served as the dependent variable, whereas type of treatment and initial number of prey offered were fixed factors. Survival rates are expressed as a percentage and were therefore transformed using arcsine square root prior to analysis to satisfy the assumptions of ANOVA.

\subsection{RESULTS}

\subsubsection{The relationship between predator and mosquito populations}

The only mosquito species that was observed to utilize animal drinking troughs during the entire study was Culex pervigilans. The three predator species observed in same habitat were Anisops wakefieldi (91.8\%), Rhantus

rhantus larvae (6.6\%), and Onychohydrus hookeri (1.6\%). The total number of Cx. pervigilans larvae collected in $2007 / 2008$ was 3293 , with only 715 individuals in $2008 / 2009$ over the same sampling duration. The total number of predators was high in 2007/2008 with 916 individuals; but, only 419 individuals were recorded in 2008/2009.

In $2007 / 2008$ the highest numbers of predators (300) was observed after the first week of sampling during summer but densities declined closer to autumn (Figure 2.1A). In the same trough in the following year (2008/2009), the situation 
changed with a high abundance of mosquitoes. However, only two predators were observed for the entire study period (Figure 2.1A).In most troughs the pattern of population dynamics of mosquitoes and predators were similar to that shown in Figure 2.1B.

The model resulting from the logistic regression indicated that with each increase in the abundance of predators the probability of mosquito population existence also increased; however, it is not statistically significant (Figure 2.2). For each increase in the abundance of predators, the odds of mosquitoes being present (vs. absent) positively increased by the factor of 1.006 . The probability of mosquito presence significantly decreased with increasing water volume and week of observation $(P<0.05$; Table 2.1).

Predator abundance increased significantly with increasing water volume in both years of the study $\left(r^{2}=0.176, P=0.011\right.$; Table 2.2 and Figure 2.3), but was not correlated with any other environmental variable nor the abundance of mosquitoes $(P \geq 0.232)$. In comparison, mosquito abundance decreased significantly with increasing water volume $\left(r^{2}=-0.159, P=0.022\right.$; Table 2.2) and wind speed $\left(r^{2}=0.142, P=0.041\right)$, but was not correlated with any other environmental variable $(P \geq 0.220)$. 


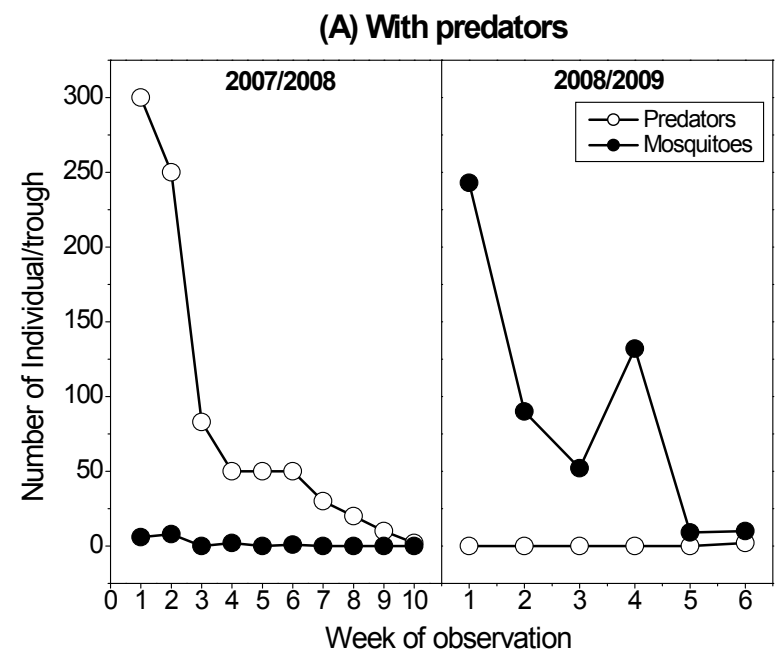

(B) No predator

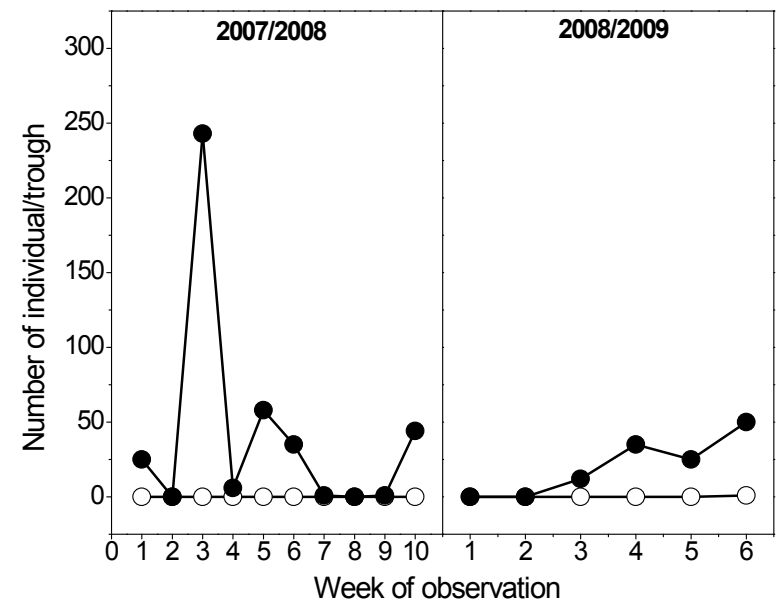

Figure 2.1: Examples of the relationship between predators and mosquitoes in water troughs at Queen Elizabeth II Park, Waikanae, New Zealand. These graphs show two of the 13 troughs examined in the study, one trough with predators (A) and one without predators (B). The open circles represent predators and closed circles represent mosquitoes. 


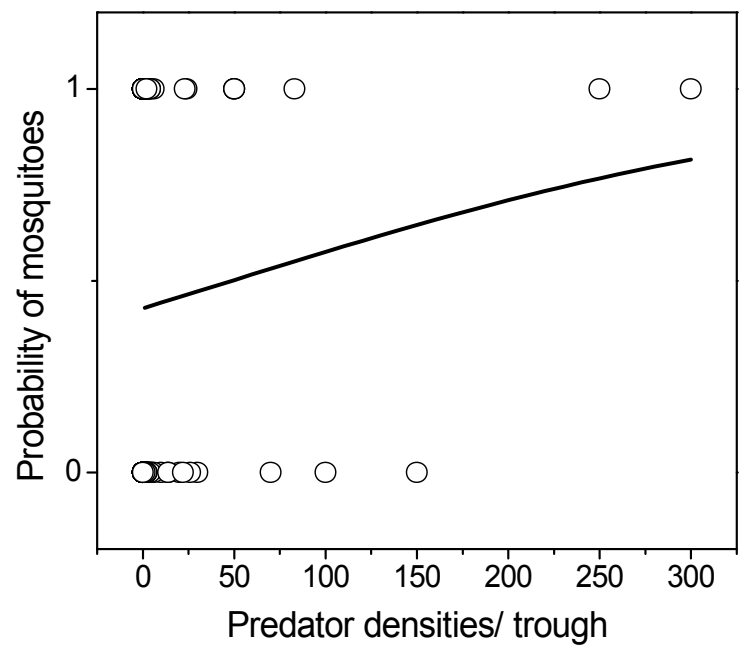

Figure 2.2: Logistic regression of the presence or absence of mosquitoes in association with predator abundance.

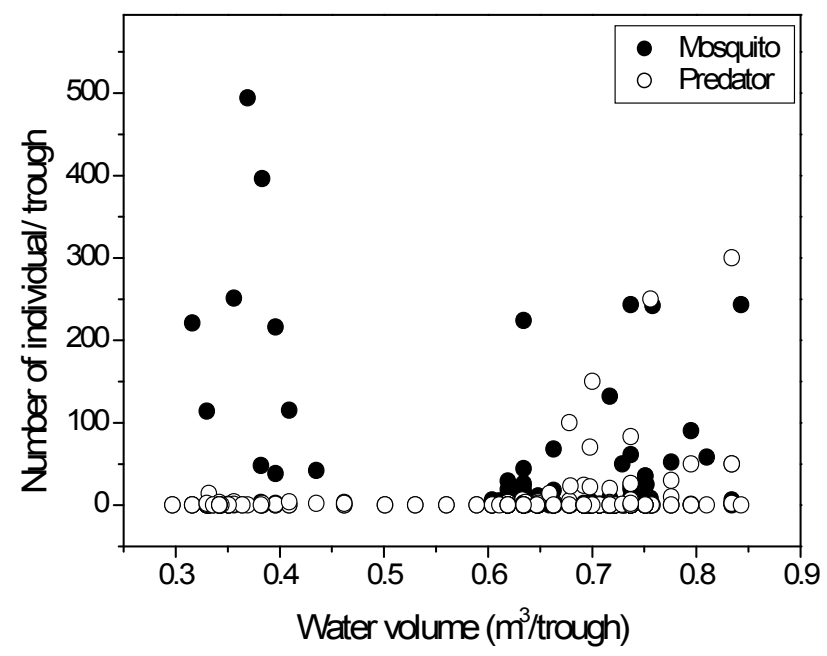

Figure 2.3: Abundance of mosquito larvae and predators recorded in animal drinking troughs compared to cumulative water volume. 
Table 2.1: Logistic regression analysis for the predictor variables included in the model that effect the presence or absence of mosquito populations in the water troughs. $d f=202\left({ }^{* *}=P<0.001,{ }^{* *}=P<0.01,{ }^{*}=P<0.05\right)$.

\begin{tabular}{lcccc}
\hline & Estimates & Std Error & z-value & P-value \\
\hline Intercept & 4.937 & 1.561 & 3.163 & $0.002^{* *}$ \\
Predator & $7.217^{\mathrm{e}-03}$ & $6.343^{\mathrm{e}-03}$ & 1.138 & 0.255 \\
Water Volume & $-2.194^{\mathrm{e}-06}$ & $1.114^{\mathrm{e}-06}$ & -1.969 & $0.049^{*}$ \\
Water trough & $5.201^{\mathrm{e}-02}$ & $6.036^{\mathrm{e}-02}$ & 0.862 & 0.389 \\
Temperature & $1.196^{\mathrm{e}-01}$ & $7.143^{\mathrm{e}-02}$ & -1.675 & 0.094 \\
Wind speed & $3.939^{\mathrm{e}-02}$ & $2.376^{\mathrm{e}-02}$ & 1.658 & 0.097 \\
Rainfall & $2.658^{\mathrm{e}-02}$ & $2.062^{\mathrm{e}-02}$ & 1.289 & 0.197 \\
Humidity & $-1.477^{\mathrm{e}-02}$ & $9.551^{\mathrm{e}-03}$ & 1.289 & 0.197 \\
Week & $-1.976^{\mathrm{e}-01}$ & $5.084^{\mathrm{e}-02}$ & -3.887 & $<0.001^{* * *}$ \\
\hline \hline
\end{tabular}


Table 2.2: Results of Pearson correlation tests between Anisops wakefieldi or mosquito populations with environmental factors (temperature, rainfall, wind speed, humidity and pressure) and water volume. Data were collected from animal water troughs during the Southern Hemisphere summer (December to February 2007/08 and 2008/09) for two consecutive years. Significant values are in bold with $d f=207$. Data represent Pearson's correlation (2-tailed).

\begin{tabular}{lcc}
\hline & \multicolumn{1}{c}{ Predator } & Mosquito \\
\hline Mosquito & $-0.052,0.454$ & \\
Water volume & $0.176, \mathbf{0 . 0 1 1}$ & $-0.159, \mathbf{0 . 0 2 2}$ \\
Temperature & $-0.020,0.773$ & $-0.085,0.220$ \\
Rainfall & $-0.041,0.558$ & $0.049,0.484$ \\
Wind speed & $-0.063,0.365$ & $0.142,0.041$ \\
Humidity & $-0.023,0.741$ & $0.064,0.357$ \\
Pressure & $0.083,0.232$ & $0.022,0.748$ \\
\hline \hline
\end{tabular}




\subsubsection{Predator translocation experiment}

The translocated predators had a major effect on mosquito populations. The maximum number of mosquito prey left alive was one mosquito in two days post-treatment. Even at the highest number of 70 prey, with the largest water volume of $0.72 \mathrm{~m}^{3}$, the predator successfully consumed all of the prey (Figure 2.3). The two-way ANOVA showed that the mosquito larvae survival rate in treatments with predators was significantly lower than in the control treatment without predators $(F=443.92, d f=3, P<0.001)$. There was no significant effect of initial mosquito number on mosquito survival rate $(F=0.87, d f=6, P=0.524)$, and the interaction between treatments and mosquito abundance was also non-significant $(F=0.53, d f=$ $6, P=0.780)$. Post-hoc comparisons showed that treatments with predators (1, 3, and 9 predators) were not significantly different from each other ( $P \geq$ 0.704 ), but had a significantly lower prey survival (Tukey, $P<0.005$ ) than in the control treatment without predators. These results clearly demonstrate the ability of this predator to reduce the number of mosquitoes in water troughs within only two days. In the control treatments, where mosquito larvae were present in the water troughs without predators, the mortality rate of mosquitoes was less than $5 \%$. 


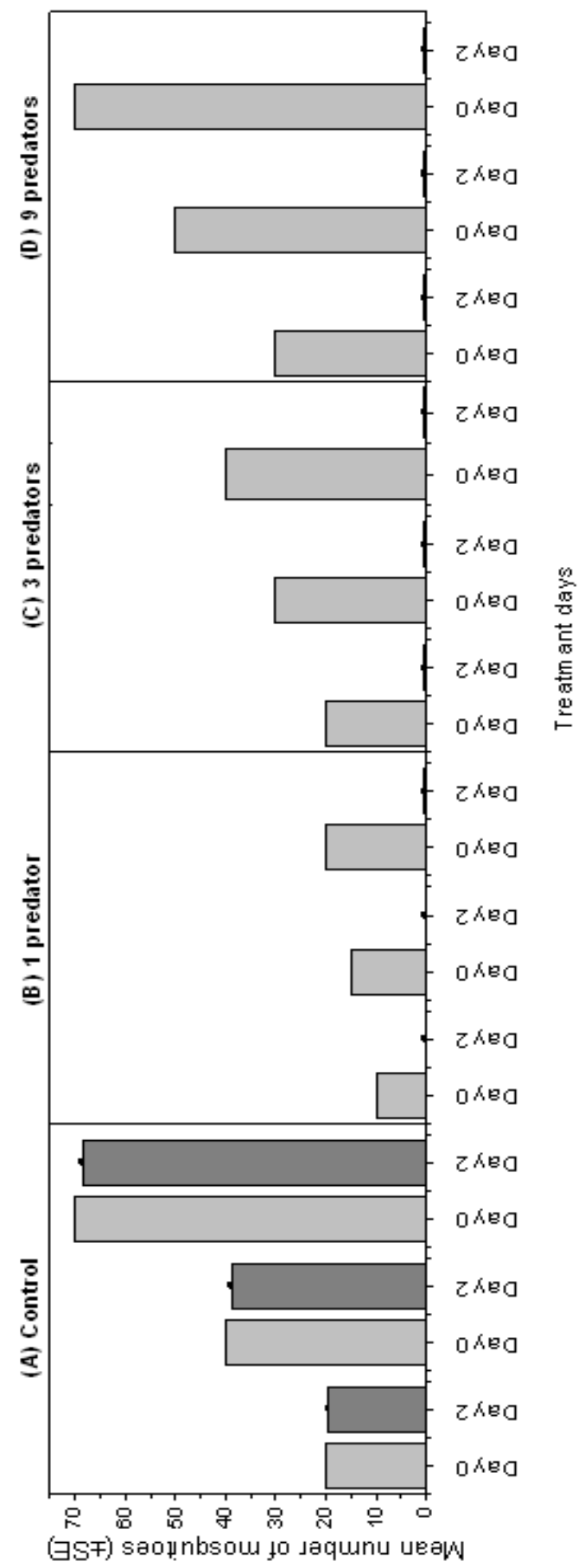

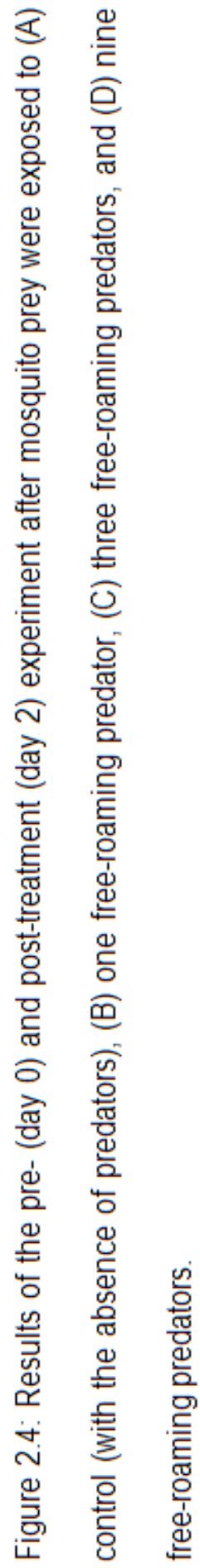




\subsection{DISCUSSION}

The only mosquito observed in this study was Cx. pervigilans. Culex pervigilans is the most common mosquito in New Zealand, utilizing many water containers and habitat types (Graham 1939, Belkin 1968, Laird 1990, Laird 1995). It has been found to prefer organically rich water bodies (Graham 1939, Dumbleton 1968, Urbinatti 2001), but has wide tolerance for a variety of water qualities (Graham 1929, Derraik and Slaney 2004). The predators A. wakefieldi, R. rhantus and $\mathrm{O}$. hookeri are also widely distributed throughout the North Island of New Zealand (Brown 1943, Winterbourn et al. 2006). At my sampling site $A$. wakefieldi was the most abundant predator observed; only $2 \%$ of all predators were $R$. rhantus and $O$. Hookeri. In my study, most of the water troughs utilized by predators had low densities of mosquitoes. Some of the water troughs that were utilized by large numbers of predators in 2007/08 had few predators and large numbers of mosquitoes in 2008/2009. There are at least two hypotheses to explain these results. Firstly, predators may consume large numbers of mosquitoes and control their population numbers. Secondly, mosquito adults may have an ability to detect the presence of a predator and will not oviposit in troughs with predators.

To test the hypothesis that the predators consumed a large number of mosquitoes, I undertook a translocation experiment in which $A$. wakefieldi and mosquitoes were placed together in the same environment. My translocation experiment showed that within two days, all mosquitoes were consumed by predators. Other laboratory studies confirm that a single $A$. wakefieldi predator in 
$500 \mathrm{ml}$ of water can kill about 18 individual mosquitoes within 24 hours (Zuharah and Lester, In Press B). In my study, it appears that even in large water volumes A. wakefieldi are voracious predators. Both adults and nymphs of $A$. wakefieldi prey upon mosquito larvae. This predator is believed to be most effective against immature stages of third and fourth instar mosquitoes (Hazelrigg 1963, Lee 1967, Ellis and Borden 1970, Bay 1974). Additionally, Anisops spp. prefers mosquito larvae over other prey when given a choice (Hazelrigg 1963, Ellis and Borden 1970).

My second hypothesis to explain the relationship between predators and mosquitoes was that mosquito adults may have the ability to detect the presence of a predator and consequently do not oviposit in troughs with predators. Predators may therefore regulate prey abundance without directly killing mosquitoes (Brown et al. 1997). Stav et al. (1999) suggested that the distribution and abundance of a mosquito species is dependent on their ability to selectively oviposit according to predator abundance. Other mosquitoes such as Culiseta longireolata can detect chemicals from Notonecta predators for periods of up to eight days after their removal from the pool (Blaustein et al. 2004) and this period is as low as two days for Culex species (Blaustein et al. 2005). It thus seems reasonable to expect that the mosquitoes would have shown a response to this predator. With increasing predator densities, the concentration of kairomones also increase and may result in reduced oviposition (Eitam and Blaustein 2004). A reduction in oviposition activities by mosquitoes may be expected with increasing numbers of predators, due to the ability of these prey species to 
detect the presence of a predator above a threshold density (Angelon and Petranka 2002) or a specific concentration of kairomones (Eitam and Blaustein 2004). In a separate experiment I examined the oviposition of Cx. pervigilans in response to the presence of $A$. wakefieldi and kairomones. Unlike work elsewhere (e.g. Blaustein et al. 2004, 2005), I observed no response of mosquitoes to the presence of these predators (Zuharah and Lester 2010).

It thus appears that the primary effects of predators were through predation, rather than sub-lethal effects such as a change in oviposition behaviour. This is in accordance with the voracious nature of these predators (Zuharah and Lester, In Press B). However, my logistic data indicated a positive relationship between mosquito and predator densities, though this relationship was only significant at the $p<0.10$ level. Adult Anisops predators frequently disperse and may fly up to $1.6 \mathrm{~km}$ between habitats (Brier 1998). It is possible that these predators periodically move between habitats and are more likely to stay longer in habitats with high numbers of mosquitoes. Further work is needed to confirm such a hypothesis.

The abundance of mosquitoes was observed to be dramatically different between the two years of this study. None of the environmental factors I examined correlated with the abundance of predator and mosquito populations. Wind speed correlated only with the abundance of mosquitoes. Mosquitoes need 10- 15 minutes to oviposit therefore, slow velocity winds are important as they allow female mosquitoes to place their eggs without disturbance in water containers (Service 2000). The lack of any other relationship between mosquito 
abundance, and that of predators, with environmental variables may be a result of averaging. The environmental data analyzed are the average conditions over each weekly period of sampling; but within any one week there may have been conditions suitable for brief periods of oviposition or predator movement.

Water volume was highly correlated with predator and mosquito abundance in water troughs. Larger water troughs may be advantageous to $A$. wakefieldi colonies because they are less likely to dry out or overflow (Wilton 1968, Frank and Curtis 1977). A larger space offered by bigger water troughs can increase larval survivorship and reduce mortality risks such as cannibalism (Sota 1998, Sunahara et al. 2002). I also found that mosquito populations were negatively correlated with water volume. Female mosquito may oviposit in all types of habitats even if the water has evaporated. Browne (1994) observed female mosquitoes ovipositing in full and nearly empty containers, suggesting that these mosquitoes are incapable of assessing water depth. Similarly $C x$. pervigilans appear incapable of assessing water depth (Derraik and Slaney 2004). The positive relationship between water volume and predators, and the negative relationship between depth and mosquitoes, is in accordance with the observations that predators influence mosquito populations.

My results indicate that the predator, An. wakefieldi, can control $C x$. pervigilans densities even in relatively large volumes of water. However, the fluctuating in environmental changes from year-to-year, and even within a year, may indirectly affect the effectiveness of this predator in controlling mosquito population. 


\section{ChAPTER THREE:}

\section{Are exotic invaders less susceptible to native predators? A test using native and exotic mosquito species in New Zealand}

In part published as: Zuharah WF and Lester PJ. Are exotic invaders less susceptible to native predators? A test using native ad exotic mosquito species in New Zealand. Population Ecology.

(In Press in Population Ecology, accepted 10 July 2010) 


\subsection{ABSTRACT}

A major hypothesis in invasion ecology is that native predators have less impact on exotic prey species relative to native prey species. Here I tested this hypothesis by examining the New Zealand native predator Anisops wakefieldi consuming native (Culex pervigilans) and exotic (Aedes notoscriptus) mosquito larvae. Anisops wakefieldi exhibited a decelerating Type II functional response for both prey species, but at high prey densities consumed more of the exotic mosquito Ae. notoscriptus. A significantly higher attack rate was observed for the native predator feeding on exotic species. In the presence of both prey species, the predator showed preferences towards Ae. notoscriptus and demonstrated switching behavior towards this exotic species. The preference of the native predator towards the exotic mosquito appeared related to behavioral differences between the two prey species. I tested the behavioral response of both mosquito species in four conditions; (1) control (without predators), (2) free-roaming predators, (3) caged predators, and (4) kairomones only. Resting activities at the water surface and wall positions were the most frequently behaviors exhibited by $C x$. pervigilans in the presence of predator. In contrast the exotic species $A e$. notoscriptus demonstrated significantly higher levels of "thrashing" behaviors with vigorous lateral movement of body, apparently making itself more obvious to the predators. The behaviors showed by $C x$. pervigilans fulfilled the "threat sensitivity hypothesis". No evidence here supported the idea that exotic mosquito species are less prone to the influence of native predators and the "escape from natural enemies" hypothesis seems not apply in my 


\section{CHAPTER 3: ARE EXOTIC INVADERS LESS SUSCEPTIBLE TO NATIVE PREDATORS?}

study. In fact, I observed that this invader was more susceptible to the predator.

Keywords: Behavior - Escape from natural enemies - Exotic $\cdot$ Native $\cdot$ Threat sensitivity · Predation 


\subsection{INTRODUCTION}

Is the establishment of exotic mosquitoes facilitated by a lack of predation from native predators? The "escape from natural enemies" hypothesis (Elton 1958 ) is one of the famous explanations for successful establishment by non-native species, which was first noted by Darwin in 1859. This hypothesis suggests that escape from predation, parasitism, and herbivory, may permit non-native species to survive, grow and reproduce at higher rates in their new habitat range (Elton 1958, Blossey and Notzold 1995, Maron and Vilá 2003). Escaping from key natural enemies enables non-native species to grow explosively and become more abundant in the community into which they were introduced (Maron and Vilá 2003). For example, Russell et al. (2001) reported the native freshwater fish (fly-specked hardyhead, Craterocephalus stercusmuscarum stercusmuscarumon) consumed fewer exotic than native mosquito species. Liu and Stiling (2006) also found that insect herbivore richness is higher and caused greater damage to native plants than to introduce plants, which may allow introduced plants to establish successfully in a new environment.

A key factor for the population dynamics of predator-prey systems is the functional response. The functional response is the relationship between prey density and a predator's consumption rate. It describes the rate at which predator kills its prey at different prey densities and can thus help determine the efficacy of a predator in regulating prey populations (Murdoch and Oaten 1975). Functional response curves enable a prediction of predation intensity and predator behavior over a range of conditions, providing a baseline for 
predicting stability of predator-prey interactions (Griswold and Lounibos 2005). Holling (1959) classified three mains types of functional response. Type 1 responses involve prey consumption increasing with the prey density to a plateau, type 2 responses are decelerating rates of prey consumption to a plateau, and in type 3 responses a sigmoidal relationship of prey consumption is observed to a plateau. It is important to differentiate between type II and type III functional responses at relatively low prey numbers (Murdoch 1969, Lester et al. 2005, Pervez and Omkar 2005). Most of the functional response analyses of mosquito predators were suggested to be fitted by type II response curves, including the two dipteran predators Toxorhynchites rutilus and Corethrella appendiculata (Griswold and Lounibus 2005).

The long-term stability of predator and prey populations is thought to be through mechanisms of density-dependent predation and prey switching (Holling 1965, Murdoch and Oaten 1975, Hassell and Comins 1978). Prey switching involves two or more prey species and one predator species. When all prey species are in equal abundance, predators may indiscriminately select between prey species. But if one prey species is more abundant, predators may develop a search pattern resulting in a preference for the more common species (Murdoch and Oaten 1975, Tschanz et al. 2007). This effect of prey switching based on density-dependent prey availability may stabilize the coexistence of two or more prey species.

Why should functionally similar prey species be different in their susceptibility to a predator? In aquatic ecosystems there are several 
potential mechanisms that limit the effects of a predator on prey species. These mechanisms include the chemical detection of a predator by the prey (Blaustein et al. 2004, Eitam and Blaustein 2004). Similarly, variability in prey behaviour may differentially expose one species to predators. Other possible mechanisms includes habitat complexity that may reduce the incidence of encounters with some prey but not others (Alto et al. 2005), and abiotic changes such as the oxidation of sediments or chemical changes in water that may limit the susceptibility of prey to predators (Bay 1974).

One of the main responses exhibited by prey is to altering their behaviour in the presence of predators in an attempt to increase their survival (Sih 1980; 1986, Van Buskirk 2000, Kesavaraju et al. 2006). The "threat sensitivity hypothesis" states that prey species alter their avoidance response according to the magnitude of the threat: with increasing predation risk prey exhibit increasing avoidance behaviour (Helfman 1989). The result of predation on prey behaviour thus may be different from one organism to the next. Prey may reduce their feeding and foraging activity, migrate to less favourable habitats, and reduce mating efforts or alter their life history (Bishop and Brown 1992, Peckarsky 1996, Boersma et al. 1998, Moses and Sih 1998, Peacor and Werner 2000, Smith and Belk 2001, Turner 2004, Mirza et al. 2006). Aquatic insects frequently receive warning of predation risk by chemical cues released by predators known as kairomones. Kairomones that indicate the presence of a predator may also be released by injured prey (Dodson et al. 1994, Kats and Dill 1998, Kusch et al. 2004). 
In reference to "the escape from natural enemies" hypothesis, I examined the functional response of predator Anisops wakefieldi consuming larvae of the exotic mosquito Aedes notoscriptus and the native mosquito Culex pervigilans. By examining each prey species singly, the preferences for a particular prey species can be predicted by estimating the attack constant and handling time in the experiments (Cock 1978). The attack rate and handling time by $A$. wakefieldi for each prey species was also determined using the Rogers (1972) equations and by actual observation. I examined the effects of alternative prey and prey switching by $A$. wakefieldi predator when Ae. notoscriptus and Cx. pervigilans were presented together. I also examined the hypothesis that $C x$. pervigilans and Ae. notoscriptus will alter their behavior in the presence of free-roaming $A$. wakefieldi, caged predators and kairomones remnant from the predator treatments. Finally, I investigated how these prey behaviorally mediate their anti-predator response in different water volumes. I made the following predictions for both mosquito larvae species in order to escape from a predator: (1) prey larvae that encounter the predator directly or its kairomones will likely minimize their movement in the water, and (2) prey larvae will modify their behavior to minimize capture by predators. The evolutionary history of predator and prey relationships may be critically important in determining prey susceptibility to predators, especially in scenarios with native and exotic prey species. Due to coevolution, I might expect that the native mosquito species $C x$. pervigilans might behave more adaptively than Ae. notoscriptus to the presence of the predator. 


\subsection{MATERIALS AND METHODS}

\subsubsection{Predator and prey colonies}

Predator and prey colonies

Predatory backswimmers (Anisops wakefieldi) were captured from water troughs in Queen Elizabeth Park II, Waikanae, New Zealand (4057'S, $\left.174^{\circ} 58^{\prime} \mathrm{E}\right)$. These predators are commonly found in such water containers in New Zealand (Laird 1990). All A. wakefieldi were at third and fourth nymphal instar stages with body sizes between $6-9 \mathrm{~mm}$. Methods used by these predators in finding and attacking the prey include behaviors such as flushing prey from the bottom, capturing mosquitoes as they hang beneath the water surface, and pursuit or semi-stalking through the water column (Toth and Chew 1972, Bay 1974).

Larvae of two species of mosquito, the exotic Ae. notoscriptus and native Cx. pervigilans, were utilized as prey. Culex pervigilans were also collected from Queens Elizabeth Park II and Ae. notoscriptus were collected in the Manawatu area $\left(40^{\circ} 33^{\prime} \mathrm{S}, 175^{\circ} 24^{\prime} \mathrm{E}\right)$.

\subsubsection{Functional response study}

The functional response of backswimmers ( $A$. wakefieldi) to two species of mosquito larvae, Ae. notoscriptus and $C x$. pervigilans was examined. All experiments were conducted at $25 \pm 1^{\circ} \mathrm{C}$ in photoperiod $\mathrm{L}: \mathrm{D}$; 14 : $10 \mathrm{~h}$, using $A$. wakefieldi that were captured within a week prior to use in the experiment. Late third and early fourth instars mosquito larvae were used 
for this experiment. Each predator was placed in seasoned water in a plastic tube measuring $19 \times 17.5 \times 17 \mathrm{~cm}$ (height $\times$ length $\times$ width). Seasoned water is water that has been left standing $24 \mathrm{~h}$ before the experiment to standardize hunger levels (Murdoch 1973).

To determine the functional response, predators were offered $1,3,6$, $10,15,20,30,40$ or 50 mixed late third instar and early fourth instar larvae of Cx. pervigilans or Ae. notoscriptus in separate experiments. Five replicates were used in each experiment. Two hours after placing the prey in $500 \mathrm{ml}$ of seasoned water the predator was introduced. The numbers of prey remaining alive were counted after $24 \mathrm{~h}$. Control (prey only) treatments indicated the mortality rate without predators was low at approximately 1 $2 \%$. Prey were not replaced as they were eaten. Data were analyzed in two steps. In the first step, the shape (type) of functional response was determined as either a type II or III functional response. In type II functional responses the proportion of prey eaten declines monotonically with prey density. For type III functional responses, the proportion of prey eaten is positively density-dependent on prey up to the inflection point of the sigmoid curve, which is then followed by a monotonic decrease (Schenk and Bacher 2002, Allahyari et al. 2004, Lester et al. 2005, Pervez and Omkar 2005). To determine the shape of the functional response I used the method by Juliano (2001), which relates the proportion of prey eaten $\left(\mathrm{N}_{\mathrm{e}}\right)$ to amount of prey offered $\left(\mathrm{N}_{0}\right)$. The polynomial function was fitted to the data that describes the relationship between $\mathrm{N}_{\mathrm{e}} / \mathrm{N}_{0}$ and $\mathrm{N}_{0}$ : 
$\frac{N_{e}}{N_{0}}=\frac{\exp \left(L_{0}+L_{1} N_{0}+L_{2} N_{0}{ }^{2}+L_{3} N_{0}{ }^{5}+L_{4} N_{0}{ }^{4}\right)}{1+\exp \left(L_{0}+L_{1} N_{0}+L_{2} N_{0}{ }^{2}+L_{3} N_{0}{ }^{3}+L_{4} N_{0}{ }^{4}\right)}$

Where $\mathrm{N}_{e}=$ the number of prey eaten, $\mathrm{N}_{0}=$ the initial number of prey available, and thus $\mathrm{N}_{e} / \mathrm{N}_{0}$ is the probability an individual is eaten. Maximum-likelihood estimates of the parameters $L_{0}$ to $L_{4}$ were obtained using PROC CATMOD in SAS® (SAS Institute Inc. 1999) to the dichotomous variable that equals 0 for surviving prey and 1 for consumed prey. The parameters $L_{0}, L_{1}, L_{2}$, and $L_{3}$ (being the intercept, linear, quadratic and cubic coefficients respectively) were estimated using the method of maximumlikelihood. If $L_{1}>0$ and $L_{2}<0$, the proportion of prey consumed is positively density dependent, thus describing a type III functional response. If $L_{1}<0$, the proportion of prey consumed declined monotonically with the initial number of prey offered, thus describing a type II functional response (Juliano 2001).

Once the shape and type of functional response was determined, nonlinear least squares was used to estimate the parameters associated with the response. As no prey were replaced during the experiment, the "randompredator" equation by Rogers (1972) was used as a description of the Type II functional response:

$N_{e}=N_{0}\left\{1-\exp \left[a\left(T_{h} N_{e}-T\right)\right]\right\}$

where $T_{h}$ is the time required to handle a prey item, a is the instantaneous searching rate or attack coefficient, and $\mathrm{T}$ is the total time the prey and predator were exposed to the each other. Previous studies (e.g., Colin et al. 
1981, Carter et al. 1984) have used the random prey equation by Rogers (1972) because this model allows an analysis of the functional response despite depletion of prey by predators.

I ran independent t-tests in order to compare the differences between the number of prey (Cx. pervigilans and Ae. notoscriptus) that were consumed by $A$. wakefieldi. Differences between the handling time and attack rates by $A$. wakefieldi of these two prey species were also examined using t-tests.

I examined if different estimates were obtained for the attack rate and handling time when I used the Rogers (1972) equation compared with actual observations of $A$. wakefieldi feeding on the two species of mosquito larvae, Cx. pevigilans and Ae. notoscriptus. I used the same experimental containers with seasoned water as described above. Mosquito larvae were introduced into $500 \mathrm{ml}$ of water and kept for $2 \mathrm{~h}$ before introducing $A$. wakefieldi. Only one mosquito larva was introduced to one $A$. wakefieldi at any one time. The duration of attacks, from initial attack until prey release was recorded. I compared the values of attack rate and handling time of $A$. wakefieldi using paired t-tests with values from actual observations and values estimated from the "random-predator" equation by Rogers (1972) as described in Eq. 2. 


\subsubsection{Attack rate and handling time using two methods}

I examined if different estimates were obtained for the attack rate and handling time when used the Rogers (1972) equation compared with actual observations of $A$. wakefieldi feeding on the two species of mosquito larvae, Cx. pevigilans and Ae. notoscriptus. I used the same experimental containers with seasoned water as described above. Mosquito larvae were introduced into $500 \mathrm{ml}$ of water and kept for two hours before introducing $A$. wakefieldi. Only one mosquito larva was introduced to one $A$. wakefieldi at any one time. The duration of attacks, from initial attack until prey release was recorded. I compared the values of attack rate and handling time of $A$. wakefieldi using paired t-tests with values from actual observations and values estimated from the "random-predator" equation by Rogers (1972) as described in Equation 2.

\subsubsection{Prey preferences and prey switching}

I examined the prey preferences of $A$. wakefieldi when offered the two species of mosquito larvae Ae. notoscriptus and Cx. pervigilans. To examine prey preference experiments were conducted using a total of 100 prey in $1000 \mathrm{ml}$ of seasoned water. The size of the plastic container used in this experiment was $19 \times 17.5 \times 17 \mathrm{~cm}$ (height $\times$ length $\times$ width). Each predator was offered mosquito prey at ratio of $0: 100 ; 20: 80 ; 40: 60 ; 50: 50 ; 60$ : 40; $80: 20 ; 100: 0$ (Ae. notoscriptus : Cx. pervigilans). Each treatment was replicated 5 times. The prey densities chosen represent a range of conditions 
which a Notonectid predator might reasonably experience near the water surface (Chesson 1989). After $24 \mathrm{~h}$ exposure the predator was removed and any remaining prey were counted and identified to species under a microscope. This experiment was maintained at a temperature of $25 \pm 1^{\circ} \mathrm{C}$ in photoperiod L : D 14 : $10 \mathrm{~h}$. Prey preferences were determined using Manly's $\alpha$ (Manly 1974) with Chesson's (1982) alteration to account for prey depletion:

$\alpha=\frac{\ln \left(\mathrm{N}_{A e}-\mathrm{C}_{A e}\right) / \mathrm{N}_{A e}}{\ln \left(\left(\mathrm{N}_{A e}-\mathrm{C}_{A e}\right)+\ln \left(\mathrm{N}_{C_{X}}-\mathrm{C}_{C X}\right) / \mathrm{N}_{C X}\right)}$

where $\mathrm{N}$ is the initial number and $\mathrm{C}$ is the number consumed of $A e$. notoscriptus $\left({ }_{A e}\right)$ and $C x$. pervigilans $\left({ }_{C x}\right)$. Using the attack constant from the functional response experiment I can predict the preferences $(\alpha)$ for each predator with this multiplicative model:

$\alpha_{\mathrm{a}}=\frac{\alpha_{\mathrm{Ae}}}{\alpha_{\mathrm{Ae}}+\alpha_{\mathrm{Ae}}-\left(\alpha_{\mathrm{Ae}} \alpha_{\mathrm{Cx}}\right)}$

Eq. 4

where $\alpha_{a}$ is the predicted preference for Ae. notoscriptus, $\alpha_{A e}$ and $\alpha_{C x}$ are attack constants for Ae. notoscriptus and Cx. pervigilans, respectively. A ttest was performed to determine any significant differences in the preference of predators for these two mosquito species.

Prey switching is defined as predator's preference for a specific species of prey as that prey increases in abundance. In nature a predator may show strong preferences for the most abundant prey and weak 
preferences for rare prey. The prey switching model was first described by Murdoch (1969) as the relationship between the proportion of prey offered in environment and the ratio of prey consumed by predator. It was described by this equation:

$E_{1} / E_{2}=c\left(N_{1} / N_{2}\right)$

where $N_{1}$ and $N_{2}$ are the abundance of prey species 1 and 2 in the environment and $E_{1}$ and $E_{2}$ are the abundances of the same prey species consumed by the predator. $\mathrm{c}=1$ when the two prey species are attacked at the same rate. If $c$ increases with $N_{1} / N_{2}$, prey switching is presumed to have occurred. The opposite of prey switching is when a predator eats disproportionately more of the rarest prey than would be expected by chance. From the equation above this would occur when $c$ (the preference) increases as $N_{1} / N_{2}$ (amount in the environment) increases. Data were analyzed using logistic regression based on the proportion of two prey species offered to $A$. wakefieldi.

\subsubsection{Predator avoidance behavior}

In this experiment I examined the avoidance behavior of Ae. notoscriptus and Cx. pervigilans larvae in four different treatments: (1) control, without any predators; (2) when prey were placed with a free-roaming predator; (3) when prey were with a caged predator; and (4) when prey were placed in water which had predator kairomones but no predators. All treatments above were 
conducted in $200 \mathrm{ml}$ and $500 \mathrm{ml}$ of water volume, in order to test for different behaviours depending on water volume. All experiments were conducted at $25 \pm 1^{\circ} \mathrm{C}$ in photoperiod L : D $14: 10 \mathrm{~h}$. Experiments were replicated six times. Experiments were conducted in seasoned water in a plastic tube measuring $19 \times 17.5 \times 17 \mathrm{~cm}$ (height $\times$ length $\times$ width).

First, A. wakefieldi were placed in plastic cylinders within the containers ( $4 \mathrm{~cm}$ in diameter $\times 6 \mathrm{~cm}$ in height) I then added Ae. notoscriptus larva or $C x$. pervigilans larva. After 5 min of acclimation time I released the predator from the plastic cylinder. For the control treatment no predator was used and the prey remained alone. For the caged predator treatment the $A$. wakefieldi remained in the plastic cylinder in a vertical position with the open side covered with mesh. Behavior was recorded after 5 min acclimation time. For the kairomone treatment the water contained only remnant kairomones without the actual predator. To get kairomones into the water a predator was released in $500 \mathrm{ml}$ of water and fed with 10 mosquito larva for $48 \mathrm{~h}$ prior to start of the experiment. The predator and remaining mosquito larva were then removed from the water.

The activity and position of mosquito larva were recorded every $30 \mathrm{~s}$ for either 30 min or until all the prey were captured (Juliano and Reminger 1992). To classify mosquito behavior I used the method described by Juliano and Reminger (1992) with four activities: (1) resting- larva neither feeding nor moving; (2) browsing- larva propelled along the surface of the container by the movement of their mouthparts; (3) filtering- larva floating in the water column propelled by the movement of their mouthparts; (4) thrashing- 
vigorous lateral movements of the larval body, propelling themselves through the water. Four positions were recorded: (1) surface- spiracular siphon of the larva in contact of the water-air interface; (2) bottom- larva within $1 \mathrm{~mm}$ of the bottom of the container; (3) wall- larva within $1 \mathrm{~mm}$ from any surface of the container walls; (4) middle- larva more than $1 \mathrm{~mm}$ from any surface of the container and not in contact with the water surface.

The behavioral data were analyzed using multinomial logistic regression in SPSS 15.0 (2006). I score the behavior categories from 1 - 4 for activities and 5 - 8 for positions as follows: (1) resting; (2) browsing; (3) filtering; (4) thrashing; (5) surface; (6) bottom; (7) wall; and (8) middle, which were then modeled as being dependent on prey species (Ae. notoscriptus and Cx. pervigilans), and treatments (control, free-roaming predator, caged predator and kairomones).

\subsection{RESULTS}

\subsubsection{Functional response study}

The logistic regression results showed that the linear parameter $L_{1}$ was negative for the interaction between the predator and both $C x$. pervigilans and Ae. notoscriptus, indicating that type II functional responses were observed (Table 3.1). T-tests showed that the functional responses with the prey Ae. notoscriptus and Cx. pervigilans were significantly different $\left(t_{88}=\right.$ 1.88, $P=0.002 ;$ Figure 3.1). The average maximum number of prey consumed by $A$. wakefieldi was $18 \pm 0.01$ ( \pm SE) Cx. pervigilans and $31 \pm$ 0.01 Ae. notoscriptus per day. This result indicated that $A$. wakefieldi were 
better able to catch and consume on Ae. notoscriptus compared to $C x$. pervigilans, or that Ae. notoscriptus were comparatively more preferred.

The attack rate and handling time were estimated using Rogers (1972) equation. The attack rate estimated by this model was significantly lower at $4.35 \pm 0.14$ for $C x$. pervigilans than for $5.69 \pm 0.10$ for Ae. notoscriptus $\left(t_{8}=2.41, P=0.043\right)$. The handling time needed by $A$. wakefieldi when feeding on Cx. pervigilans and Ae. notoscriptus was 20.41 $\min \pm 1.08$ and $17.97 \min \pm 0.21$, respectively. This difference in handling time was significantly different $\left(t_{8}=-7.13, P<0.001\right)$.

I examined differences in attack rate and handling time by estimating these variables via the "random-predator" equation (Roger 1972) and by actual observation. No significant differences were detected in handling time by $A$. wakefieldi for $C x$. pervigilans and Ae. notoscriptus when using these two methods. However, significant differences were observed between these two different methods for estimating attack rates for both mosquito species (Table 3.2). I found that the attack rate values for $A$. wakefieldi were significantly higher in the observations compared with Roger's equation for both prey species. 


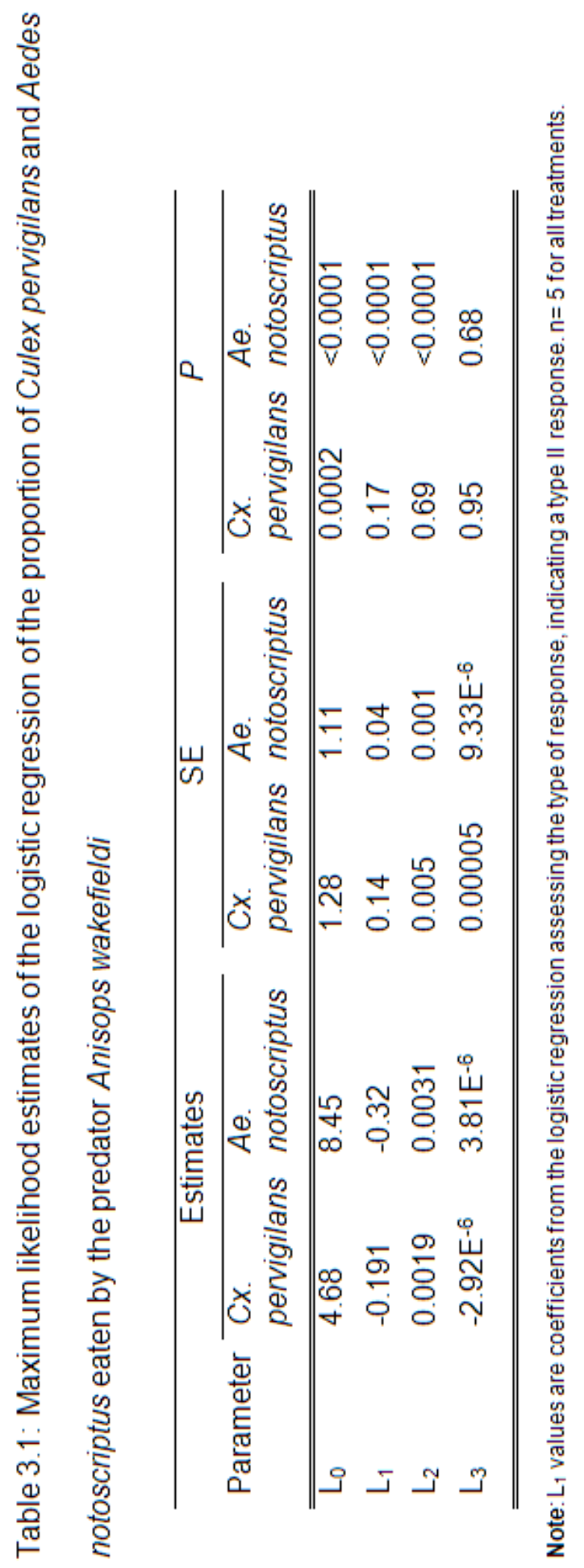




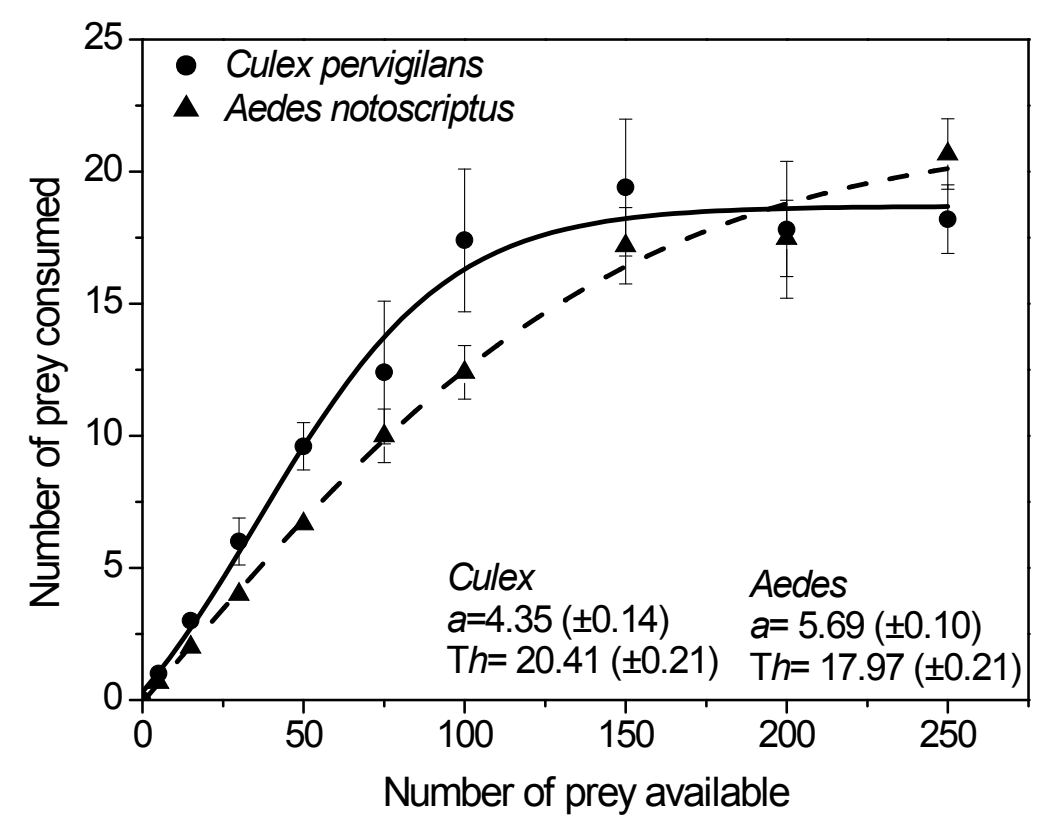

Figure 3.1: Type II functional responses displayed by $A$. wakefieldi while consuming late $3^{\text {rd }}$ and $4^{\text {th }}$ instar mosquito larvae of native $C x$. pervigilans and exotic Ae. notoscriptus. Data are means with $95 \%$ confidence intervals. 


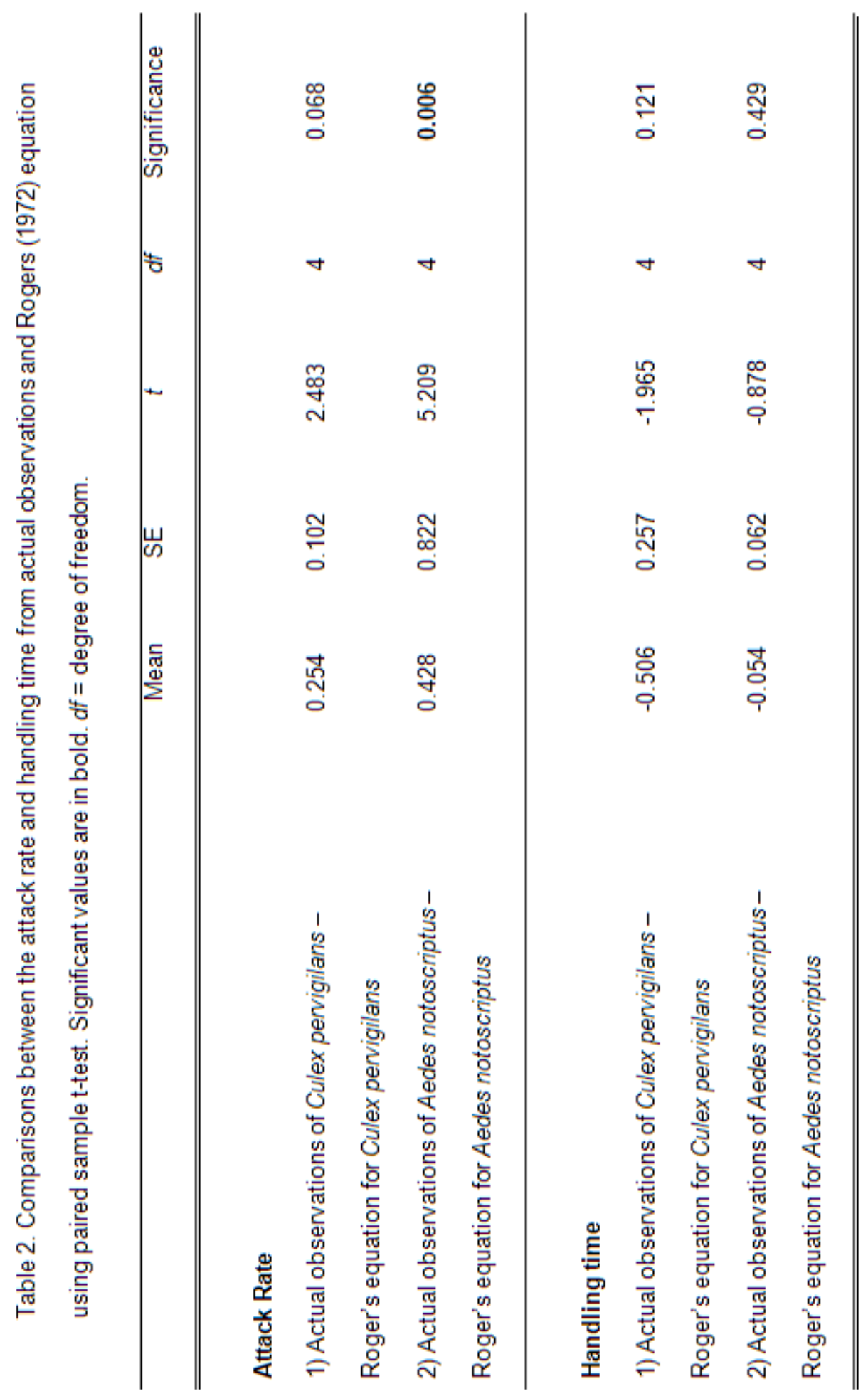




\subsubsection{Prey preferences and prey switching study}

Predator preference, estimated using Manly's $\alpha$, showed a significant difference in preference between Ae. notoscriptus and $C x$. pervigilans $\left(F_{6,21}\right.$ $=144.08, P<0.05)$. Anisops wakefieldi consumed more Ae. notoscriptus even in treatments even when there were proportionally fewer $\mathrm{Ae}$. notoscriptus relative to $C x$. pervigilans (Figure 3.2).

Switching behavior was observed in this experiment as A. wakefieldi consumed more Ae. notoscriptus when their population in the pool became more abundant $\left(r_{135}=1.85, P<0.05\right)$. Fig 3.3 illustrates that switching behavior was observed when the prey ratio crossed the ratio available line at $N_{1} / N_{2}=1$ and then lay below the available ratio line. This result indicated that $A$. wakefieldi demonstrated a switching reaction, consuming the prey species that were more abundant. 


\section{CHAPTER 3: ARE EXOTIC INVADERS LESS SUSCEPTIBLE TO NATIVE PREDATORS?}

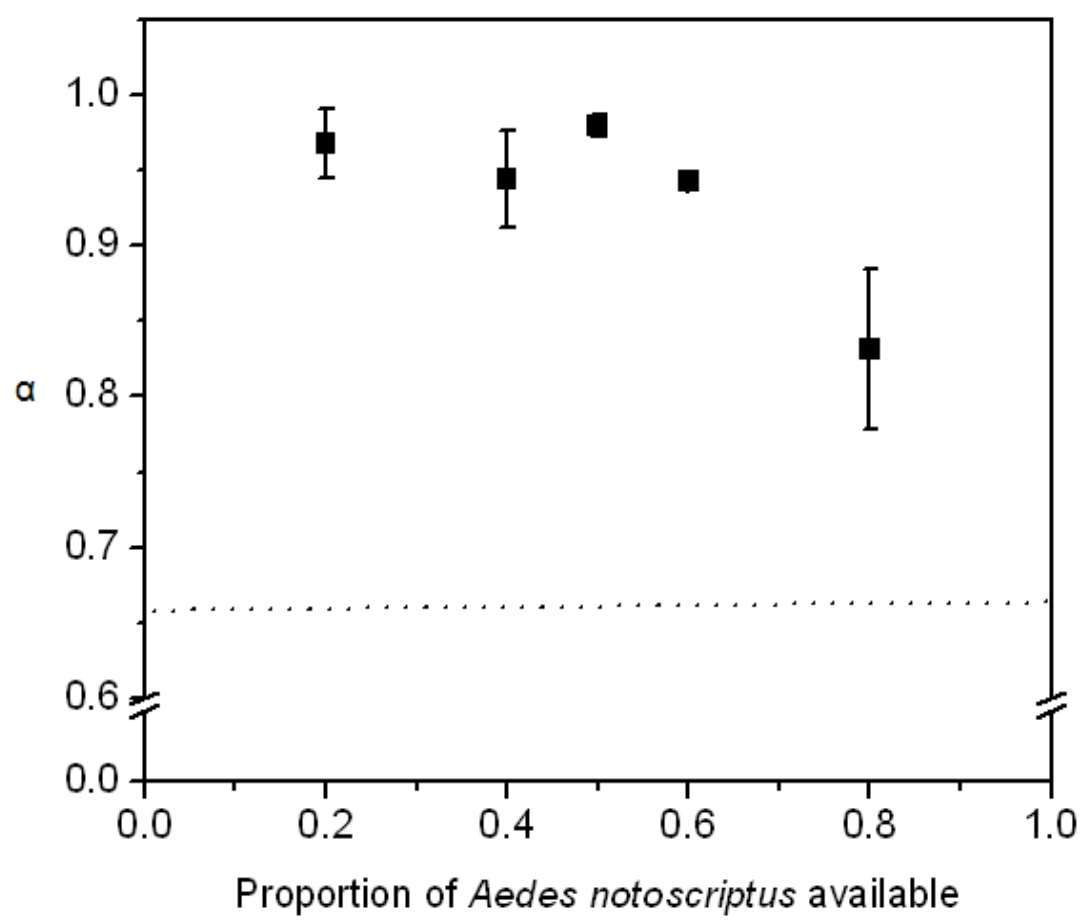

Figure 3.2: The preference of $A$. wakefieldi for exotic Ae. notoscriptus larvae compared to native Cx. pervigilans larvae, indicated by Manly's alpha ( $\alpha$ ) ( $\pm S E)$. The dash line indicates no preferences for either mosquito larvae, at $\alpha$ $=0.667 . \alpha=$ Manly's $\alpha$ used to determined prey preferences by predator. 


\section{CHAPTER 3: ARE EXOTIC INVADERS LESS SUSCEPTIBLE TO NATIVE PREDATORS?}

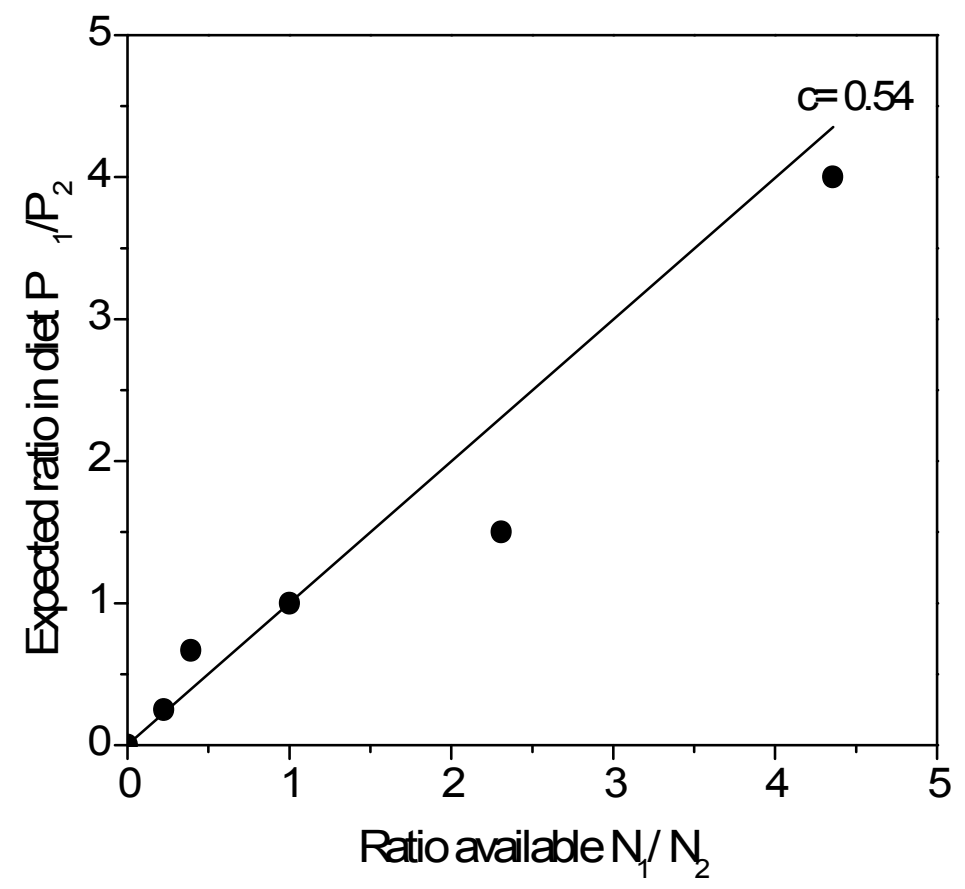

Figure 3.3: Switching behavior by $A$. wakefieldi when two prey species were offered: native $C x$. pervigilans $\left(\mathrm{N}_{1}\right)$ and exotic Ae. notoscriptus $\left(\mathrm{N}_{2}\right)$. The solid line $(c=0.54)$ indicates the expected ratio in the case of no switching. 


\subsubsection{Predator avoidance behavior}

The multinomial logistic regression likelihood ratio test showed significant effects of species $\left(X^{2}=201.08, d f=1, P<0.01\right)$, types of treatment $\left(X^{2}=\right.$ 36.76, $d f=3, P<0.01)$, activities $\left(X^{2}=1421.20, d f=7, P<0.01\right)$, and water volume $\left(X^{2}=53.91, d f=1, P<0.01\right)$. In all $500 \mathrm{ml}$ treatments $C x$. pervigilans showed a high frequency of "resting" activity at "surface", "wall" and "middle" positions, except for in the free-roaming predator treatment (Figure 3.4a). In contrast, Ae. notoscriptus displayed an approximately equally distributed frequency of behaviors. Aedes notoscriptus displayed a high frequency of "thrashing" activity with movement of their mouthparts in treatments with free-roaming predators and kairomones (Figure 4.4b). Table 3.3 shows the nominal parameter estimates from the model, in which the response of each factor is compared with a reference factor. The free-roaming predator treatment showed significant differences in behavior between Ae. notoscriptus and Cx. pervigilans (odds ratio $=0.084, P<0.001$ ). Similarly, Cx. pervigilans exhibited more "resting" behavior compared to Ae. notoscriptus (odds ratio $=197.94, P<0.001$ ). The Cox and Snell's pseudo statistic showed that less than half the variation in prey behavior was explained by the model $\left(R^{2}=0.32\right)$. 
(A) Culex pervigilans in $500 \mathrm{ml}$ of water

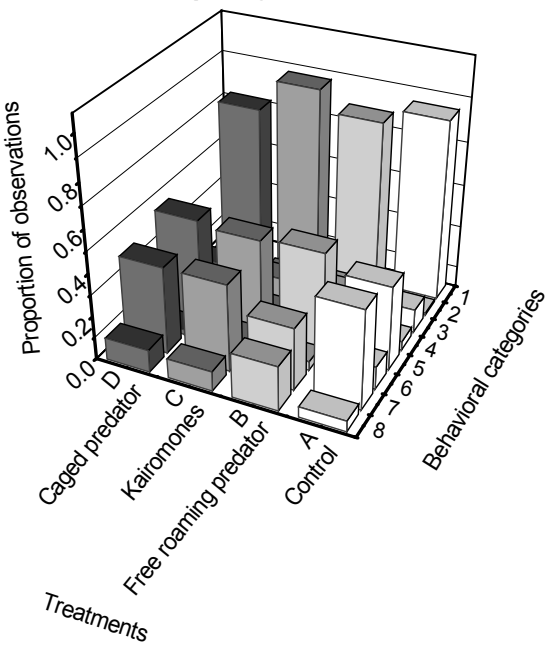

(C) Culex pervigilans in $200 \mathrm{ml}$ of water

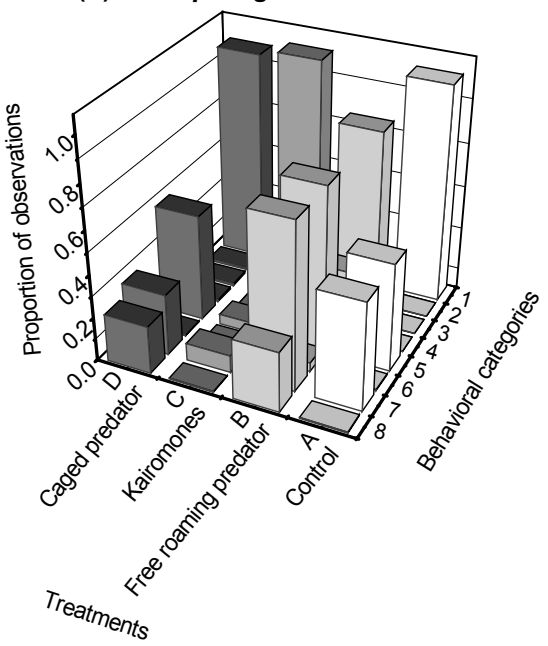

(B) Aedes notoscriptus in $500 \mathrm{ml}$ of water

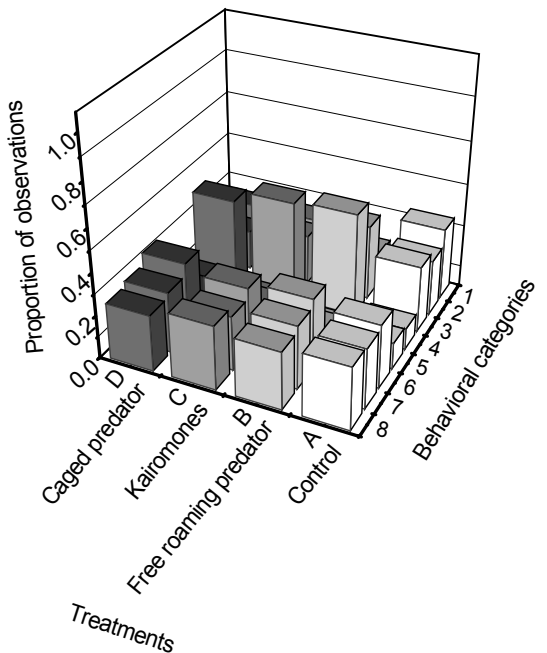

(D) Aedes notoscriptus in $200 \mathrm{ml}$ of water

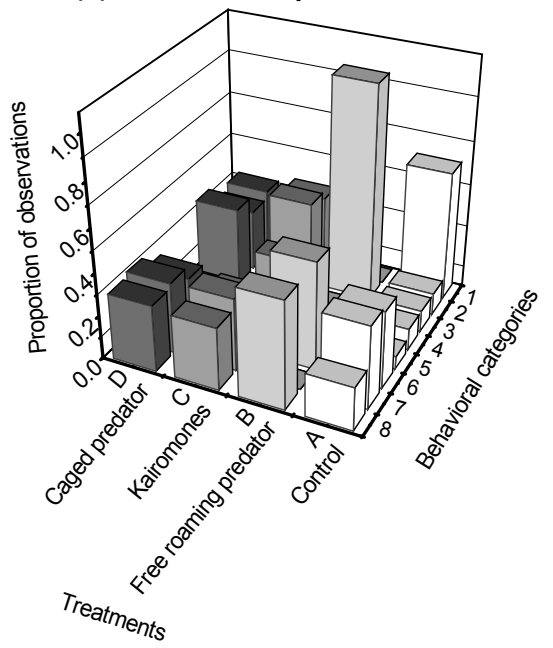

Figure 3.4: Native Cx. pervigilans and exotic Ae. notoscriptus behavior in $200 \mathrm{ml}$ and $500 \mathrm{ml}$ of seasoned water. The treatments were control (absence of predators); free roaming predators; caged predators; and water with predator kairomones. The mosquito behaviors were 'resting' (1); 'thrashing' (2); 'browsing' (3); and 'filtering' (4); 'surface' (5); 'bottom' (6); 'wall' (7); and 'middle' (8). 
Table 3.3: Results from multinomial logistic regression showing the nominal parameter estimates from the model. Mosquito species, type of treatments, activities, and position functions were analyzed in two different water volumes. The reference category was Aedes notoscriptus. Significant values are in bold.

\begin{tabular}{|c|c|c|c|c|c|c|}
\hline $\begin{array}{l}\text { Water } \\
\text { volume }\end{array}$ & & $B$ & Std. error & Wald & $d f$ & Significance \\
\hline In 500ml & Treatments & & & & & \\
\hline Culex & Control & -1.468 & 0.165 & 79.603 & 1 & $<0.001$ \\
\hline \multirow[t]{14}{*}{ pervigilans } & Free-roaming & 0.079 & 0.27 & 0.084 & 1 & $<0.001$ \\
\hline & predator & & & & & \\
\hline & Kairomones & 0.043 & 0.13 & 0.11 & 1 & 0.734 \\
\hline & Caged predator & 0 & . & . & 0 & . \\
\hline & Activities & & & & & \\
\hline & Resting & 2.981 & 0.212 & 197.941 & 1 & $<0.001$ \\
\hline & Thrashing & -1.102 & 0.412 & 7.171 & 1 & 0.007 \\
\hline & Browsing & -0.014 & 0.248 & 0.003 & 1 & 0.958 \\
\hline & Filtering & 0.979 & 0.312 & 9.835 & 1 & 0.002 \\
\hline & Position & & & & & \\
\hline & Surface & 2.231 & 0.209 & 114.217 & 1 & $<0.001$ \\
\hline & Bottom & -0.958 & 0.287 & 11.106 & 1 & 0.001 \\
\hline & Wall & 1.411 & 0.915 & 52.161 & 1 & $<0.001$ \\
\hline & Middle & 0 & & & & \\
\hline
\end{tabular}




\section{CHAPTER 3: ARE EXOTIC INVADERS LESS SUSCEPTIBLE TO NATIVE PREDATORS?}

\begin{tabular}{|c|c|c|c|c|c|c|}
\hline In 200ml & Treatments & & & & & \\
\hline Culex & Control & 1.315 & 0.180 & 53.438 & 1 & $<0.001$ \\
\hline \multirow[t]{14}{*}{ pervigilans } & Free-roaming & 5.734 & 0.877 & 42.715 & 1 & $<0.001$ \\
\hline & predator & & & & & \\
\hline & Kairomones & -0.114 & 0.189 & 0.363 & 1 & 0.547 \\
\hline & Caged predator & 0 & . & . & 0 & . \\
\hline & Activities & & & & & \\
\hline & Resting & 6.703 & 1.114 & 36.231 & 1 & $<0.001$ \\
\hline & Thrashing & 1.100 & 1.430 & 0.592 & 1 & 0.442 \\
\hline & Browsing & 1.778 & 1.282 & 1.924 & 1 & 0.165 \\
\hline & Filtering & 3.006 & 1.316 & 5.214 & 1 & 0.022 \\
\hline & Position & & & & & \\
\hline & Surface & 5.937 & 1.119 & 28.128 & 1 & $<0.001$ \\
\hline & Bottom & -0.243 & 1.514 & 0.026 & 1 & 0.873 \\
\hline & Wall & 4.675 & 1.114 & 17.618 & 1 & $<0.001$ \\
\hline & Middle & 0 & . & . & 0 & . \\
\hline
\end{tabular}


In all $200 \mathrm{ml}$ treatments Cx. pervigilans displayed "resting" activity at "surface", "wall" and "middle" positions, except for the kairomones treatment where Cx. pervigilans larvae were "resting" at all positions tested (Figure $3.4 c)$

Aedes notoscriptus displayed an approximately equal probability of all behavioral activities except for in the free-roaming predator treatment, when larvae showed a high frequency of "thrashing" at the "bottom" and "middle" of the containers (Figure 4.4d). This "thrashing" behavior may have attracted predators towards Ae. notoscriptus larvae. The multinomial logistic regression indicated significant differences in behavioral categories 1 (resting) and 4 (filtering) at positions 5 (wall) and 7 (surface), indicating that Cx. pervigilans mosquito larvae are more likely to exhibit "resting" behavior (odds ratio $=36.23, P<0.001$ ) and "filtering" (odds ratio $=5.21, P<0.05$ ) when they were faced with predation by $A$. wakefieldi. In response to predators Cx. pervigilans also altered their positions at "surface" (odds ratio $=28.13, P<0.001$ ) and "wall" of the containers (odds ratio $=17.62, P<$ 0.001; Table 3.2). These behaviors seem to be defensive, and reduced their chances of being taken by the predator.

When comparing activities by Cx. pervigilans in $200 \mathrm{ml}$ of water with those in $500 \mathrm{ml}$ of water, I found that water volume had a significant effect on their activities (odds ratio $=609.75, d f=7, P<0.01$ ). Culex pervigilans in the free-roaming predator treatment displayed "resting" activities but also a very high frequency of positioning at the "wall" of containers in $200 \mathrm{ml}$ compared to the $500 \mathrm{ml}$ treatment. In contrast, Ae. notoscriptus in the free- 
roaming predator treatments were more likely to display "thrashing" activities at the "bottom" and the "middle" of the containers. Different activity patterns by Ae. notoscriptus were observed even in the control treatment (in the absence of predators) in $200 \mathrm{ml}$ compared to $500 \mathrm{ml}$, when larvae showed more "resting" behavior on the bottom of the containers.

\subsection{DISCUSSION}

I found no evidence to support the "escape from enemies" hypothesis. The native predator showed a preference for the exotic mosquito species, Ae. notoscriptus, over the endemic species, Cx. pervigilans. The predator consumed similar numbers of both mosquitoes except at high prey densities. The maximum rate of $C x$. pervigilans consumption was attained with approximately 19 larvae. However, I observed no evidence of a plateau in prey consumption when A. wakefieldi were feeding on Ae. notoscriptus. The functional response equation predicted the plateau would occur only when densities of Ae. notoscriptus exceeded 50. A Type II functional response best described the predatory behavior of $A$. wakefieldi toward the two mosquito species. This functional response has also been found for a number of other insect and arthropod species (Murdoch 1969, Lester and Harmsen 2002, Beier et al. 2004, Griswold and Lounibos 2005). Also contrary to my expectations, the native predator preferentially consumed the exotic mosquito species. This preference was supported by the predators attack rate, in which the predator showed higher attack rates for the exotic mosquito species compared to native mosquito species. A study by Griswold 
and Lounibos (2005) also found that dipteran predators, Toxorhynchites rutilus and Corethella appendiculata showed preferences and consumed more invasive mosquito species, Ae. albopictus than the native species, Ochelarotatus triseriatus.

The preference and attack rates of the predator seem likely to be related to mosquito behavior. Clearly there was a difference in behavior that was substantial enough to result in prey switching by the predator. The role of behavioral plasticity is one of the key factors mediating a species' invasion success (Sol et al. 2002, Sagata and Lester 2009) and prey frequently adjust their behavior according to the level of predation risk (Sih 1987). Aedes notoscriptus appeared to be more visible and more attractive to predators by exhibiting thrashing behavior. In contrast the native mosquito species did not display any behavior that required a lot of movement and frequently displayed resting behavior in the presence of predators. The low risk behaviors of mosquito larvae least likely to result in predation are resting and staying near the water surface in response to $T$. rutilus (Juliano and Reminger 1992). These behaviors were also displayed by $C x$. pervigilans when confronted with $A$. wakefieldi. This seems to be a successful strategy to reduce the chances of being attacked by predators and seems to fulfill the "threat sensitivity" hypothesis, which states that prey alter their avoidance response according to the magnitude of the threat. The conclusion that there is variation in the ability of different species to detect potential threats and adjust their behavior accordingly has wide support (e.g., Laurila et al. 1997, Rochette et al. 1997, Jackson et al. 2002). It seems logical that a native 
species should be better able than an exotic species to detect and appropriately alter its behavior when confronted with a native predator due to predator-prey co-evolution.

The "escape from enemies" hypothesis is frequently used in reference to specialist predator-prey interactions (e.g., Helfmann 1989, Gyssels and Stoks 2005, Bailey et al. 2009). When an invasive species enters a food web containing generalist predators, lack of an ability to detect native predators and modify their behavior accordingly may frequently make these invaders more susceptible to attack. Also, in a newly invaded habitat range, exotic and non-native species often quickly gain a large number of enemies because they are essentially naïve and strongly affected by interactions with enemies (Case and Crawley 2000, Colautti et al. 2004). This increased susceptibility to generalist predator attack is effectively the opposite of the "escape from enemies" hypothesis.

Changes in prey behavior were observed in different water volumes. This result suggests that the mosquitoes may make themselves more or less apparent to predators in different environments. In nature the available habitats are diverse. Natural aquatic environments may contain different substrate, with different aquatic vegetation and flow velocities which can provide sub-habitats to prey species (Taniguchi et al. 2003, Taniguchi and Tokeshi 2004). Variable behavior may influence the susceptibility of mosquitoes to predators. In addition, in lower volume habitats the concentration of predator kairomones is presumably higher than that in larger volumes when the number of predators is at equal. Higher concentrations 
could indicate a greater probability of encountering the predators within the small volume (Kesavaraju et al. 2006) and may indicate proximity of a predator by concentration of the cues (Kusch et al. 2004). Consequently, it is impossible to conclude that the exotic mosquito Ae. notoscriptus would always be more susceptible to native predators than the native $C x$. pervigilans in all habitats, just as it would be impossible to make definitive conclusions about any predator-prey interaction in all potential habitats. Variable behavior or susceptibility to predators in different environments may help explain the establishment of Ae. notoscriptus in New Zealand despite it's relatively higher susceptibility to this predator.

At this stage there is insufficient evidence to support the "escape from enemies" hypothesis as a major mechanism facilitating species invasions. Invasion success may depend on the ability of exotic species to respond adaptively to predators. In the absence of other adaptive responses, behavioral responses from prey may become one of the important factors in mediating the effect of predators on prey species. 


\section{CHAPTER FOUR:}

\section{Can adults of the New Zealand mosquito Culex pervigilans (Bergorth) detect the presence of a key predator in larval habitats?}

In part published as: Zuharah WF and Lester PJ (2010) Can adult of New Zealand mosquito Culex pervigilans (Bergorth) detect the presence of a key predator in larval habitat?. Journal of Vector Ecology. 35(1): 100 - 105 (see Appendix C). 


\subsection{ABSTRACT}

The influence of predators on mosquito populations may be direct through predation, or indirect through sub-lethal responses of adult mosquitoes in life history traits such as oviposition behavior. In New Zealand, the backswimmer, Anisops wakefieldi, is a common predator of mosquito larvae found in temporary and permanent water bodies. I predicted that the New Zealand native mosquito, Culex pervigilans, whose larvae are vulnerable to predation of $A$. wakefieldi, would likely avoid the containers with the presence of $A$. wakefieldi or its kairomones remnant. I established temporary water containers without predators, free-roaming predators, caged predators (which were unable to eat mosquitoes), or containers from which predators were removed immediately prior to the experiment (these containers would have remnant kairomones from the predators). Each treatment with $A$. wakefieldi had predator densities of one, three or nine A. wakefieldi. Contrary to my predictions, when choosing oviposition habitats, Cx. pervigilans appeared to ignore the presence of free-roaming $A$. wakefieldi, caged $A$. wakefieldi and water with $A$. wakefieldi kairomones. I thus observed no significant differences between the numbers of egg rafts laid by $C x$. pervigilans in the different predator treatments nor were the number of egg rafts significantly affected by the density of predators. Rather than the presence of predators, environmental factors including temperature, humidity and pressure were significantly correlated with mosquito oviposition. These mosquitoes appeared to either ignore the presence of the predator, had no ability to detect the presence of predators, or perhaps the cues from $A$. 


\section{CHAPTER 4: CAN ADULT MOSQUITOES DETECT THE PRESENCE OF PREDATOR?}

wakefieldi predators were not sufficiently strong enough to provide alarm to these mosquitoes. I argue that the mosquito has not evolved ability to detect the presence of these predators while ovipositing.

Keywords: Predation · Oviposition · Predator density · Kairomones . Environmental factors. 


\subsection{INTRODUCTION}

The survival and growth of organisms without parental care is thought to be strongly dependent on the quality of habitat into which they are deposited. Adults of insects in which juveniles are incapable of migrating away from low quality habitat should be evolved to select oviposition sites that improve the likelihood of their offspring survival and growth (Kiflawi et al. 2003a, Blaustein et al. 2004, Bond et al. 2005). Thus a female mosquito should be able to detect and avoid ovipositing in sites which have a high risk of predation for their eggs or juvenile stages. Mosquitoes also compete with one-another and should selectively oviposit to minimize inter- or intra-specific competition. Blaustein et al. (2004) suggested that five factors have shaped the ability of mosquitoes to respond to the risk of predation during ovipositing: 1) mosquito larvae are highly vulnerable to predation, 2) they have only one or a few lifetime reproductive events, 3) their eggs are often laid together, 4) their predators have highly heterogeneous distributions, and finally, 5) the distribution of predators is often highly fixed from the time of prey oviposition event until prey progeny can either leave the patch or become large enough to be invulnerable to predation. Ideally, mosquitoes may have an ability to detect the presence of predators or competitors based on chemical or physical cues released (Stav et al. 1999).

Wisenden (2000) showed that chemical cues are released by the predator during detection, attack, capture and ingestion of prey. Prey may use these cues to minimize their exposure to predators. Several species of 
mosquitoes have been shown to be able to detect the presence of predatory notonectid bugs and avoid ovipositing in pools containing these predators. In the presence of only one predatory backswimmer (Notonecta maculata Fabricious) in 10 litres of water, Culiseta longirealata (Macquart) oviposition was strongly reduced (Blaustein et al. 1995, Blaustein 1998, Kiflawi et al. 2003a, Kiflawi et al. 2003b). Eitam and Blaustein (2004) found that Cs. longiareolata and $C x$. laticintus oviposited less in pools containing predators, but this avoidance of predators was unrelated to predator densities. Their work was also supported by Blaustein et al. (2005), who found that Culex mosquitoes strongly avoided ovipositing in pools containing the Notonecta predators. Mosquitoes continued to avoid ovipositing in pools with predators for two additional days after the predator was removed, suggesting a predator-released kairomones was the cue used by mosquitoes to detect the presence of predators.

Stav et al. (1999) suggested that the distribution and abundance of a mosquito species is dependent on their ability to selectively oviposit according to predator abundance. The density of predators may affect mosquito oviposition due to the ability of mosquitoes to detect predator densities and thus to assess the severity of predation risk. With increasing predators densities, concentration of kairomones are also increased and may result in reduced oviposition (Eitam and Blaustein 2004). Reduced oviposition by mosquitoes may be expected with increasing numbers of predators, due to the ability of these prey species to detect the presence of a 
predator above a threshold density (Angelon and Petranka 2002) or concentration of kairomones (Eitam and Blaustein 2004).

My aim in this study is to examine the oviposition behaviour of the New Zealand mosquito $C x$. pervigilans in response to the notonectid predator $A$. wakefieldi under the field conditions. Anisops spp. are known to be predators of mosquito larvae and are commonly found in permanent and temporary water bodies in New Zealand (Graham 1939, Laird 1990; 1995). Culex pervigilans is a vector species of the human and avian Whataroa virus (Maguire et al. 1967, Miles 1973), is suggested to be a vector of avian malaria caused by Plasmodium relictum (Holder et al. 1999, Massey et al. 2007), and has been highlighted as a species requiring further investigation for its potential to vector exotic arboviruses (Weinstein et al. 1997). I hypothesized that $C x$. pervigilans are likely to avoid ovipositing in pools containing A. wakefieldi or its kairomones, and that the influence of the kairomones released by $A$. wakefieldi predator may last for several days after the predators are removed. I also hypothesized environmental factors could play a role in influence mosquito oviposition rates. Bentley and Day (1989) suggested temperature, rainfall, wind speed and relative humidity may affect the initiation of ovipositional flights by mosquitoes. 


\subsection{MATERIALS AND METHODS}

\subsubsection{Study sites}

The study was undertaken in Otari-Wilton's Bush in Wellington, New Zealand $\left(14^{\circ} 14^{\prime} \mathrm{S}, 174^{\circ} 45^{\prime} \mathrm{E}\right)$. Otari-Wilton's Bush is Wellington's largest area of original native forest. Experiments were undertaken on the edge of the forest in plant nursery, with no overhead canopy or shading. Temperatures over the period of experiments ranged from $14.8^{\circ} \mathrm{C}$ to $18.2^{\circ} \mathrm{C}$ and relative humidity was between $62.8 \%$ and $89.3 \%$. Experiments were conducted during the southern hemisphere summer season for two consecutive summers (2007/08 and 2008/09). These experiments ran from $18^{\text {th }}$ December 2007 to $11^{\text {th }}$ February 2008, and from $7^{\text {th }}$ December 2008 until $19^{\text {th }}$ January 2009.

\subsubsection{Predator colonies}

The A. wakefieldi third and fourth instar (nymphal) used in this experiment were collected from permanent water troughs (with approximately volume of 800 liters of water) in Queen Elizabeth II Park near Waikanae, New Zealand (405' S, $\left.174^{\circ} 58^{\prime} \mathrm{E}\right)$, approximately $70 \mathrm{~km}$ from Wellington city. These predators were brought back to the laboratory for identification and deprived of food for 24 hours prior to their release into the experimental containers. 


\subsubsection{Study design}

Eleven black plastic containers $(25.5 \times 25.5 \times 23.5 \mathrm{~cm})$ served as temporary pools for the experiment. Containers were filled with 10 I of water: 9.75 I of aged tap water (tap water that was left standing for more than 48 hours to reduce the chlorine content) mixed with 0.25 I of stream water from the nearest stream (Kaiwharawhara Stream). Water was left to age for 48 hours prior to initiating experiment. Stream water was taken from nearest river to introduce bacterial inoculates for food sources for mosquito larvae and was filtered with $0.2 \mathrm{~mm}$ mesh before being added to the containers. The water level was maintained at 10 I throughout the experiment by adding aged tap water or by natural rain to account for any loss due to evaporation. Nutrients were added once prior to experiment to the water in the form of "Kiwi" brand pelletised sheep manure which contained $3 \%$ nitrogen, $2 \%$ phosphorus and $4 \%$ potassium at a weight of $5 \mathrm{~g} / \mathrm{l}$ of water, 24 hours prior to the experiment. Previous work has shown such conditions to be ideal for $C x$. pervigilans (Leisnham et al. 2006). Containers were then covered with $1.0 \mathrm{~cm}$ wire mesh to prevent vertebrate animals from drinking or falling into the water.

These containers were set up so that the distance between containers was at least $\sim 0.5 \mathrm{~m}$ from its flanking neighbor. Treatments established were as follows: 1) controls without predators; 2) free-roaming $A$. wakefieldi (with one, three or nine $A$. wakefieldi per container); 3) caged $A$. wakefieldi (empty cage without predator, with one, three or nine $A$. wakefieldi in a cage, which were unable to consume mosquito larvae or directly seen by ovipositing 
adults); and 4) A. wakefieldi kairomones remnant (with kairomones from one, three or nine A. wakefieldi which were present in the water for $24 \mathrm{~h}$ prior to the experiment, but removed at the start of each trial). All treatments were replicated for three times for each year. Cages used to contain predators in the caged $A$. wakefieldi treatment were constructed using $1.5 \mathrm{I}$ clear plastic drinking bottles, each with one opening windows $(10 \mathrm{~cm} \times 3 \mathrm{~cm})$ on each of two sides of the bottle and one end of the tops of the bottle was covered with $2 \mathrm{~mm}$ nylon mesh. The mesh was used to ensure that the predator could breathe and any predator-released kairomones from $A$. wakefieldi could diffuse into the main water-body. The cages were placed in a horizontal orientation within the water containers so that most of the cage was submerged. In the kairomones remnant treatment, $A$. wakefieldi were kept in the water for 48 hours immediately prior to the beginning of the experiment before their removal. Therefore, the water only contained kairomones without the presence of an actual predator.

All containers were set up 48 hours before the experiments began in order to introduce and familiarize mosquitoes to the new oviposition sites. All mosquito egg rafts were counted 48 hours after containers were introduced to the field. Each day for 12 days after the $A$. wakefieldi was added, A. wakefieldi was counted and any missing or dead A. wakefieldi were replaced. The eggs were daily collected into small containers with water and were brought back to laboratory for counting and identification at larval stages. 


\subsubsection{Statistical analysis}

I used a repeated-measures general linear model (GLM) to test for significant effects of predator treatment (free-roaming, caged predators or no predators), predator density, and time on $C x$. pervigilans oviposition rate in SPSS (2006). Data were tested for normality using a one-sample Kolmogorov-Smirnov test. All data were log $(x+1)$ transformed prior to analysis to satisfy the assumptions of ANOVA. Sphericity could not be assumed in the study $(\varepsilon=0.704, p=0.009)$ and Huynh-Feldt epsilon value were used in the F-tests. The repeated measures within- subjects factor were period with 4 levels; day 1-3, day 4-6, day 7-9 and day 10-12. Predator treatment and density were treated as between-subjects factors.

The number of egg rafts observed during each period was correlated with five environmental factors: temperature, wind speed, rainfall, humidity and pressure, using a Pearson correlation coefficient. The environmental data were obtained from the Kelburn weather station approximately $3 \mathrm{~km}$ from my study site, by National Institute of Water and Atmospheric Research (NIWA), New Zealand. Any significant correlation data from Pearson's correlation test were then analyzed using t-test in order to determine the mean effects between years. 


\subsection{RESULTS}

No significant differences in mosquito oviposition rates were detected between treatments with the presence of predators, either cages or uncaged, the presence of their kairomones remnant, and the control treatment with no predators $(F=1.389, d f=3, P=0.284$; Table 4.1 and Figure 4.1). Similarly, no statically significant effects of predator densities were observed on oviposition rates $(F=0.224, d f=3, P=0.879)$. Thus, $C x$. pervigilans mosquitoes appeared choose their oviposition habitat without taking into account of predator presence or density. There were no significant differences in oviposition between all four periods tested, nor was there any significant interaction between periods and treatments or a significant three way interaction ( $P \geq 0.500$; refer to Table 4.1). Thus, mosquito oviposition rates were similar irrespective of how long the predators were in the water containers (or in the case of the kairomones remnant treatment, how long the predator had been removed). These results suggested that $C x$. pervigilans mosquitoes were not able to detect, or ignored, the presence of $A$. wakefieldi or its kairomones remnant.

A total of 284 egg rafts were collected in 2007/2008, which was significantly more than 2008/09 when only 28 egg rafts were collected $(t=$ 3.801, $d f=114, P<0.001)$. All of the egg rafts were identified as $C x$. pervigilans. There were significant correlations between the number of $C x$. pervigilans egg rafts and temperature, humidity, and pressure (Table 4.2). Ttests examining the mean effects between years indicated that fewer egg 


\section{CHAPTER 4: CAN ADULT MOSQUITOES DETECT THE PRESENCE OF PREDATOR?}

rafts were oviposited by $C x$. pervigilans mosquitoes when the temperature was significantly higher $(t=67.43, d f=35, P<0.001)$ with significantly lower humidity and pressure $(t=35.94, d f=35, P<0.001 ; t=798.08, d f=35, P<$ 0.001 respectively) in $2008 / 09$ summer season compared to $2007 / 08$ summer season. 

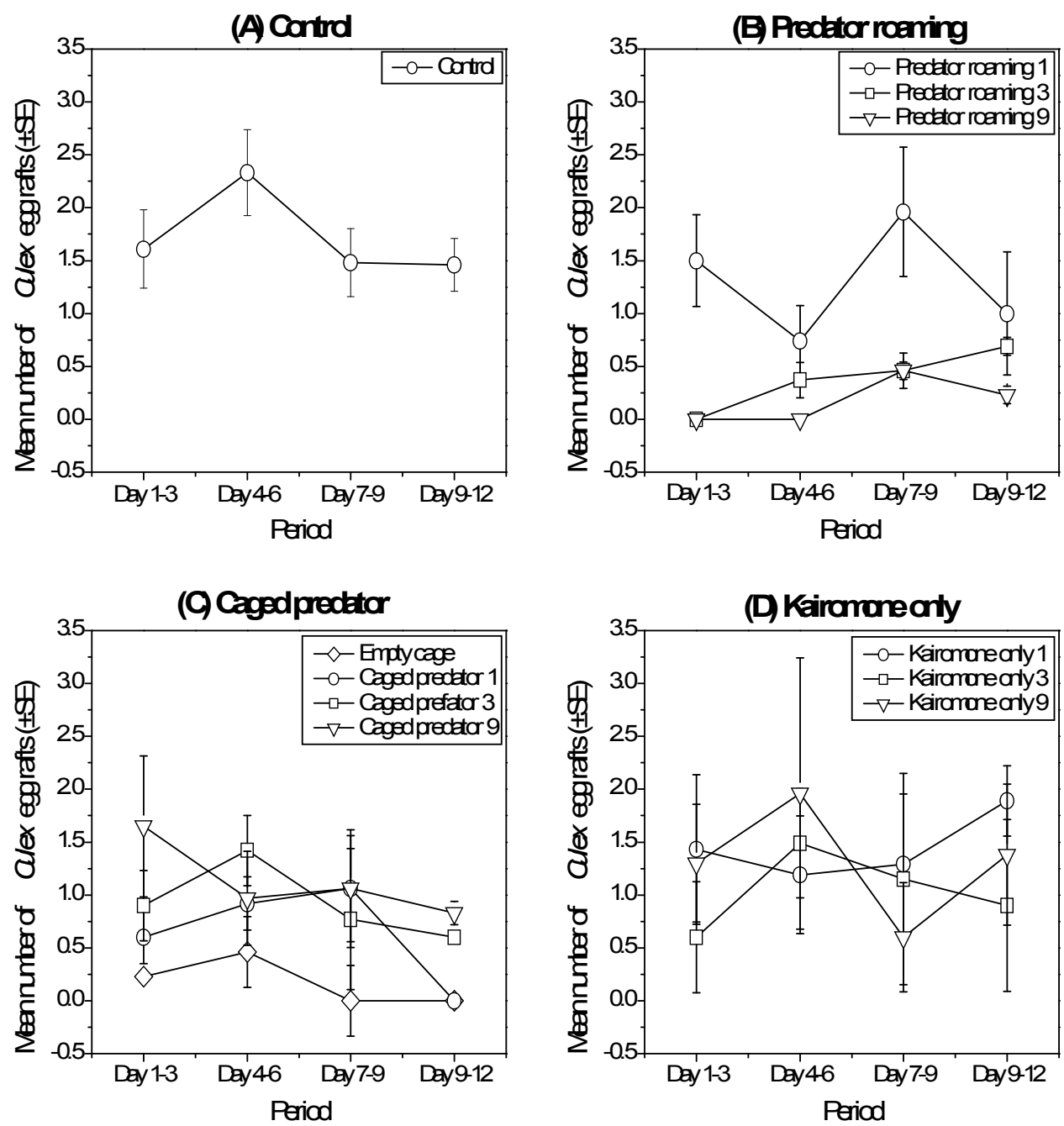

Figure 4.1: The effects of predator treatment and predator density ( $A$. wakefieldi) on number of $C x$. pervigilans egg rafts (mean \pm SE) based on 4 periods time tested; (A) control (B) free-roaming predators, (C) caged predators (D) water with predator kairomones. 
Table 4.1: Results of repeated measures ANOVA examining the cumulative number of $C x$. pervigilans egg rafts in response different types of predator treatments and densities $(A n$. wakefieldi). $d f=$ degree of freedom, $M S=$ mean squared values. Significant values are in bold. Data were log transformed prior to analysis.

\begin{tabular}{|c|c|c|c|c|}
\hline Source & $F$ & $d f$ & MS & Significance \\
\hline Treatments ( $T$ ) & 1.389 & 3 & 0.032 & 0.284 \\
\hline Densities (D) & 0.224 & 3 & 0.005 & 0.879 \\
\hline Period $(P)$ & 1.030 & 3 & 0.004 & 0.381 \\
\hline Year $(Y)$ & 3.791 & 1 & 0.013 & 0.100 \\
\hline$P \times T$ & 0.931 & 9 & 0.003 & 0.500 \\
\hline$P \times D$ & 0.828 & 6 & 0.003 & 0.591 \\
\hline$P \times Y$ & 1.689 & 3 & 0.006 & 0.173 \\
\hline$P \times T \times D$ & 0.693 & 12 & 0.002 & 0.600 \\
\hline$P \times Y \times T$ & 1.281 & 6 & 0.005 & 0.271 \\
\hline$P \times T \times D \times Y$ & 0.395 & 12 & 0.001 & 0.963 \\
\hline Period $x$ Subject within groups & & 126 & 0.004 & \\
\hline Period $x$ Subject between groups & & 42 & 0.014 & \\
\hline
\end{tabular}


Table 4.2: Pearson correlation analysis results between temperature, wind speed, rainfall, humidity, and pressure with Cx. pervigilans egg rafts after 12 days post-treatment based on two years study periods. Significant values are in bold. * indicated that the significant value is at $P<0.05$ and ** are at 0.01 . $d f=271$ for all factors

\begin{tabular}{lcc}
\hline Factor & Pearson's $r$ & Significance \\
\hline \hline Temperature & $0.159^{*}$ & $\mathbf{0 . 0 1 2}$ \\
Wind speed & -0.104 & 0.098 \\
Rainfall & -0.084 & 0.182 \\
Humidity & $0.187^{* *}$ & 0.003 \\
Pressure & $-0.504^{* *}$ & $<0.001$ \\
\hline \hline
\end{tabular}




\subsection{DISCUSSION}

I predicted that the mosquito $C x$. pervigilans would alter its oviposition behaviour in the presence of the predator $A$. wakefieldi or its kairomones. This prediction was based on several other studies that have found evidence for Culex spp. and Culiseta spp. avoiding oviposition in the presence of Notonecta sp. or its chemical traces (Blaustein et al. 1995, Blaustein 1998, Kiflawi et al. 2003a, Blaustein et al. 2004, Eitam and Blaustein 2004, Blaustein et al. 2005). Eitam et al. (2002) also found that in the presence of free swimming $A$. sardea, Culiseta mosquitoes were repelled from ovipositing in pools, resulting in a significant low number of eggs than in control pools. In contrast, I found no evidence that $C x$. pervigilans modifies its oviposition behaviour in response to predators. I postulate that $C x$. pervigilans either ignored the presence of the predator or that the cues from $A$. wakefieldi predators were not sufficiently strong enough to provide an alarm to these mosquitoes

The densities of predators that I used have elicited avoidance responses in Culex mosquitoes elsewhere. The densities of predators in my study were more than twice that used in the study by Eitam and Blaustein (2004), but I observed no significant response by mosquitoes to the predator or its kairomones. In regard to kairomones, other mosquitoes such as Culiseta longireolata can detect chemicals from Notonecta predators for periods of up to eight days after their removal from the pool (Blaustein et al. 2004) and at least two days for Culex species (Blaustein et al. 2005). It thus 
seems reasonable to expect that the mosquitoes would have shown a response to this predator in my experimental design and I are relatively confident that no such response occurred. Nevertheless, I cannot rule out the possibility that the mosquito would have shown a response to the predator at higher predator densities.

Given the substantial effects of individual predators on $C x$. pervigilans populations, I would have expected this mosquito to have evolved an ability to detect the densities of this predator that I used in the experiment. In laboratory experiments I have observed $A$. wakefieldi to kill large numbers of Cx. pervigilans (Zuharah and Lester, In Press B). A single adult predator can kill an average of 10-82 Culex larvae per day based on prey and predator size and density (Nabaneeta et al. 2007). There was thus clearly no reason why $C x$. pervigilans should have ignored the presence of the $A$. wakefieldi predator. In the absence of any behavioural modification of oviposition, these lethal effects of $A$. wakefieldi seem likely to be the mechanism resulting from the near complete absence of mosquitoes co-occurring with this predator in my field studies (Zuharah and Lester, In Press A).

Given the lethal effects of $A$. wakefieldi on mosquito populations, why hasn't an ability to detect predators evolved in this mosquito? I can only speculate on explanations. It is possible that until recently, this species may have not naturally co-occurred together. Greig (2008) found that Anisops sp. in Canterbury, New Zealand, is likely to inhabit either in permanent or semipermanent water bodies, but not in temporary pools. However, $C x$. 
pervigilans is able to breed in a wide variety of any water habitat. Culex larvae can easily found in fresh and polluted waters, permanent and temporary ground pools, natural and artificial containers and also slow moving streams (Belkin 1968, Dumbleton 1968, Holder et al. 1999). With the creation of water troughs by humans in farming industry, A. wakefieldi predators have perhaps only recently started to share the same habitat with Cx. pervigilans. Statistics New Zealand (2008) indicated that $76 \%$ of agricultural land was used for animal farming industries in year 2002 with many thousands of existing water troughs as potential habitat for $C x$. pervigilans, A. wakefieldi and other aquatic insects. Culex pervigilans are now the most common species observed in water bodies such as animal trough where A. wakefieldi also occur (Laird 1990). Because of the immense selection pressure exerted by $A$. wakefieldi on $C x$. pervigilans in this new habitat, the mosquito may develop an ability to detect this predator, but the evolution of such ability would be likely to take a long time to develop.

Given the lack response of $C x$. pervigilans to $A$. wakefieldi predator, I predicted that variation within and between years in mosquito oviposition behaviour might be explained by environmental factors. Changes in temperature or precipitation may drive changes in mosquito density and populations (Canyon et al. 1998, Ritchie and Rochester 2001, Koenraadt et al. 2004, Hsu et al. 2008, Platonon et al. 2008). Similarly, my results also indicated that more egg rafts were oviposited by Culex mosquitoes when the temperatures were higher, humidity and pressure were lower as demonstrated in 2007/08 summer season. In my experiment, environmental 


\section{CHAPTER 4: CAN ADULT MOSQUITOES DETECT THE PRESENCE OF PREDATOR?}

variables clearly had a far greater influence on oviposition than the presence of $A$. wakefieldi predators.

In summary, I found that $C x$. pervigilans did not alter their oviposition behaviour in response to $A$. wakefieldi predators (or its kairomones), presence of different densities of predator and also environmental factors. This is the first published study to demonstrate that $C x$. pervigilans do not alter their oviposition behaviour according to the presence of a voracious predator. The complexity of Culex sp. ability to detect predator presence still remains to be seen and should continue to be studied. 


\section{Chapter Five:}

\section{Lethal and sub-lethal exposure of prey to predators substantially influences the survival rate and life history traits of a mosquito}

In part published as: Zuharah WF and Lester PJ. Lethal and sub-lethal exposure of prey to predators substantially influences the survival rate and life history traits of a mosquito.

(In review in Population Ecology, submitted on 10 June 2010) 


\subsection{ABSTRACT}

The presence of predators can have dramatic consequences on prey communities, not only by the direct effects of consumption but also through sub-lethal effects. I investigated the survival rate and subsequent life history of the mosquito Culex pervigilans (Bergorth) under the influence of its major predator, the backswimmer Anisops wakefieldi (White). I established a field experiment with various treatments: 1) control without predators; 2) freeroaming A. wakefieldi (with one, three or nine A. wakefieldi per container); 3) caged A. wakefieldi (empty cage without predators, or with one, three or nine A. wakefieldi in each cage; and 4) A. wakefieldi kairomones remnant from predators (with kairomone concentrations of one, three or nine A. wakefieldi which were present in the water for $24 \mathrm{~h}$ prior to the experiment but removed at the start of each trial). Culex pervigilans eggs were then taken from these experiments and reared in two different laboratory conditions: $(A)$ in clean water without any traces of predators, or $(B)$ in water with the same treatments as in field. The survival rate of $C x$. pervigilans was significantly reduced by the presence of predators or their kairomones. Even though the eggs were only exposed briefly to water containing either predators or kairomones in the field, and then were reared in clean water without any traces, sub-lethal effects still impacted the remaining survivors. These results were observed when adult mosquitoes were exposed to predators at the time of oviposition and when the predators or kairomones were present throughout the life history of the mosquito. The percentage of eggs that hatched, and the resulting mosquito population was influenced by the 
presence of predators or their kairomones. No effect was observed on $C x$. pervigilans sex ratio or changes in development times of each life stage. My results suggested that sub-lethal effects may be carried by surviving individuals primarily through the effects of stress, perhaps by epigenetic mechanisms. We may expect to observe similar plasticity in species or populations with high temporal or spatial variability in predation.

Keywords: Culex pervigilans · Anisops wakefieldi $\cdot$ Hatching rate $\cdot$ Sex ratio - Development time $\cdot$ Survival rate $\cdot$ 


\subsection{INTRODUCTION}

Predators influence prey populations not only through direct consumption but also by indirect effects, which include any type of interaction between the predator and prey that does not result in death. These sub-lethal effects may affect prey traits such as life history and growth rate (Havel 1987, Havel and Dodson 1987, Black and Dodson 1990, Laurila et al. 1998), morphology (Havel and Dodson 1984, Dodson 1988, Gilbert and Hartmen 1996, Johansson and Wahlström 2002), delayed or reduced fecundity (Havel and Dodson 1987, Walls and Ketola 1989, Black and Dodson 1990), and behavior (Lima 1998). Such sub-lethal effects typically induce a cost for prey populations (Lima 1998).

Avoiding predators may result in a reduction of food intake and ultimately a reduction in the reproductive success of prey (Gerritsen and Stickler 1977, Werner and Anholt 1996). For example, Bond et al. (2005) found that predatory fish reduced larval mosquito feeding opportunities. As a result the mosquitoes exhibited extended larval development times, adult mosquitoes were significantly smaller and had higher mortality compared to when predators were absent (Peckarsky et al. 1993, Bond et al. 2005, Mikolajewski et al. 2005). The sub-lethal influence of predators may even be sex-specific. Braune and Rolff (2001) suggest that mass and size are relatively important for female prey as predators likely affect their survival and fecundity. Male mosquitoes may emerge earlier as a trade-off in presence of predator to maximize their fitness (Nylin and Gothard 1998). 
Chemical recognition of predators by prey may play be important for many aquatic insects, especially for those that live in limited visibility habitats or where predators are cryptic (Kats and Dill 1998). Prey may be able to detect the presence of a predator by their chemical cues (or 'kairomones'); these are usually released directly by a potential predator or by injured conspecific prey (Beketov and Liess 2007). Upon sensing kairomones released by potential predators, prey may display diverse changes in behavior, morphology, or even life history (Kats and Dill 1998). However, it is unlikely an individual prey species can detect kairomones from all potential predators. Understanding if prey can detect predator kairomones and how this may modify their life history is important for understanding the population dynamics of prey populations.

The mosquito Cx. pervigilans (Bergorth) is New Zealand's most common native mosquito species observed in artificial containers (Laird 1990; 1995). This mosquito is a vector of the human and avian Whataroa virus (Maguire et al. 1967, Miles 1973) and is suggested to be a vector of avian malaria (Holder et al. 1999, Massey et al. 2007). A common predator is the backswimmers, A. wakefieldi (White). These predators are known to consume mosquito larvae and are commonly found in permanent and temporary water bodies in New Zealand (Graham 1939, Laird 1990; 1995). My aim in this study was to examine the lethal and sub-lethal effects of these predators and their kairomones on the mosquito. I examined the lethal and sub-lethal effects of this predator on egg hatching rates, development time of each life stage, sex ratio, and survival rate of $C x$. pervigilans first progeny 
after exposure to $A$. wakefieldi. These scenarios differed in the length of time the developing mosquitoes were exposed to predators or their kairomones; (1) only the eggs were exposed to predators or their kairomones in the field but then reared in clean water without any traces of predator. (2) eggs were hatched and the larvae maintained in treatments that had free-roaming predators or predators in cages, from the treatment with predator kairomones remnant, and from the control treatment where no predators or their traces were present.

\subsection{MATERIALS AND METHODS}

\subsubsection{Insect colonies}

The predators, A. wakefieldi, used in this experiment were collected from water troughs in Queen Elizabeth II Park near Waikanae, New Zealand $\left(40^{\circ} 57^{\prime} \mathrm{S}, 174^{\circ} 58^{\prime} \mathrm{E}\right)$, approximately $70 \mathrm{~km}$ from Wellington city. These predators were brought back to laboratory and fed daily with mixed instar mosquito larvae.

Egg rafts of $C x$. pervigilans were obtained opportunistically from another experiment on mosquito oviposition behavior (Zuharah and Lester 2010). Briefly, this experiment utilized black circular 10 I containers $25.5 \times$ $25.5 \times 23.5 \mathrm{~cm}$, at Otari-Wilton's Bush in Wellington, New Zealand $\left(14^{\circ} 14^{\prime} \mathrm{S}\right.$, $\left.174^{\circ} 45^{\prime} \mathrm{E}\right)$. Nutrients were added to the water in the form of "Kiwi" brand pelletised sheep manure which contained $3 \%$ nitrogen, $2 \%$ phosphorus and $4 \%$ potassium at a rate of $5 \mathrm{~g} / \mathrm{l}$ of water, 1 day prior to the experiment. 
Previous work has shown such conditions to be ideal for $C x$. pervigilans (Leisnham et al. 2006). Containers were then covered with $1 \mathrm{~cm}$ wire mesh to prevent vertebrate animals from drinking or falling into the water. The treatments from which eggs were collected were as follows: 1) control without predators; 2) free-roaming $A$. wakefieldi (with one, three or nine $A$. wakefieldi per container); 3) caged A. wakefieldi (empty cage without predators, or with one, three or nine $A$. wakefieldi in each cage, these predators were either unable to consume mosquito larvae or been directly seen by ovipositing mosquito adults); and 4) A. wakefieldi kairomones remnant from predators (with kairomone concentrations of one, three or nine A. wakefieldi which were present in the water for $24 \mathrm{~h}$ prior to the experiment but removed at the start of each trial). Cages used to contain predators in the caged Anisops treatment were constructed using 1.5 I clear plastic drinking bottles, each with one opening windows $(10 \mathrm{~cm} \times 3 \mathrm{~cm})$ on each of two sides of the bottle and one end of the tops of the bottle was covered with $2 \mathrm{~mm}$ nylon mesh. Eggs laid by wild female adult mosquitoes were collected daily at 0900 , brought back to laboratory and immediately counted under the microscope. Experiment with treatments above was replicated for three times. Temperatures over the period of experiments ranged from $14.8^{\circ} \mathrm{C}$ to $18.2^{\circ} \mathrm{C}$ and relative humidity was between $62.8 \%$ and $89.3 \%$. These containers were set up in the southern hemisphere summer season from December to January 2007/08 and 2008/09. 


\subsubsection{Life-history influence of predators at the time of oviposition}

In this trial I tested for any life-history effects of the presence of predators, when these predators were present only at the time of oviposition by adult mosquitoes. After oviposition, the eggs were reared away from predators or their kairomones. I collected eggs that had been oviposited into the above treatments that had predators' present, free-roaming, or in cages, from the treatment with predator kairomones, and from the control treatment where no predators or kairomones were present. These eggs were then transferred into clean water (aged tap water) and monitored daily from egg hatch until adult mosquito death. I used between 2 -32 replicates in which I considered single egg raft as one replicate. These replicate varied according to the availability of egg rafts collected in the field. This experiment and the below experiment investigating the life-history influence of predators throughout the mosquito life history were conducted in 1 I containers $(20 \mathrm{~cm} \times 13 \mathrm{~cm} \times 5 \mathrm{~cm})$, each with $500 \mathrm{ml}$ of water. Each of egg rafts from various treatments were placed in separate containers and reared under laboratory controlled conditions at $25 \pm 1^{\circ} \mathrm{C}$ in photoperiod LD 14: 10 hours. Hatching larvae were fed with a mixture of cat biscuit, beef liver, yeast and milk powder in the ratio of 2:1:1:1 by weight, prepared as a fine powder and added to the water at a rate of $10 \mathrm{mg} / \mathrm{ml}$, as proposed by WHO (1996). Water was changed every 4 days to avoid a film of yeast forming on the water surface causing larval mortality (Bar-Zeev 1957). Adult mosquitoes were then placed in cage size $30.5 \times 30.5 \times 22.8 \mathrm{~cm}$ and fed with $10 \%$ sucrose. 
I monitored the percentage of eggs hatching and the survival of mosquitoes until adult death. Data for egg hatching rates are presented as mean percentages $( \pm \mathrm{SE})$. I tested the hatching rate of eggs between treatments with two separate water conditions using one-way ANOVA followed by a post hoc comparison (Tukey HSD). Prior to statistical analysis I examined this and all subsequent data for heteroscedasticity using Levene's test, and for fit to a normal distribution using the one-sample KolmogorovSmirnov test in SPSS (2006).

Larvae were counted, sorted according to larval stages, and transferred each day to new containers. Pupae were removed daily from the containers and placed in $250 \mathrm{ml}$ paper cups covered with $0.2 \mathrm{~mm}$ mesh and were left until emergence of adults. The sex of the emerged adults was then determined. I used chi-square test to detect deviations from expected 1:1 ratio between male: female in the adult mosquito sex. All treatments were compared with control where the ratio was 1:1 (there were insufficient data in some treatments, such as in treatments with predators, for other tests such as contingency tables).

Mosquito development and mortality during larval, pupal and adult stages was recorded daily. To analyze differences in stage-specific developmental time I used a MANOVA with the dependent variables being life stage (4 larval instars, pupae, and male or female adults), treatments were the independent variables. Post-hoc comparisons between treatments 
were performed using Tukey HSD tests in order to calculate the significant effects of development times for each stage.

The survival rate of $C x$. pervigilans from egg hatch until adult death was analyzed using Kaplan-Meier survival analysis with 95\% confidence intervals in SPSS (2006). Survival analysis was used to estimate population survival curve from the treatments tested. Types of treatment served as factor whereas status was defined as 0 for alive and 1 for dead. All treatments were compared with the survival rate in the control treatment (without any predators). I then ran pair-wise comparisons using log-rank tests in order to determine the survival differences between types of treatment tested.

\subsubsection{Life-history influence of predators throughout mosquito life history}

In the previous experiment I tested for any influence of predators, when these predators were present only at the time of oviposition. In this experiment I examined the direct influence of $A$. wakefieldi on mosquitoes from oviposition until adult death, with treatments in which the predators were maintained with the mosquito larvae. In these treatments I collected eggs from the various treatments in the field experiment as detailed above. After the egg rafts were brought back to the laboratory I allocated them to containers with $A$. wakefieldi, or water with its traces with either: 1) one, three or nine free-roaming $A$. wakefieldi; 2 ) one, three or nine $A$. wakefiledi in cages; or 3) kairomone treatments. These kairomone treatments consisted of 
containers in which one, three or nine $A$. wakefieldi were present in the water for $24 \mathrm{~h}$ immediately prior to experiment and were then removed before the introduction of eggs. The kairomones were not replaced during the remainder of the experiment as such a replacement may have significantly disturbed the mosquitoes and their food supply. These eggs, developing larvae, and adults were monitored daily until mosquito death. I used between 2 - 15 replicates in these experiments which I considered single egg raft as one replicate. These replicates were varied according to the availability of eggs collected in the field.

The egg hatching rate and sex ratio of adults were analyzed using oneway ANOVA and sex ratio were analyzed using chi-square test with same procedure as above. I used a MANOVA with the same variables as in the oviposition experiment for examination of the effects of each life-stage. The survival rate of $C x$. pervigilans from egg hatch until adult death was analyzed using Kaplan-Meier survival analysis as in the oviposition experiment with 95\% confidence intervals in SPSS (2006).

\subsection{RESULTS}

\subsubsection{Life-history influence of predators at the time of oviposition}

In this trial I tested for any life-history effects of the presence of predators, when these predators were present only at the time of oviposition by adult mosquitoes. After oviposition, the eggs were reared away from predators or their kairomones. I examined egg hatching, mosquito development and 
survival rates after eggs were collected from a field experiment with nine different treatments (with free roaming predators, predators in cages, etc). These eggs were reared to adult stage in clean water without any predators or kairomones.

The mean percentage of eggs that hatched ranged between 70.8 92.18\%. One-way ANOVA revealed no significant difference in the percentage of eggs that hatched between treatments $(F=1.06, d f=9, P=$ 0.41 ; Figure 5.1A). In the treatment with three free-roaming predators the ratio of emerged females was lower than male adult mosquitoes at a ratio of $1: 0.42$, though this was significant $\left(x^{2}=28.051, d f=1, P=0.000\right)$. In kairomones treatment with three predators the sex ratio was also significantly different from control $(1: 1)$ with ratio of 1 male to 0.78 females $\left(x^{2}=8.718\right.$, $d f=1, P=0.003 ;$ Table 5.1).

I monitored the developmental period of eggs until they emerged to adult stage, including the duration of the four larval instars, pupae, and male or female adults. The MANOVA test indicated that the development period of all 4 stages of larvae and female adults were not significantly different between treatments $(P>0.05$, Figure 5.2). However, the post-hoc test revealed that eggs collected from the field treatment with one free-roaming predator showed significantly longer development times at the pupal stage $(P$ $=0.046)$ and time to male adult emergence $(P=0.011)$ than control conditions with no predators present at the time of oviposition. 


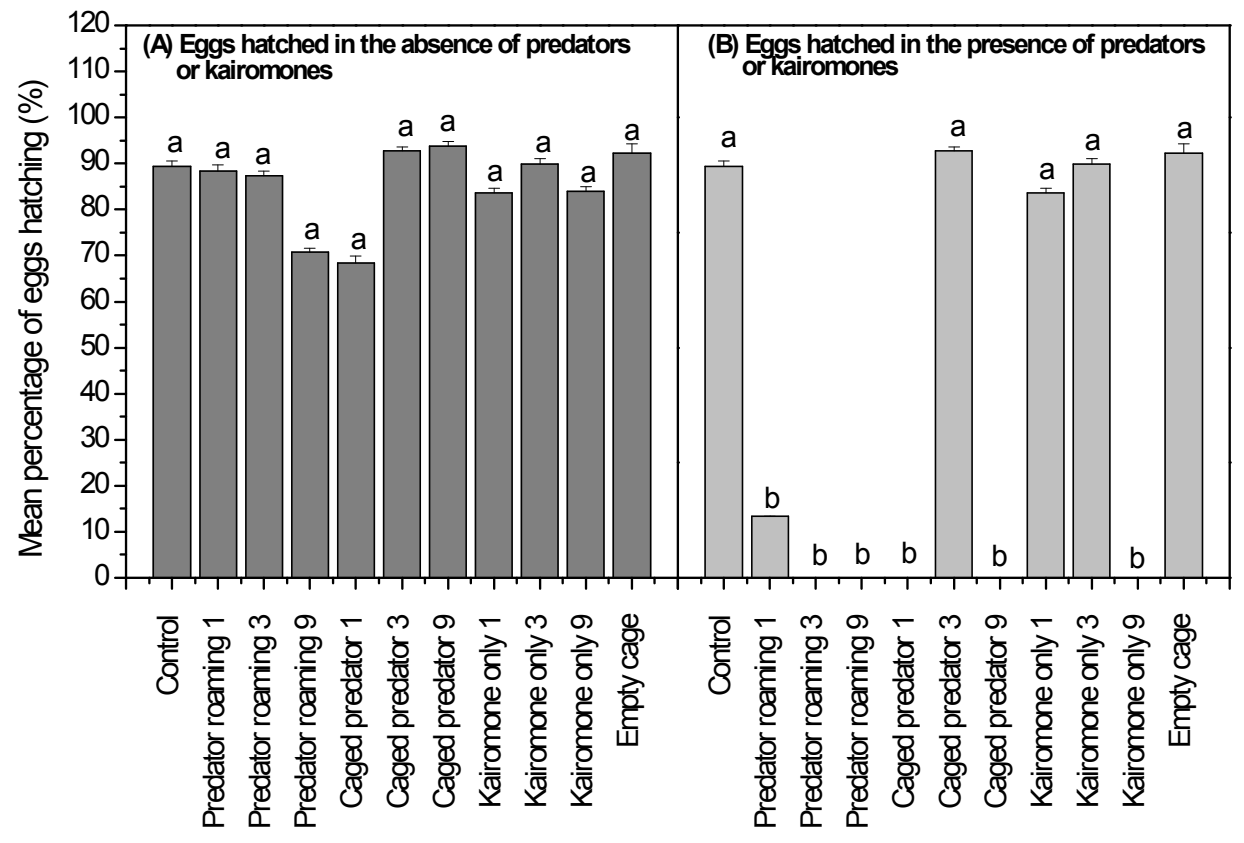

Types of treatment

Figure 5.1: Egg hatching rates in the absence or presence of the predator $A$. wakefieldi. (A) shows the hatching rates of eggs collected from field experiments with varying predator treatments (free-roaming predators, caged predators, etc), but then with these eggs removed and then reared in water without predators or kairomones. (B) shows hatching rates of eggs collected from field experiment with the same treatments and then reared in the laboratory with those same predator treatments. The control treatment and empty cage treatments are repeated on both graphs. Treatments with the same letter represent no significant difference, at $P<0.05$, based on Tukey HSD tests after analysis using one-way ANOVA. 


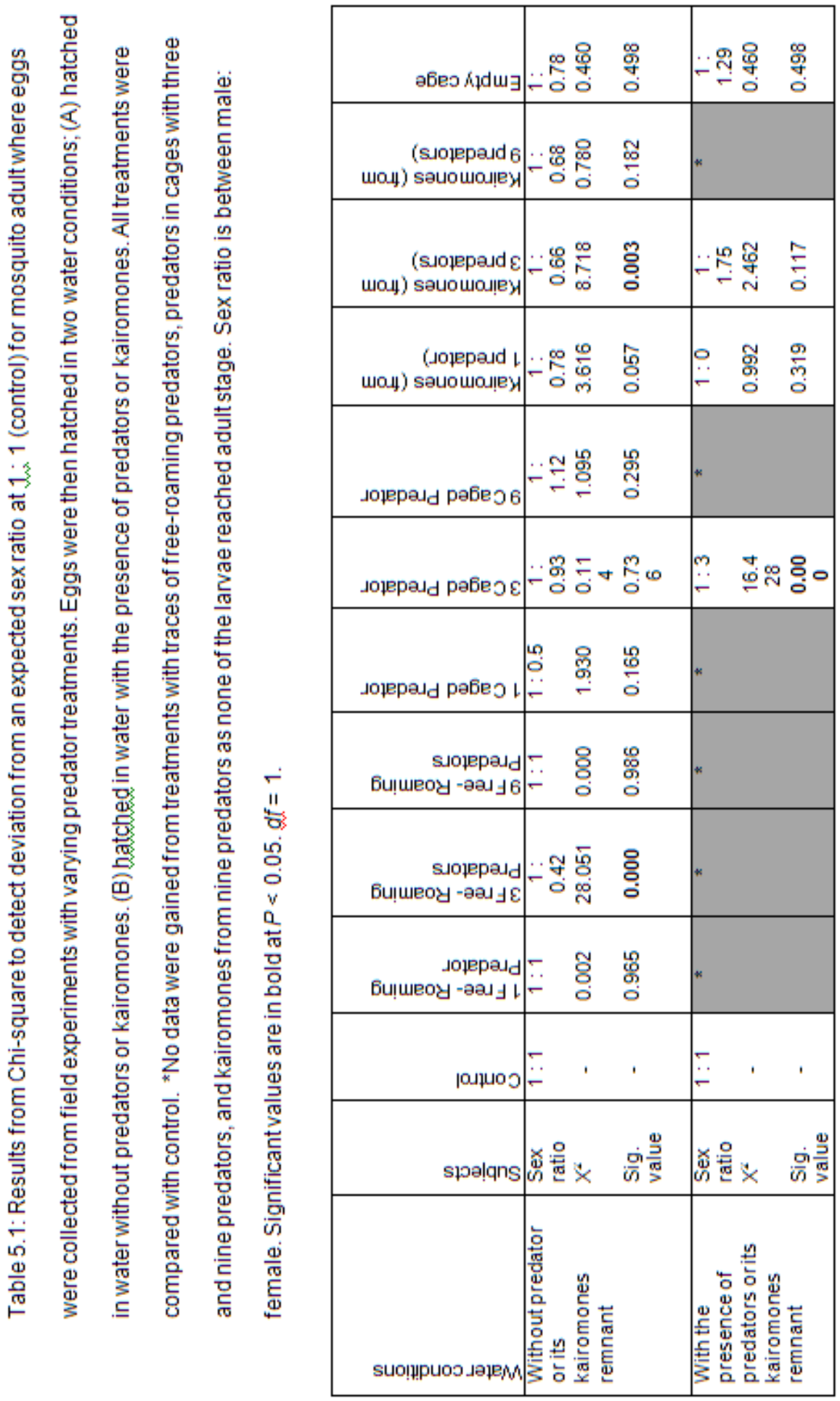


Overall, survival probabilities varied significantly between treatments, as revealed by log-rank test $(P<0.05$, Table 5.2$)$. Surprisingly, significant differences were observed in mosquito survival when the eggs were deposited in treatment containers in the field and hatched in water without the traces of predators or its kairomones (Table 5.2 and Figure 5.4). The time to death was significantly shorter in all nine treatments which were less than 48 days as performed in the control treatment (Figure 5.4). For example, for eggs collected from the one free-roaming predator treatment, the overall survival time of mosquitoes from eggs until adult death was shorter and died faster than control mosquitoes. It appears that survival rates and survival times were reduced even when the eggs were only exposed briefly to predators or kairomones, and spent the remainder of their life stages without contact with predators or kairomones. 
(A) Progeny reared in the absence of predators or kairomones

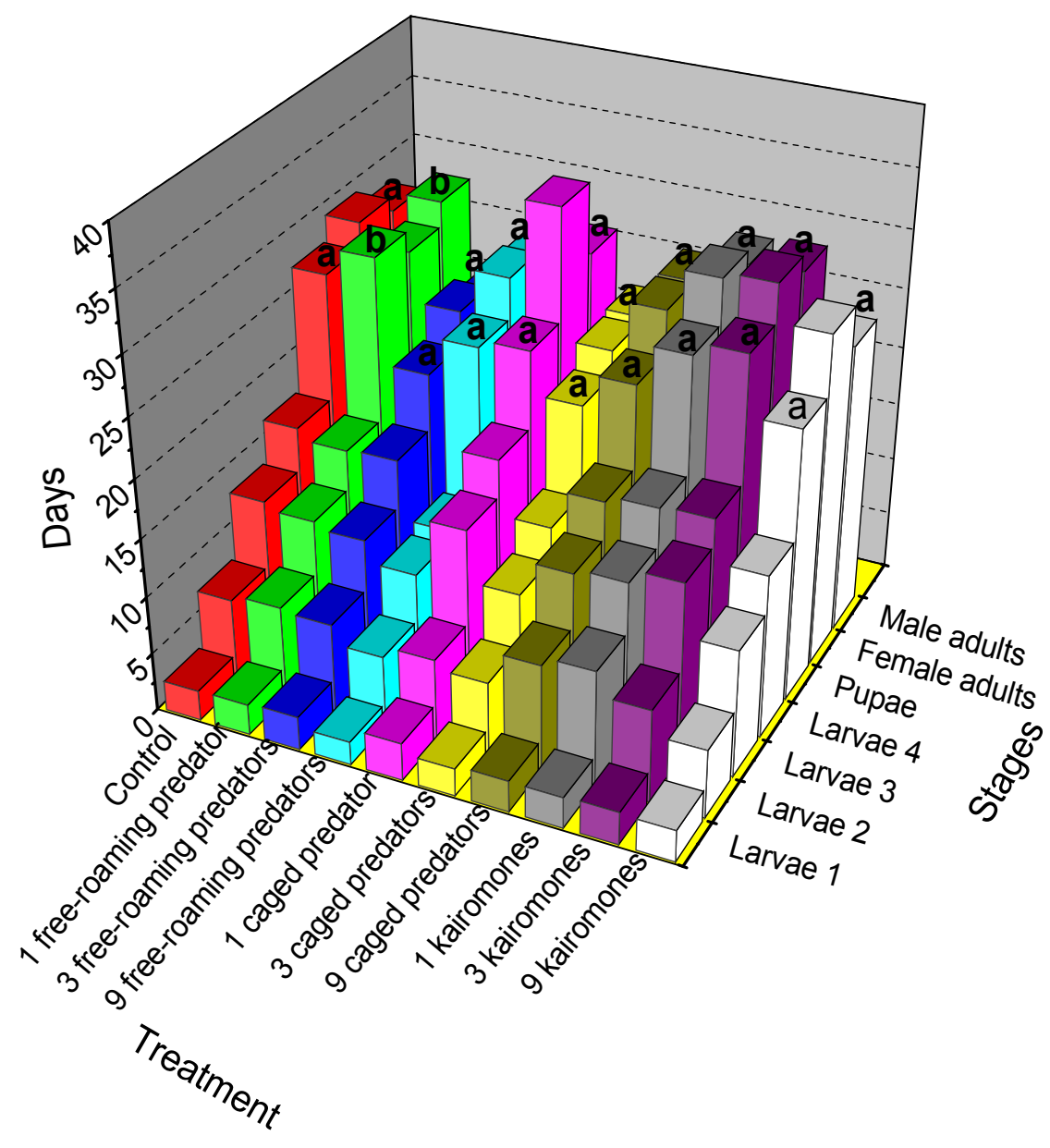

Figure 5.2: The development time needed by eggs that were exposed to the predators or kairomones in the field. Progeny was then reared in the absence of predators and sorted into stage-specific treatments (4 larval instars, pupae, and male or female adults). Treatments with the same letter represent no significant difference, at $P<0.05$, based on Tukey HSD tests, after analysis using MANOVA. 

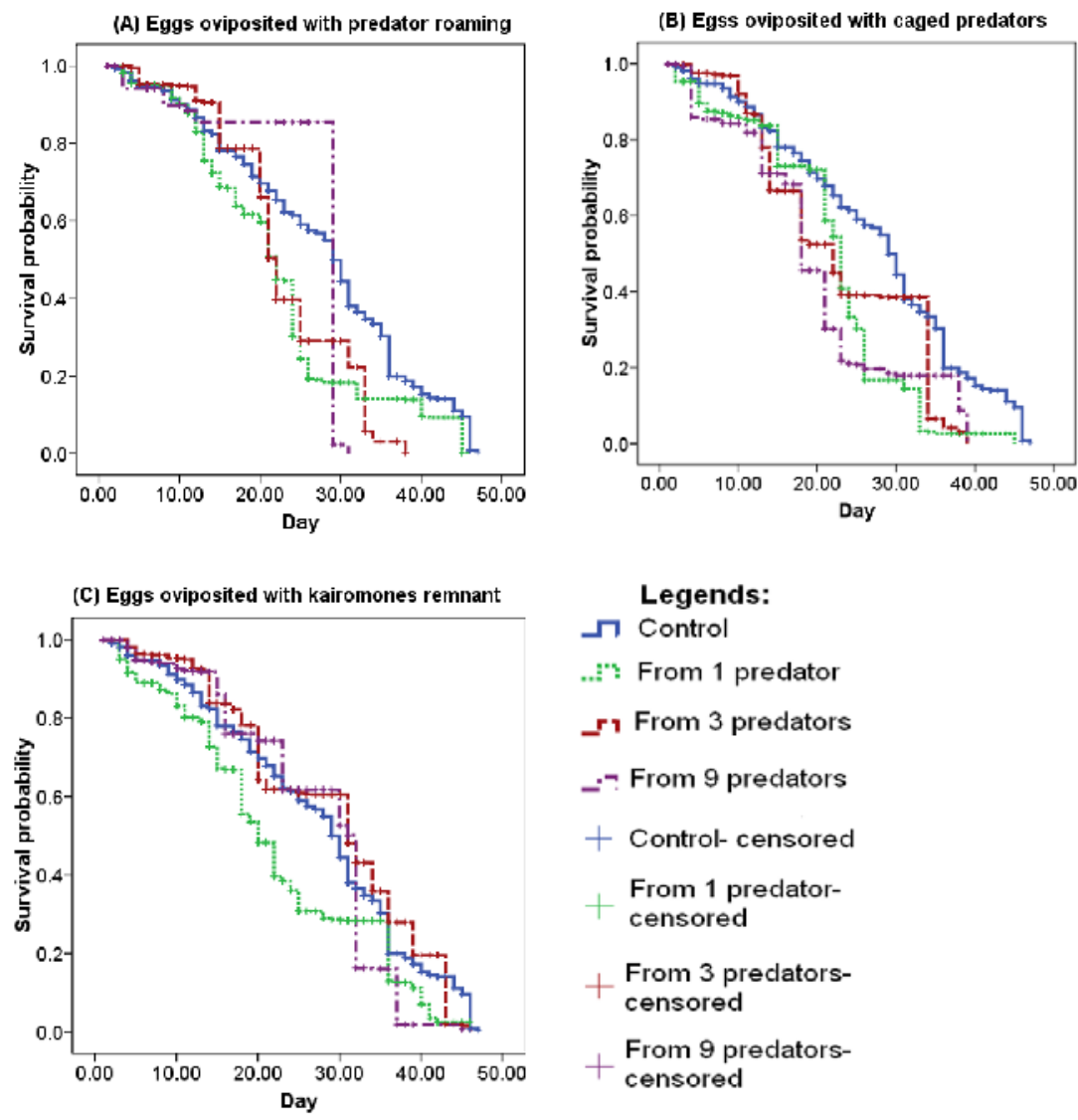

Figure 5.3: The influence of the presence of predators at the time of oviposition by adult mosquitoes on the survival rate of developing mosquitoes. Eggs were collected from treatments that (A) had predators' present free-roaming or (B) in cages, (C) from the treatment with kairomones, and from the control treatment where no predators or their traces were present (survival in the control treatment is represented by the same line on all three graphs). These eggs were then transferred into clean water and monitored from egg hatch until adult mosquito death. 


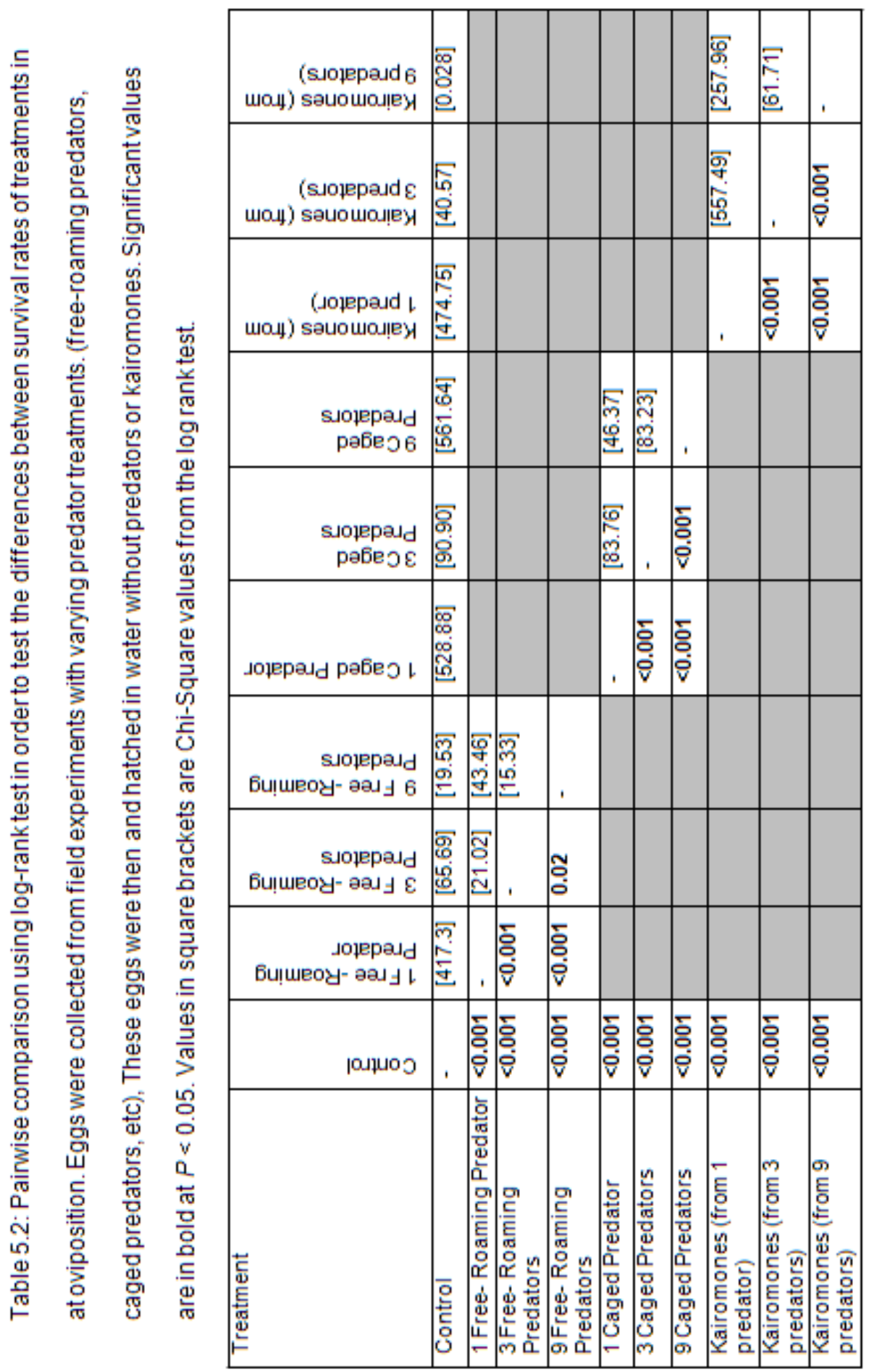




\subsubsection{Life-history influence of predators throughout mosquito life history}

In this experiment I examined the direct influence of $A$. wakefieldi on mosquitoes from oviposition until adult death, with treatments in which the predators were maintained with the mosquito larvae. I examined egg hatching, mosquito development and survival rates after eggs were collected from a field experiment with nine different treatments (with free roaming predators, predators in cages, etc), and reared to adult stage in the laboratory in water subject to the same predator treatments.

The mean percentage of eggs that hatched ranged between 0 $92.74 \%$. The one-way ANOVA results showed a significant difference in egg hatching rates between treatments $(F=139.09, d f=10, P<0.01)$. In the treatments with three and nine free-roaming $A$. wakefieldi, no eggs hatched, the predators attacked and killed all eggs in these treatments. Additionally, no eggs hatched in the treatments with nine caged predators, or the treatment with kairomones of nine predators (with no predators present) (Figure 5.1B). Only a small percentage of eggs lived to hatch in the treatment with one predator. The post-hoc analysis revealed egg hatching rates in the other treatments tested were not significantly different from the control treatment with no predators or kairomones $(P \geq 0.05)$. When larvae were reared in water with the presence of predators, predators in cages or kairomones, few or no larvae survived until eclosion. Several treatments had low numbers of adults, resulting in difficulties analyzing aspects such as 
mosquito sex ratio. The emerging adults in three caged predator treatmets were at ratio of 1 male: 3 females. This ratio were statistically significant when compared to control treatment at ratio of 1:1 $\left(x^{2}=16.428, d f=1, P=\right.$ 0.000; Table 5.1).

The availability of data for developmental times for each life-stage of $C x$. pervigilans were similarly affected by the predator treatments, with no information available from the treatments with three and nine free-roaming predators, one and nine predators in cages and kairomones from nine predators. Only 33 larvae hatched from 248 eggs in treatments with single free-roaming predators, but these larvae failed to grow into second instars as they were all consumed by the predator. The post-hoc test from the MANOVA revealed that all stage-specific growth rates for mosquitoes in the three caged predator treatments were significantly shorter from the control with no predators present $(P>0.05)$, and $4^{\text {th }}$ instar larvae failed to grow to pupae stage perhaps due to the effect of kairomones (Figure 5.3). The development time to reach each life stage was shorter, but not significantly so, in the treatments with kairomones with one or three predators in comparison with the control with no predators $(P<0.05)$. The presence of an empty cage in the containers had no effect on development time of the mosquitoes at any development stage $(P>0.05)$.

The survival analysis indicated that when the eggs were reared in water with the presence of predators or its kairomones remnant, all treatments tested were significantly different $(P<0.001$, Table 5.3). All of treatments tested showed that the time to adult death was faster than in the 
control treatment (Figure 5.5). No survival curves were plotted for the free roaming predator treatments with three and nine predators, caged predator treatments with one and nine predators, and kairomone only treatments from nine predators, because all $C$. pervigilans eggs failed to hatch in these treatments (Figure 5.5). In the treatment with one free roaming predator, all of the first instar larvae were eaten by the predators on the first day of treatment after being placed in water with predators (Figure 5. 5A). The presence of an empty cage showed no significant effect on $C x$. pervigilans mosquito survival rate when compared with the control treatment $(\alpha=0.01, P$ $=0.92$, Table 5.3; Figure 5.5B). 
(B) Progeny reared in the presence of predators and kairomones

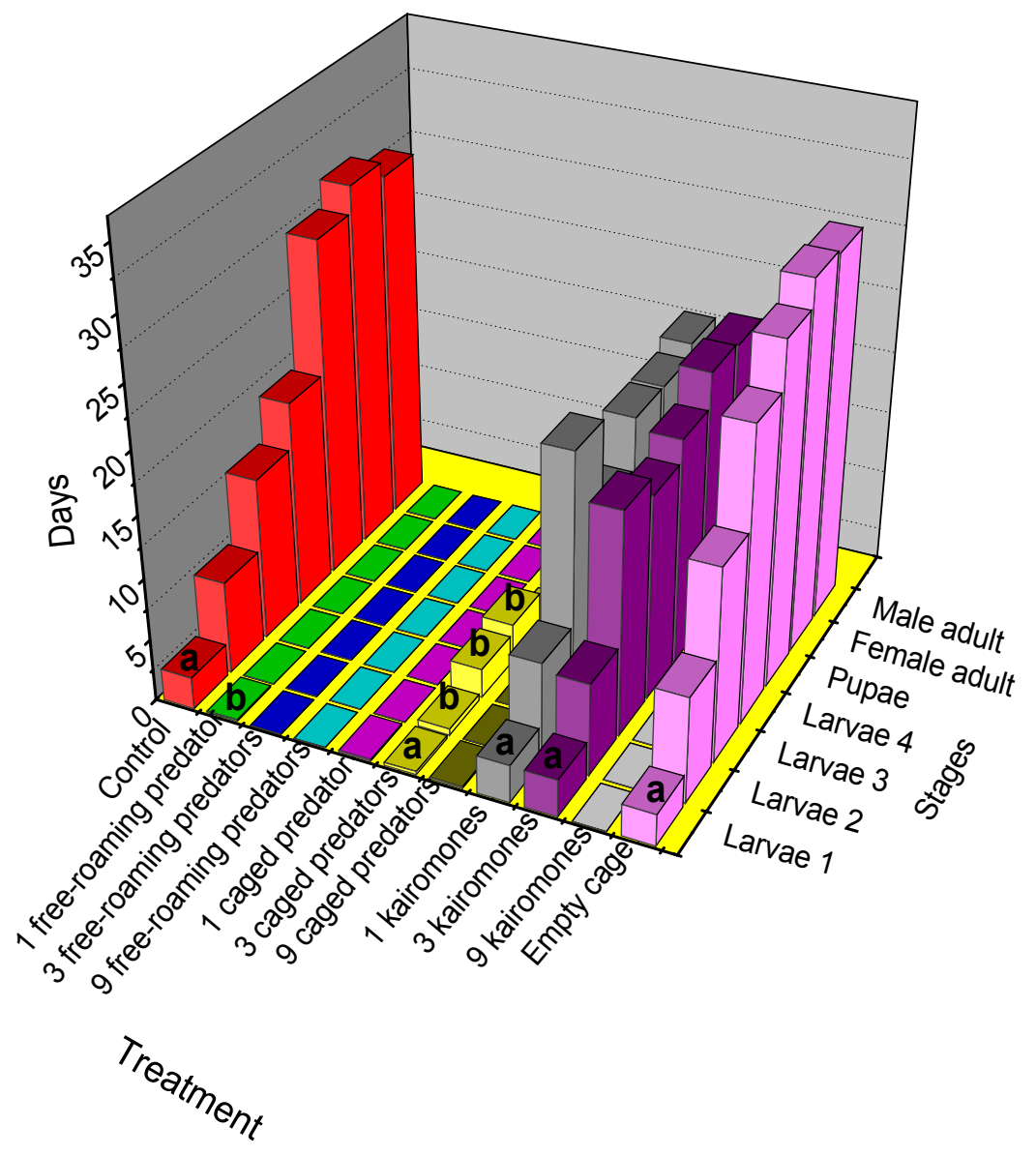

Figure 5.4: The influence of direct exposure to the presence of predators or kairomones on development time of stage-specific progeny (4 larval instars, pupae, and male or female adults) in ten different treatments (control, freeroaming predator, etc.). Treatments with the same letter represent no significant difference, at $P<0.05$, based on Tukey HSD tests, after analysis with MANOVA. Some points are omitted due to insufficient data. 

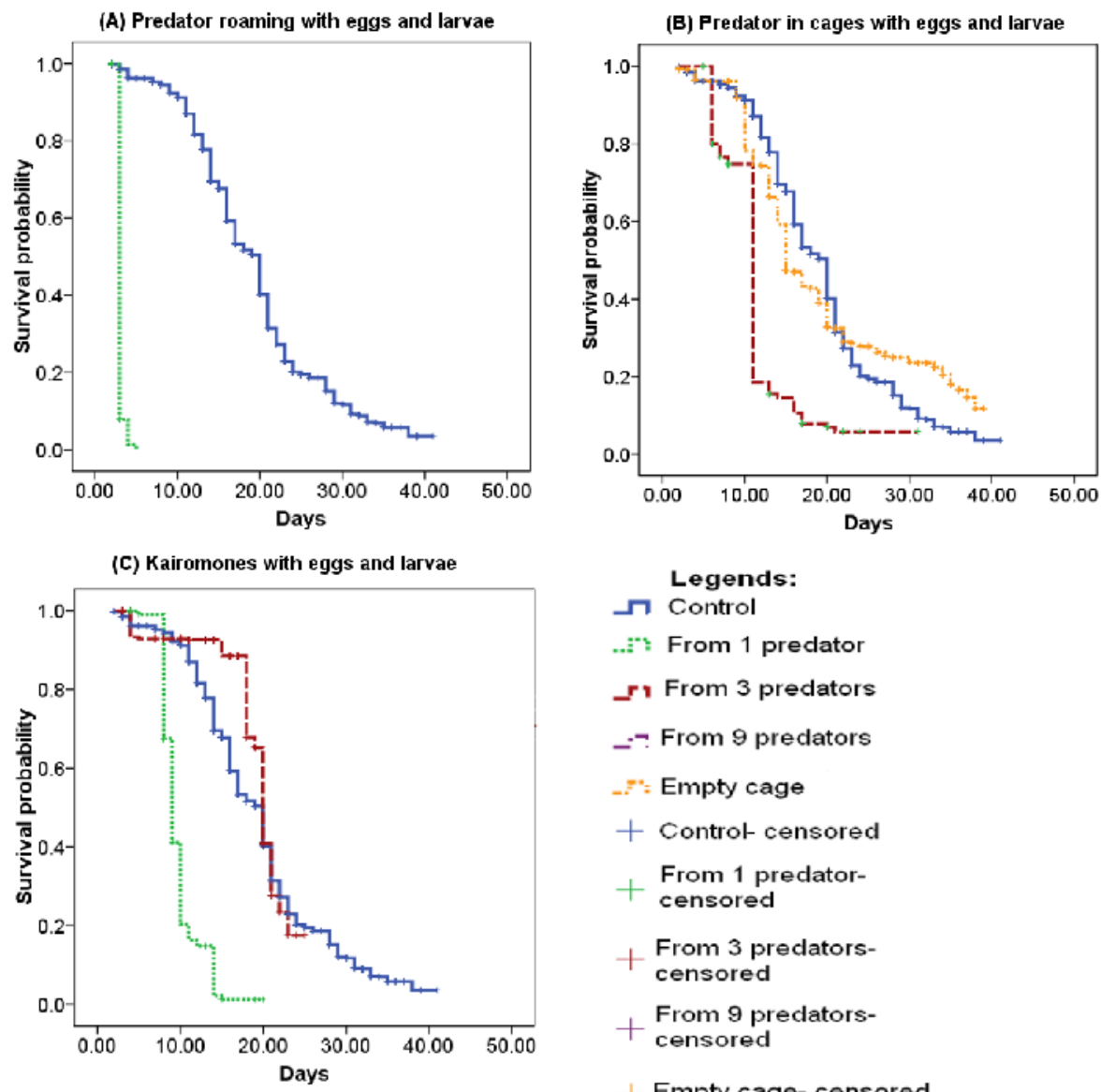

Legends:

$\neg$ Control

.." From 1 preclator

r. From 3 predators

- From 9 predators

-": Empty cage

+ Controt censored

From 1 predator-

censored

+ From 3 predatorscensored

From 9 predators-

+ censored

+ Empty cage- censored

Figure 5.5: Survival rate of developing $C x$. pervigilans mosquito progeny until adult death after eggs were hatched and larvae were reared in the water with the presence of predators or kairomones. Graphs represents survival rate that had (A) predators' present free-roaming, (B) caged predator (C) kairomones remnant from predators, and from the control treatments with the absence of predators or kairomones. (Survival in the control treatment is represented by the same line on all three graphs). 


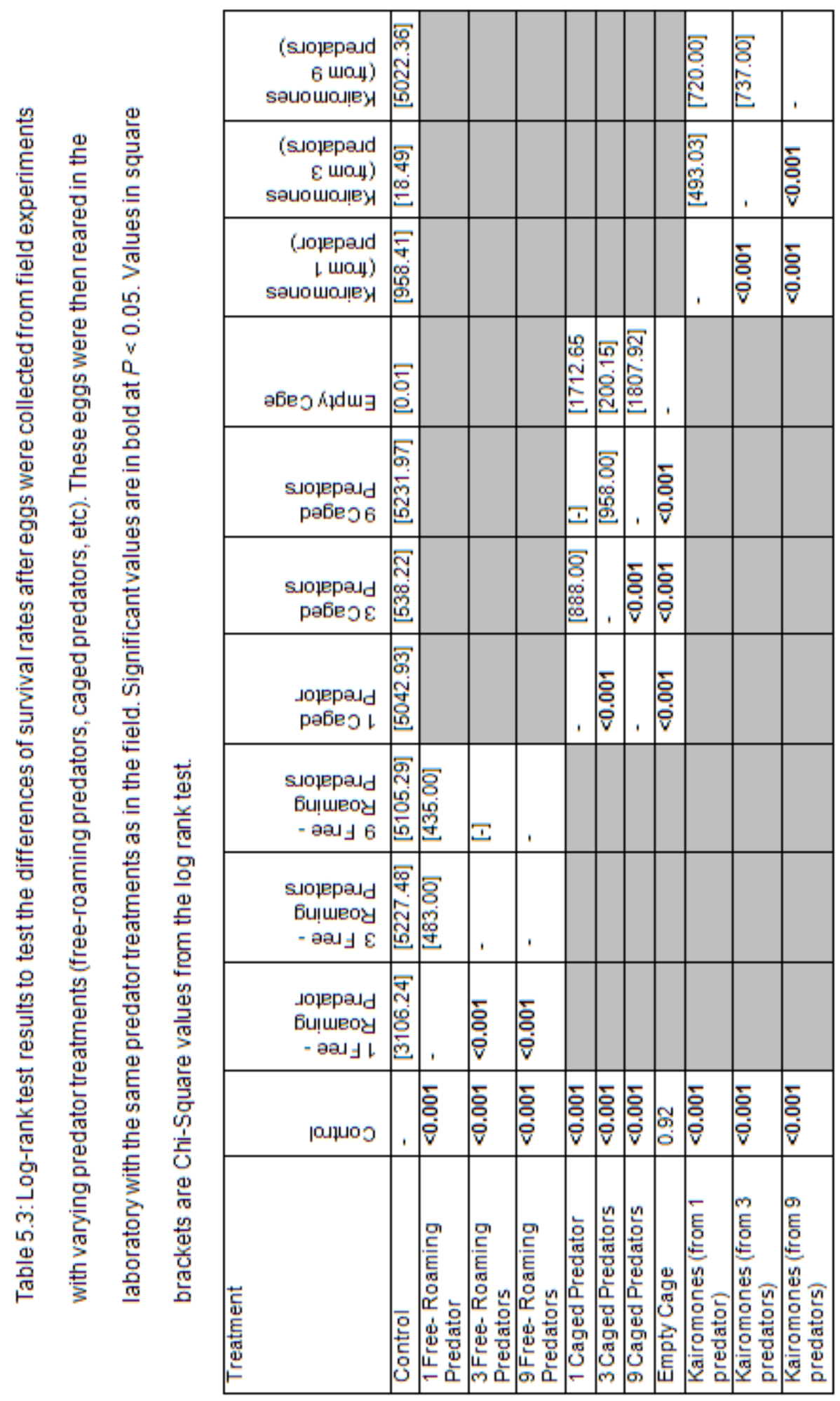




\subsection{DISCUSSION}

The predators that I examined had a lethal effect, and dramatic sub-lethal effect on the survival rate of the mosquitoes, even when only the egg stage was briefly exposed to predators or kairomones. Even though the eggs were exposed only to water containing predators or kairomones in the field and were then reared in clean water without any traces afterward, sub-lethal effects still continued in the remaining survivors. My study demonstrated a significant reduction in the survival rates and survival time as a result of exposure to predators or their chemical cues. These results were observed when adult mosquitoes were exposed to predators at the time of oviposition and when the predators or kairomones were present throughout the life history of the mosquito.

Other studies have demonstrated major changes in life-history after only a short exposure to predators. For example, within 3 - 5 weeks of exposure to chemical cues released from predatory fish Daphnia lumholtzi formed rigid head spines as a defense system against these predators (Laforsch and Beccara 2006, Engel and Tollrian 2009). Inducible defense tends to be a trade-off with life history as an adaptation to heterogeneity in predation risk (Tollrian 1995). Chiver et al. (2001) also noted a change in the life-history of frogs as a result of exposure to predator stimuli. Chemical cues from leech predators demonstrated that injured Pacific tree-frog eggs tended to hatch earlier, resulting in smaller and less developed individuals (Chiver et al. 2001). Sih and Moore (1993) found that salamander eggs delayed their hatching response when exposed to chemical cues from predators. The sub- 
lethal effects of predation can be seen in changes on metamorphosis time and size for a variety of other animals (See Werner 1991, Lounibos et al. 1993, Perkarsky et al. 1993, Ball and Baker 1996, Hetchel and Juliano 1997).

The sub-lethal effects of predators on $C x$. pervigilans were carried by the progeny throughout their whole life history and appeared to be triggered by the predator's chemical cues (kairomones) without any direct contact with the actual predators. It is likely that an egg embryo that is exposed to stressful stimuli from predation during development may cause this change in postembryonic physiology or behavior. Early warning of predators through chemical cues, without direct contact with predators, can benefit the prey by detecting an early risk of predation (Lima and Dill 1990). Herper (1996) suggested that the embryo's learning traits have been primarily associated with maternal and/or auditory recognition. The anxiety-like behavior in mothers which receive stressful stimuli is passed down to the embryo (Kats and Dill 1998) and long lasting disturbances may persist throughout adulthood (Dugovic et al. 1999). Exposure to predator stimuli experienced by Ambystoma annulatum (ringed salamander) embryos later appeared to influence larvae by reducing activity and provoking greater shelter-seeking behavior as an anti-predator strategy (Manthis et al. 2003; 2008). But without the reinforcement of risk, the embryo learned to recognize stimuli of predator as non-threatening agent (Ferrari and Chiver 2008).

Adult females of some mosquito species appear able to detect and actively avoid ovipositing in water containing predators or kairomones 
(Blaustein 1988, Blaustein et al. 1995, Kiflawi et al. 2003a; 2003b). This avoidance does suggest mosquitoes can interpret stressful stimuli that may be passed down to their offspring, as suggested by Kats and Dill (1990). However, my previous work has found no evidence that $C x$. pervigilans can $\operatorname{detect} A$. wakefieldi when making a choice where to lay their eggs (Zuharah and Lester 2010). While it is still possible that those adult female mosquitoes in some way indicate stress to their offspring it seems more likely that the developing eggs or larvae directly interpreted the presence of a predator through chemical cues. This detection appears to result in stress for the larvae and in shorter life histories. Trade-offs in life history characteristics often results in a change in survival and fitness (Calow 1973, Crowl and Covich 1990). Such threat-sensitive learning may allow Cx. pervigilans to optimize the trade-off between anti-predator behaviors by enabling individuals to reach earlier maturity. However, I did not observe significantly shorter larval periods for the mosquitoes in this study except when the larval were exposed in treatment with three caged predators. These results indicate that while the mosquitoes detected predators, this detection may have resulted primarily in stress rather than a change in life history. The stress may have come about through anti-predatory behavior such as reduced feeding activity (Peckarsky 1996, Moses and Sih 1998). This potential mechanism would be consistent with the significantly reduced survivorship of mosquitoes in kairomone only treatments. In subsequent experiments I have observed that these mosquitoes do change their behavior in the presence of predators, appearing to feed less and exhibiting 
more resting behavior associated with escape from predators (Zuharah and Lester, In Press B).

The change in survival rate of mosquitoes as a consequence of exposure to predators only at the egg stage could be consistent with epigenetic effects. Epigenetic effects are observed as changes in phenotype or gene expression caused by mechanisms other than changes in the underlying DNA sequence, and is thought to be triggered by environmental effects during development (Jaenisch and Bird 2003). DNA methylation is a central mechanism of epigenetic regulation, which has been studied in mosquito species (Marhold et al. 2004). Whether or not epigenetic effects are responsible for my results remains unknown, but are clearly one potential mechanism worthy of further investigation.

The sex ratio of mosquitoes is usually approximately equal between males and females in natural environment (Sweney and Barr 1977). In my study the sex ratio between male and female of $C x$. pervigilans in some treatment were statistically different; even when $C x$. pervigilans was only exposed to $A$. wakefieldi predation at oviposition stage. However, Hagman and Shine (2006) found that the sex ratio of emerging mosquitoes was not affected by invasive cane tadpoles. Female mosquitoes in other studies prolonged their developmental time (Banks and Thompson 1987, Stav et al. 2007). More male mosquitoes were emerged compared to female mosquitoes in my study. The results suggested that the stress induced in 
mosquitoes in this study is likely to influence female mosquito more than male mosquito.

I suspect that we are only beginning to understand the complex ways in which predators can have a dramatic sub-lethal effect on prey populations. Empirical studies examining predator-induced changes in hatching characteristics and the subsequent effects on juveniles and adults are rare. This study may have implications for the dynamics of other predator-prey systems. We may expect to observe plasticity in species or populations with high temporal or spatial variability in predation. 


\section{ChAPTER SIX:}

\section{General Discussion}


This study has made a considerable contribution towards understand the role played by an aquatic predator in shaping endemic and exotic mosquito populations dynamics in New Zealand. In particular, this study has made four specific contributions: (1) Chapter two described the association between predator and mosquito occurrence and abundance in water troughs. Using logistic regression, I investigated factors such as environmental variables and water volume that may influence the predator-prey system; (2) Chapter three described the ability of a common predator to limit the abundance of endemic and exotic mosquitoes based on two hypotheses: "escape from natural enemies" and "threat sensitivity"; (3) Chapter four examined the sublethal effects of predators on adult mosquitoes in selecting oviposition habitats; (4) Chapter five expanded the study of sub-lethal effects on mosquito progeny after eggs were taken from the field experiment in Chapter four, and reared either with or without predators. This chapter suggested that the presence of $A$. wakefieldi has a substantial impact on survival rates of $C x$. pervigilans progeny, even when the eggs were only briefly exposed to water containing predators or kairomones and then reared in clean water without any traces of the predators.

In this chapter, I will discuss the links between these empirical studies by examining the lethal and sub-lethal effects exhibited by mosquitoes in response to predators, as examined in the previous chapters. 


\subsection{Do predators influence mosquito populations?}

Predators are known to have substantial impacts on the community structure, distribution and diversity of their prey. Predators may drive prey populations to extinction, reduce the prey population, or even co-exist with a wide range of prey species. However, few studies have been undertaken relating to mosquito population dynamics in response to the presence of a predator.

The "escape from natural enemies" hypothesis is one of the better known explanations as to the successful establishment of non-native species, and reasons for their enhanced growth and higher rate of reproduction in a new habitat range (Elton 1958, Blossey and Notzold 1995, Maron and Vilá 2001). My research has found evidence that predators do influence mosquito populations, but my results did not support the "escape from natural enemies" hypothesis specifically. I found that the native predator preferentially consumed the exotic species, Ae. notoscriptus, over the endemic species $C x$. pervigilans. This behavior may have limited the invasion and subsequently reduced numbers of this exotic mosquito species in New Zealand. I suggested that when this exotic mosquito coexists with the native predator and enters the food web, this prey is more susceptible to attack because of non-adaptive changes in its behavior. This exotic mosquito species is essentially naïve to New Zealand predators. The predator appeared to preferentially consume the exotic mosquito species, but they did also respond to the endemic mosquito species. When only the endemic 
species is present the predator clearly showed that it can control and reduce the number of endemic mosquitoes. The occurrence and abundance of mosquitoes in field populations may be associated with the abundance of predators. With the presence of only nine $A$. wakefieldi predators and $70 \mathrm{Cx}$. pervigilans prey in a water trough, all prey were consumed within two days. Similar ratios of predators to prey are commonly observed in field populations.

I also found evidence that the presence of predators can have dramatic consequences for prey communities, not only by the direct effects of consumption but also through sub-lethal effects. I initially hypothesized that the extent to which mosquito populations are influenced by predation may depend on other mechanisms such as an oviposition response in adult mosquitoes, behavioral responses of prey when facing a predator, and sublethal effect of predators on prey progeny.

\subsection{What are the major mechanisms by which predators influence mosquito populations?}

In this thesis, I investigated several different mechanisms of lethal and sublethal effects of predation that may influence mosquito populations in New Zealand. My results suggest that direct consumption by $A$. wakefieldi is the primary effect of this predator on mosquito populations. The functional response describes the relationship between prey density and a predator's consumption rate. It is a key factor for understanding the population 
dynamics of predator-prey systems. However, the abundance of mosquitoes in the environment is also affected by the abundance of predators, environmental factors, and water volume (Chapters $2 \& 3$ ).

In aquatic environments predators may coexist in the same habitat with more than one prey species. In the presence of more than one prey species, predators preferentially consumed the exotic mosquito, Ae. notoscriptus, exhibiting a higher attack rate towards this species (Chapter 2). Observations show that one $A$. wakefieldi may consume an average of 31 Ae. notoscriptus larvae, but only $18 \mathrm{Cx}$. pervigilans larvae per day. The differential consumption of various mosquito species by predators has been shown to allow coexistence of different mosquito species (Griswold and Lounibos 2005).

The ability of mosquito adults to detect the presence of predators while searching for oviposition sites also affects the abundance of mosquito species in the environment (Spencer et al. 2002). Mosquitoes may have the ability to detect the presence of predators or competitors based on chemical or physical cues when choosing oviposition sites (Stav et al. 1999). In my study, I found no evidence that $C x$. pervigilans modifies its oviposition behaviour in response to predators (Chapter 4). There are two possible reasons for this result; either $C x$. pervigilans ignored the presence of the predator because the predator does not pose a threat to mosquitoes, or the cues from Anisops predators do not provoke alarm, or were not sufficiently strong enough to provoke alarm in these mosquitoes. However, other mosquito species such as Culiseta longireolata can detect chemicals from Notonecta predators in lower numbers than those were examined (Blaustein 
et al. 2004). It seems likely that the adult mosquitoes were unable to detect the presence of predators. This inability to detect predators by $C x$. pervigilans adults while choosing oviposition sites exposes their progeny to significant predation risk and is reflected in the low survival rate of larvae, as observed in chapter five of this thesis.

While adults appeared unable to detect predators, their offspring exhibited substantial sub-lethal effects in response to the presence of predators. The survival rate of $C x$. pervigilans was significantly reduced by the presence of predators and kairomones, even when the eggs were exposed only briefly to water containing either predators or kairomones in the field, and were then reared in clean water without any traces (Chapter 5). It is possible that adult female $C x$. pervigilans in some way indicate stress to their offspring after exposure to predators. However, it seems more likely that the developing eggs or larvae directly interpreted the presence of a predator through chemical cues. Trade-offs in life history characteristics often results in a change in survival and fitness (Calow 1973, Crowl and Covich 1990). In experiments in Chapter three, I observed that these $C x$. pervigilans mosquitoes do change their behavior in the presence of predators; they appeared to feed less and exhibited more of the resting behaviour associated with escape from predators. However, this behaviour did influence the mosquito's life history by influencing the development time between life stages (Chapter 5). 
Predators such as $A$. wakefieldi are voracious predators. They clearly do attack and kill exotic mosquito species. They probably have a role in limiting the invasion of new mosquito species in New Zealand.

\subsection{The variable role of sub-lethal effects of predators on mosquito populations.}

Sub-lethal effects of predators can have impacts on prey in many different ways; such as influencing feeding, growth rates, competitive ability, oviposition behaviour, movement rates, etc. In response to predation risk, prey will frequently adjust their behavior accordingly (Sih 1987). In the presence of cutthroat trout fish odours, mayflies (Baetis bicaudatus) showed sub-lethal effects by reducing drifting behavior (Mclntosh et al. 1999, McIntosh et al. 2000, McIntosh and Peckarsky 2004). This behavior reduced their entry rate to the water column which reduced the possibility of being taken by the predator. Alteration in the feeding rate and diet composition in damselfly larvae is another example of sub-lethal effects of Notonecta and fish predators (Koperski 1997). This behavior is a defense against predators that may be able to detect the presence of prey by water movement. All of these sub-lethal effects of predators can have a major role in influencing mosquito populations.

In contrast to other mosquitoes, I did not observe $A$. wakefieldi to have a sub-lethal effect on adult Cx. pervigilans, wherein oviposition behavior is changed. But clearly, substantial sub-lethal effects occurred for eggs and 
larval stages. If $C x$. pervigilans larvae escaped the lethal effects of the predator, the remaining prey still continued to display sub-lethal responses. Culex pervigilans clearly responded to predators by exhibiting more resting behavior and decreasing their movement. This behavior is known as the safest way to avoid possible threat from predators. However, this behavior may result in reduced food intake by prey. The observed increase in larval mortality, delay in developmental times, and a reduction in body size are likely to be caused by a decrease in foraging activity which results in food limitation (Beketov and Liess 2007). In my study, the decrease in food foraging activity decreases the survival rate of progeny. The threat of predation is often sufficient to modify prey populations. In this study I suggested that food scarcity and stress stimuli passing through the embryo during development both cause a decrease in survival. Lima and Dill (1990) suggested that even without direct contact from predators, prey can still detect an early risk of predation through chemical traces left by predators.

\subsection{Future research}

I suspect that we only beginning to understand the complex ways in which predators can influence mosquito population dynamics. This study may have implications for the dynamics of many predator-prey systems. However, I have several suggestions to improve or enhance similar studies in the future. In chapter two, I examined the influences of a predator on mosquito populations. The result clearly showed that $A$. wakefieldi are able 
to consume and control mosquito populations in water troughs. However, the number of predators and mosquito larvae were greater in 2007/08 than in 2008/09. What is the factor that may cause the changing in abundance between years? I suspect that changes in environmental factors such as temperature are the main drivers that may limit populations, even though I observed no such correlation during my sampling periods. Overwintering mortality may be quite variable in different years.

The interaction between mosquito populations and predators in water troughs needs to be tested more widely in other locations, and should extend to warmer areas such as the northern North Island. The warmer climate, large human population, and larger seaport and airport are potential factors in increasing the numbers of mosquito invasions that could potentially cause mosquito-borne disease outbreaks in New Zealand (Laird 1990, Laird 1995, Weinstein et al. 1997).

In Chapter three, more exotic species than endemic species were consumed by $A$. wakefieldi. Both were Type II functional responses. In nature, predator-prey populations do not consist of only one predator and one prey species. The observed functional response may change in the presence of alternative prey. Several studies have shown that the Type II functional response is not stable and does not to allow long-term population persistence, while a type III response is more demographically stabilizing (Murdoch and Oaten 1975, Hassell and Comins 1978, Pech et al. 1992). It is important that future work on functional responses involve mixed prey species and several predator species. This more natural study system would 
enable us to have a better understanding of the persistence of predator-prey systems in the natural environment.

In the situations where predators do not result in the death of prey by lethal effects, sub-lethal effects may positively or negatively affect behavior, growth rate, or life history traits of prey species. My study has confirmed that the presence of $A$. wakefieldi has sub-lethal effects on mosquito larvae (Chapter 5). This behavior was typified by an alteration in feeding behavior and resulted in a decreasing number of prey surviving to the next generation even when eggs were exposed only briefly to the predator's kairomones and then reared in clean water without any traces of the predator. However, it is possible that the sub-lethal effects may still continue in the second and third generation of mosquitoes, which is worthy of examination in the future. However, the sub-lethal effect on adult longevity is particularly important. By knowing the lifespan of adults we can easily control mosquito populations.

A better understanding of various mosquito species' response to predators and environmental factors will allow us to make more accurate predictions of the population level outcomes of mosquito invasions. 
APPENDICES 


\section{AppendiX A:}

\section{Abstract from The $25^{\text {th }}$ Annual Meeting of The Society of Population Ecology}




\title{
個体群生態学会 \\ 第 25 回年次大会 \\ プログラム・講演要旨集

\author{
Program and Abstracts \\ The 25th Annual Meeting \\ The Society of Population Ecology
}

\author{
2009 年 10 月 17 日（土）·18日（日） \\ 同志社大学寒梅館（京都市上京区） \\ October 17-18, 2009
}

Kanbai-kan, Doshisha University (Kamigyo-ku, Kyoto)

個体群生態学会

第 25 回年次大会実行委員会 
【P3-13】

\section{Can Anisops predators (Backswimmer) reducing the population abundance of New Zealand mosquito?}

OWan Fatma Zuharah (School of Biological Sciences, Victoria University of Wellington) - Phil Lester

The influence of these predators on mosquito populations may be direct, through predation, or indirectly through sublethal responses ol adult mosquitoes in lile history traits like oviposition behavior. Anisops wakefieldi are a common predator of mosquito larvae and can be found in temporary and permanent water bodies in New Zealand. We established temporary containers with four types of treatments in order to study the eflects of Anisops predator on mosquito population: 1) Control, 2) Free roaming Anisops (with one, three and nime Anisops), 3) Caged Anisops (with one, three and nine Anisops in caged and empty cage), 4) Anisops kairomone (with kairomone concentration of one, three and nine Anisops in present in the water for $24 \mathrm{~h}$ prior to the experiment, but removed at the start of each trial). We predicted that in the presence of Anisop wakefieldi or its kairomone, fewer mosquito eggs would be oviposited. Contrary to our predictions, $C x$, pervigilans appeared to ignore the presence of free roaming Anisops, caged $\wedge$ nisops, and water with Anisops kairomone when choosing their oviposition sites. As a result, no significant differences were detected between treatments $(\mathrm{F}=1.389, \mathrm{dl}=10, \mathrm{p}=() .284)$ and the presence of Anisops did not al Tect the mosquitoes' oviposition behaviour. If there were no effects of the predator's presence on oviposition behavior by mosquito, the variation in the abundance of mosquitoes in pools may be primarily driven by the lethal effects of this predator. Wc also conducted a field survey using water troughs at farming areas in Queens Elizabeth II Park, Waikanae, New Zealand. We attempted to tease apart the relationship between Anisops predator, mosquito population abundance, water depth and environmental variables; temperature, wind speed, rainfall, humidity, and pressure. We have predicted that the presence of Anisops predator may be significantly correlated with the presence of mosquito. The abundance of Anisops predators in troughs was not correlated to the abundance of mosquilu ( $\mathrm{r}=-(0.052, \mathrm{p}=() .454)$ or other environmental variables. But, their predator presence had a positive correlation with the water depth $(\mathrm{r}=0.176$, $p<0.05)$. The presence of mosquito larvae in water troughs was correlated to water depth $(r=-0.159, p=0.022)$ and wind speed ( $\mathrm{r}=0.142, \mathrm{p}=(0 .(041)$ but not other environmental variables. We conclude that the existence of Anisops predator has little role in controlling the population abundance of mosquitoes in New Zealand. 


\section{ApPendiX B:}

\section{Abstract from The $58^{\text {th }}$ Annual Conference of the Entomological Society of New Zealand}




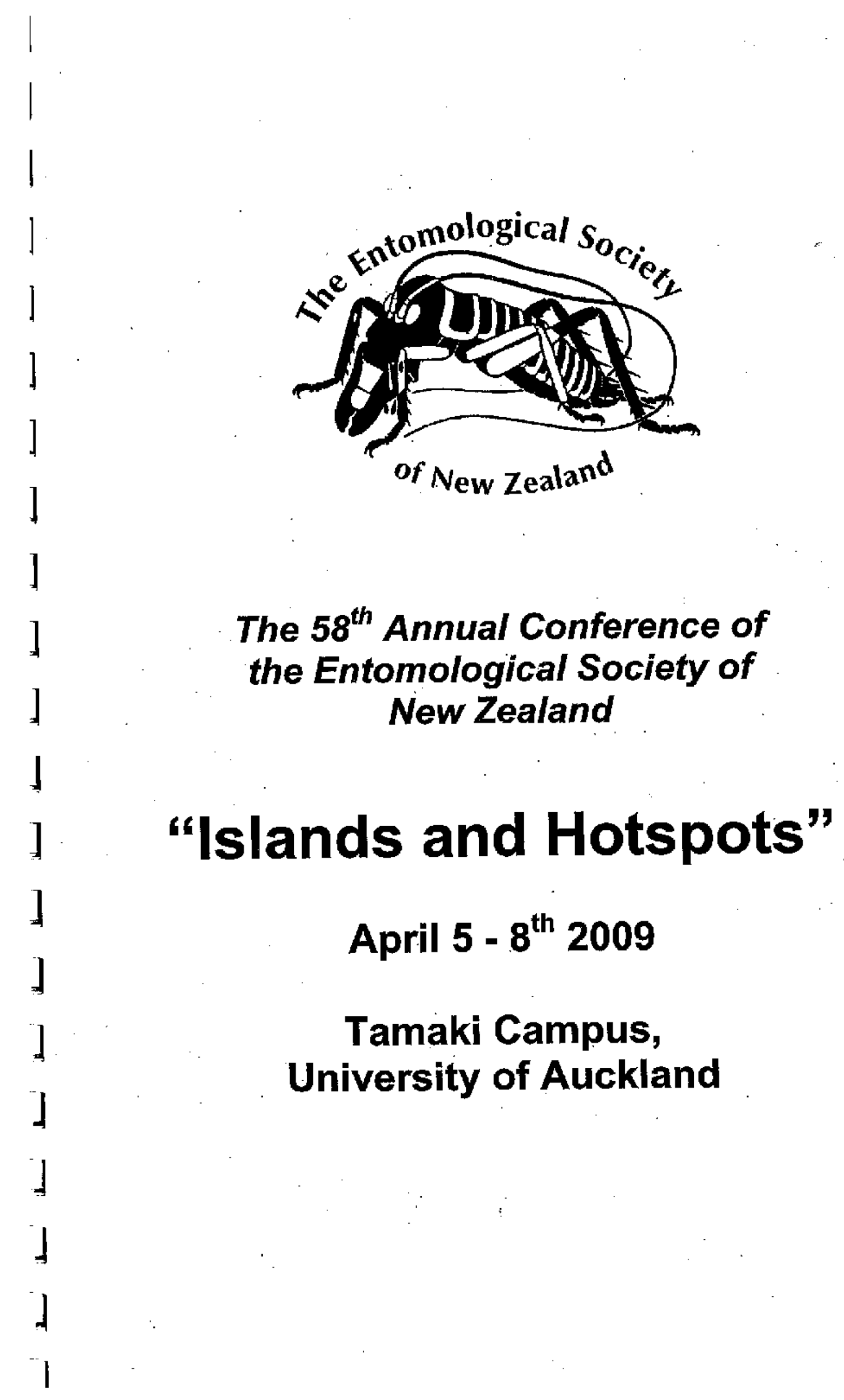




\title{
Can adults of the mosquito Culex pervigilans detect the presence of a key predator in larval habitats?
}

\author{
Wan Fatma Zuharah \& Phil Lester \\ School of Biological Sciences, Victoria University of Wellington, P.O. Box 600, \\ Wellington, New Zealand \\ wanmuswan@myvuw.ac.nz
}

Anisops wakefieldi are a common predator of mosquitoes and can be found in temporary and permanent water bodies. The influence of these predators on mosquito populations may be direct, through predation, or indirectly through sublethal responses of adult mosquitoes in life history traits like oviposition behaviour. We established temporary containers with four types of treatments: 1) Control, 2) Free roaming Anisops (with one, three and nine Anisops), 3) Caged Anisops (with one, three and nine Anisops in caged), 4) Anisops kairomone (with kairomone concentration of one, three and nine Anisops in present in the water for $24 \mathrm{~h}$ prior to the experiment, but removed at the start of each trial). We predicted that the New Zealand native mosquito, Culex pervigilans, whose larvae are highly vulnerable to predation of Anisop wakefieldi, would likely to avoid the containers with the presence of Anisops or its kairomone. Contrary to our predictions, C. pervigilans appeared to ignore the presence of free roaming Anisops, caged Anisops and water with Anisops kairomone. As a result, no significant differences were detected between treatments. We also predicted that $C$. pervigilans would be able to discriminate Anisops densities when choosing oviposition sites. The experimental evidence indicates that the number of egg rafts was not significantly affected by the density of predators. It appears that $C$. pervigilans are unable to determine the presence or absence of Anisops predators while ovipositing. Variation in the abundance of mosquitoes in pools appears to be primarily driven by the lethal effects of this predator on $C$. pervigilans. 


\section{ApPendix C:}

\section{Zuharah WF and Lester PJ (2010) Can adult of New \\ Zealand mosquito Culex pervigilans (Bergorth) detect the presence of a key predator in larval habitat?. Journal of Vector Ecology. 35(1) (In Press)}




\title{
Can adults of the New Zealand mosquito Culex pervigilans (Bergorth) detect the presence of a key predator in larval habitats?
}

\author{
Wan Fatma Zuharah ${ }^{\bowtie}$ and Philip J. Lester \\ School of Biological Sciences, Victoria University of Wellington, P.O. Box 600, Wellington 6140, New Zealand
}

Received 21 September 2009; Accepted 8 January 2010

\begin{abstract}
The influence of predators on mosquito populations may be direct through predation or indirect through sublethal responses of adult mosquitoes in life history traits such as oviposition behavior. In New Zealand, the backswimmer, Anisops wakefieldi, is a common predator of mosquito larvae found in temporary and permanent water bodies. We predicted that the New Zealand native mosquito, Culex pervigilans, whose larvae are vulnerable to predation of Anisops, would likely avoid the containers with the presence of Anisops or its kairomone. We established temporary water containers without predators, free-roaming predators, caged predators (which were unable to eat mosquitoes), or containers from which predators were removed immediately prior to the experiment (these containers would have remnant kairomones from the predators). Each treatment with Anisops had predator densities of one, three, or nine Anisops. Contrary to our predictions, when choosing oviposition habitats, Cx. pervigilans appeared to ignore the presence of free-roaming Anisops, caged Anisops, and water with Anisops kairomone. We thus observed no significant differences between the numbers of egg rafts laid by $C x$. pervigilans in the different predator treatments nor were the number of egg rafts significantly affected by the density of predators. Rather than the presence of predators, environmental factors including temperature, humidity, and pressure were significantly correlated with mosquito oviposition. These mosquitoes appeared to either ignore the presence of the predator, had no ability to detect the presence of predators, or perhaps the cues from Anisops predators were not sufficiently strong enough to alarm these mosquitoes. We argue that the mosquito has not evolved the ability to detect the presence of these predators while ovipositing. Journal of Vector Ecology 35 (1): 100-105. 2010.
\end{abstract}

Keyword Index: Predation, oviposition, predator density, kairomone, environmental factors.

\section{INTRODUCTION}

The survival and growth of organisms that lack parental care is thought to be strongly dependent on the quality of habitats into which they are deposited. Adults of insects with juveniles that are incapable of migrating away from low quality habitat should evolve to select oviposition sites that improve the likelihood of the survival and growth of their offspring (Kiflawi et al. 2003a, Blaustein et al. 2004, Bond et al. 2005). Thus, a female mosquito should be able to detect and avoid ovipositing in sites which have a high risk of predation for their eggs or juvenile stages. Mosquitoes also compete with one another and should selectively oviposit to minimize inter- or intra-specific competition. Blaustein et al. (2004) suggested that five factors have shaped the ability of mosquitoes to respond to the risk of predation during oviposition: 1) mosquito larvae are highly vulnerable to predation, 2) they have only one or a few lifetime reproductive events, 3) their eggs are often laid together, 4) their predators have highly heterogeneous distributions, and finally, 5) the distribution of predators is often highly fixed from the time of the prey oviposition event until prey progeny can either leave the patch or become large enough to better avoid predation. Ideally, mosquitoes may have an ability to detect the presence of predators or competitors based on chemical or physical cues released (Stav et al.
1999).

Wisenden (2000) showed that chemical cues are released by the predator during detection, attack, capture, and ingestion of prey. Prey may use these cues to minimize their exposure to predators. Several species of mosquitoes have been shown to be able to detect the presence of predatory notonectid bugs and avoid ovipositing in pools containing these predators. In the presence of only one predatory backswimmer (Notonecta maculata Fabricious) in 10 liters of water, Culiseta longirealata (Macquart) oviposition was strongly reduced (Blaustein 1998, Blaustein et al. 1995, Kiflawi et al. 2003a, Kiflawi et al. 2003b). Eitam and Blaustein (2004) found that Cs. longiareolata and $C x$. laticintus oviposited less in pools containing predators, but this avoidance of predators was unrelated to predator densities. Their work was also supported by Blaustein et al. (2005), who found that Culex mosquitoes strongly avoided ovipositing in pools containing the Notonecta predators. Mosquitoes continued to avoid ovipositing in pools with predators for two additional days after the predator was removed, suggesting a predator-released kairomone was the cue used by mosquitoes to detect the presence of predators.

Stav et al. (1999) suggested that the distribution and abundance of a mosquito species is dependent on their ability to selectively oviposit according to predator abundance. Mosquito oviposition may be affected by predator densities 
because gravid females may detect their densities and assess the severity of predation risk. With increasing predator densities, concentrations of kairomone are also increased and may result in reduced oviposition (Eitam and Blaustein 2004). Reduced oviposition by mosquitoes may be expected with increasing numbers of predators, due to the ability of these prey species to detect the presence of a predator above a threshold density (Angelon and Petranka 2002) or concentration of kairomones (Eitam and Blaustein 2004).

Our aim in this study was to examine the oviposition behavior of the New Zealand mosquito $C x$. pervigilans in response to the notonectid predator Anisops wakefiledi under field conditions. Anisops spp. are known to be predators of mosquito larvae and are commonly found in permanent and temporary water bodies in New Zealand (Graham 1939, Laird 1990, Laird 1995). Culex pervigilans is a vector species of the human and avian Whataroa virus (Maguire et al. 1967, Miles 1973), is suggested to be a vector of avian malaria (Holder et al. 1999), and has been highlighted as a species requiring further investigation for its potential to vector exotic arboviruses (Weinstein et al. 1997). We hypothesized that $C x$. pervigilans are likely to avoid ovipositing in pools containing Anisops or its kairomone traces and that the influence of the kairomones released by Anisops predator may last for several days after the predators are removed. We also hypothesized environmental factors could play a role in influencing mosquito oviposition rates. Bentley and Day (1989) suggested that temperature, rainfall, wind speed, and relative humidity may affect the initiation of ovipositional flights by mosquitoes.

\section{MATERIALS AND METHODS}

\section{Study sites}

The study was undertaken in Otari-Wilton's Bush in Wellington, New Zealand $\left(14^{\circ} 14^{\prime} \mathrm{S}, 174^{\circ} 45^{\prime} \mathrm{E}\right)$. OtariWilton's Bush is Wellington's largest area of original native forest. Experiments were undertaken on the edge of the forest in a plant nursery, with no overhead canopy or shading. Temperatures over the period of experiments ranged from $14.8^{\circ} \mathrm{C}$ to $18.2^{\circ} \mathrm{C}$ and relative humidity was between $62.8 \%$ and $89.3 \%$. Experiments were conducted during the southern hemisphere summer season for two consecutive summers (2007/08 and 2008/09). These experiments ran from 18 December 2007 to 11 February 2008, and from 7 December 2008 until 19 January 2009.

\section{Predator colonies}

The A. wakefieldi used in this experiment were collected from permanent water troughs (with an approximate volume of 800 liters of water) in Queen Elizabeth II Park near Waikanae, New Zealand ( $40^{\circ} 57^{\prime} \mathrm{S}, 174^{\circ} 58^{\prime} \mathrm{E}$ ), approximately $70 \mathrm{~km}$ from Wellington city. These predators were brought back to the laboratory for identification and deprived of food for $24 \mathrm{~h}$ prior to their release into the experimental containers.

\section{Study design}

Twelve black plastic containers $(25.5 \times 25.5 \times 23.5 \mathrm{~cm})$ served as temporary pools for the experiment. Containers were filled with 10 liters of water: 9.75 liters of aged tap water (tap water that was left standing for more than $48 \mathrm{~h}$ to reduce the chlorine content) mixed with 0.25 liters of stream water from the nearest stream, Kaiwharawhara Stream. Stream water was used to introduce bacterial inoculates as food sources for mosquito larvae and was filtered with $0.2 \mathrm{~mm}$ mesh before being added to the containers. The water level was maintained at 10 liters throughout the experiment by adding aged tap water or by natural rain to account for any loss due to evaporation. Nutrients were added to the water once prior to the experiment in the form of "Kiwi" brand pelletized sheep manure which contained 3\% nitrogen, $2 \%$ phosphorus, and $4 \%$ potassium at a weight of $5 \mathrm{~g} /$ liter of water, $24 \mathrm{~h}$ prior to the experiment. Previous work has shown such conditions to be ideal for $C x$. pervigilans (Leisnham et al. 2006). Containers were then covered with $1.0 \mathrm{~cm}$ wire mesh to prevent vertebrate animals from drinking or falling into the water.

These containers were set up so that the distance between containers was at least $0.5 \mathrm{~m}$ from its flanking neighbor. Treatments were established as follows: 1) controls without predators; 2) free-roaming Anisops (with one, three, or nine Anisops per container); 3) caged Anisops (empty cage without predator, with one, three, or nine Anisops in a cage that were unable to consume mosquito larvae or be directly seen by ovipositing adults); and 4) Anisops kairomone only (with kairomones from one, three, or nine Anisops which were present in the water for $24 \mathrm{~h}$ prior to the experiment but removed at the start of each trial). Cages used to contain predators in the caged Anisops treatment were constructed using 1.5 liter clear plastic drinking bottles, each with one opening window $(10 \mathrm{~cm} \mathrm{x} 3 \mathrm{~cm})$ on each of two sides of the bottle and $2 \mathrm{~mm}$ nylon mesh covering one end of the bottle tops. The mesh was used to ensure that the predator could breathe and any predator-released kairomones from Anisops could diffuse into the main body of water. The cages were placed in a horizontal orientation within the water containers so that most of the cage was submerged. In the kairomone-only treatment, Anisops were kept in the water for $48 \mathrm{~h}$ immediately prior to the beginning of the experiment before their removal. Therefore, the water only contained kairomones without the presence of an actual predator.

All containers were set up $48 \mathrm{~h}$ before the experiments began in order to introduce and familiarize mosquitoes to the new oviposition sites. All mosquito egg rafts were counted $48 \mathrm{~h}$ after containers were introduced to the field. Each day for 12 days after the Anisops were added, they were counted and any missing or dead Anisops replaced. Each day, eggs were collected into small containers with water and were brought back to laboratory for counting and identification at larval stages.

\section{Statistical analysis}

We used a repeated-measures general linear model 
(GLM) to test for significant effects of predator treatment (free-roaming, caged predators, and no predators), predator density, and time on $C x$. pervigilans oviposition rate in SPSS (2006). Data were tested for normality using a onesample Kolmogorov-Smirnov test. All data were log $(x+1)$ transformed prior to analysis to satisfy the assumptions of ANOVA. Sphericity could not be assumed in the study $(\varepsilon=$ 0.704, $\mathrm{p}=0.009$ ) and the Huynh-Feldt epsilon values were used in the F-tests. The repeated measures within- subjects factor were period with four levels; day 1-3, day 4-6, day 7-9, and day 10-12. Predator treatment and density were treated as between-subjects factors.

The number of egg rafts observed during each period was correlated with five environmental factors: temperature, wind speed, rainfall, humidity, and pressure, using a Pearson correlation coefficient. The environmental data were obtained from the Kelburn weather station approximately three $\mathrm{km}$ from our study site, by the National Institute of Water and Atmospheric Research (NIWA), New Zealand. Any significant correlation data from Pearson's correlation test were analyzed with a t-test in order to determine the mean effects between years.

\section{RESULTS}

No significant differences in mosquito oviposition rates were detected among treatments with the presence of predators, either cages or uncaged, the presence of their kairomone only, and the control treatment with no predators $(\mathrm{F}=1.389, \mathrm{df}=3, \mathrm{p}=0.284$; Table 1 and Figure 1$)$. Similarly, no statistically significant effects of predator densities were observed on oviposition rates $(\mathrm{F}=0.224, \mathrm{df}=3, \mathrm{p}=0.879)$. Thus, Cx. pervigilans mosquitoes appeared to choose their oviposition habitat without taking into account predator presence or density. There were no significant differences in oviposition among all four periods tested, nor was there any significant interaction among periods and treatments or a significant three-way interaction ( $\mathrm{p} \geq 0.500$, Table 1 ). Thus, mosquito oviposition rates were similar irrespective of how long the predators were in the water containers (or in the case of the kairomone-only treatment, how long the predator had been removed). These results suggested that $C x$. pervigilans mosquitoes were not able to detect, or ignored, the presence of Anisops or its kairomones.

A total of 284 egg rafts was collected in 2007/2008, which was significantly more than $2008 / 2009$ when only 28 egg rafts were collected $(\mathrm{t}=3.801, \mathrm{df}=114, \mathrm{p}<0.001)$. All of the egg rafts were identified as $C x$. pervigilans. There were significant correlations between the number of $C x$. pervigilans egg rafts and temperature, humidity, and pressure (Table 2). T-tests examining the mean effects between years indicated that fewer egg rafts were oviposited by $C x$. pervigilans mosquitoes when the temperature was significantly lower $(\mathrm{df}=35, \mathrm{t}=67.43, \mathrm{p}<0.001)$, with significantly higher humidity and pressure $(\mathrm{df}=35, \mathrm{t}=$ 35.94, $\mathrm{p}<0.001 ; \mathrm{df}=35, \mathrm{t}=798.08, \mathrm{p}<0.001$, respectively) in the $2008 / 2009$ summer season compared to the $2007 / 2008$ summer season.

\section{DISCUSSION}

We had predicted that the mosquito, Cx. pervigilans, would alter its oviposition behavior in the presence of the predator Anisops or its kairomone. This prediction was based on several other studies that have found evidence for Culex spp. and Culiseta spp. avoiding oviposition in the presence of Notonecta sp. or its chemical traces (Blaustein et al. 1995, Blaustein 1998, Blaustein et al. 2004, Eitam and Blaustein 2004, Kiflawi et al. 2004a, Blaustein et al. 2005). Eitam et al. (2002) also found that in the presence of free

Table 1. Results of repeated measures ANOVA examining the cumulative number of Cx. pervigilans egg rafts in response to different types of predator treatments and densities (A. wakefieldi). $\mathrm{df}=$ degree of freedom, MS = mean squared values. Significant values are in bold. Data were log transformed prior to analysis.

\begin{tabular}{lcccc}
\hline Source & F & Df & MS & Significance \\
\hline Treatments (T) & 1.389 & 3 & 0.032 & 0.284 \\
Densities (D) & 0.224 & 3 & 0.005 & 0.879 \\
Period (P) & 1.030 & 3 & 0.004 & 0.381 \\
Year (Y) & 3.791 & 1 & 0.013 & 0.100 \\
P x T & 0.931 & 9 & 0.003 & 0.500 \\
P x D & 0.828 & 6 & 0.003 & 0.591 \\
Px Y & 1.689 & 3 & 0.006 & 0.173 \\
P x T x D & 0.693 & 12 & 0.002 & 0.600 \\
Px Y x T & 1.281 & 6 & 0.005 & 0.271 \\
P x T x D x Y & 0.395 & 12 & 0.001 & 0.963 \\
Period x Subject within groups & & 126 & 0.004 & \\
Period x Subject between groups & & 42 & 0.014 & \\
\hline
\end{tabular}


Figure 1. The effects of predator treatment and predator density (A. wakefieldi) on number of $C x$. pervigilans egg rafts (mean \pm SE) based on four time periods tested; (A) control (B) free-roaming predators, (C) caged predators (D) water with predator kairomones.
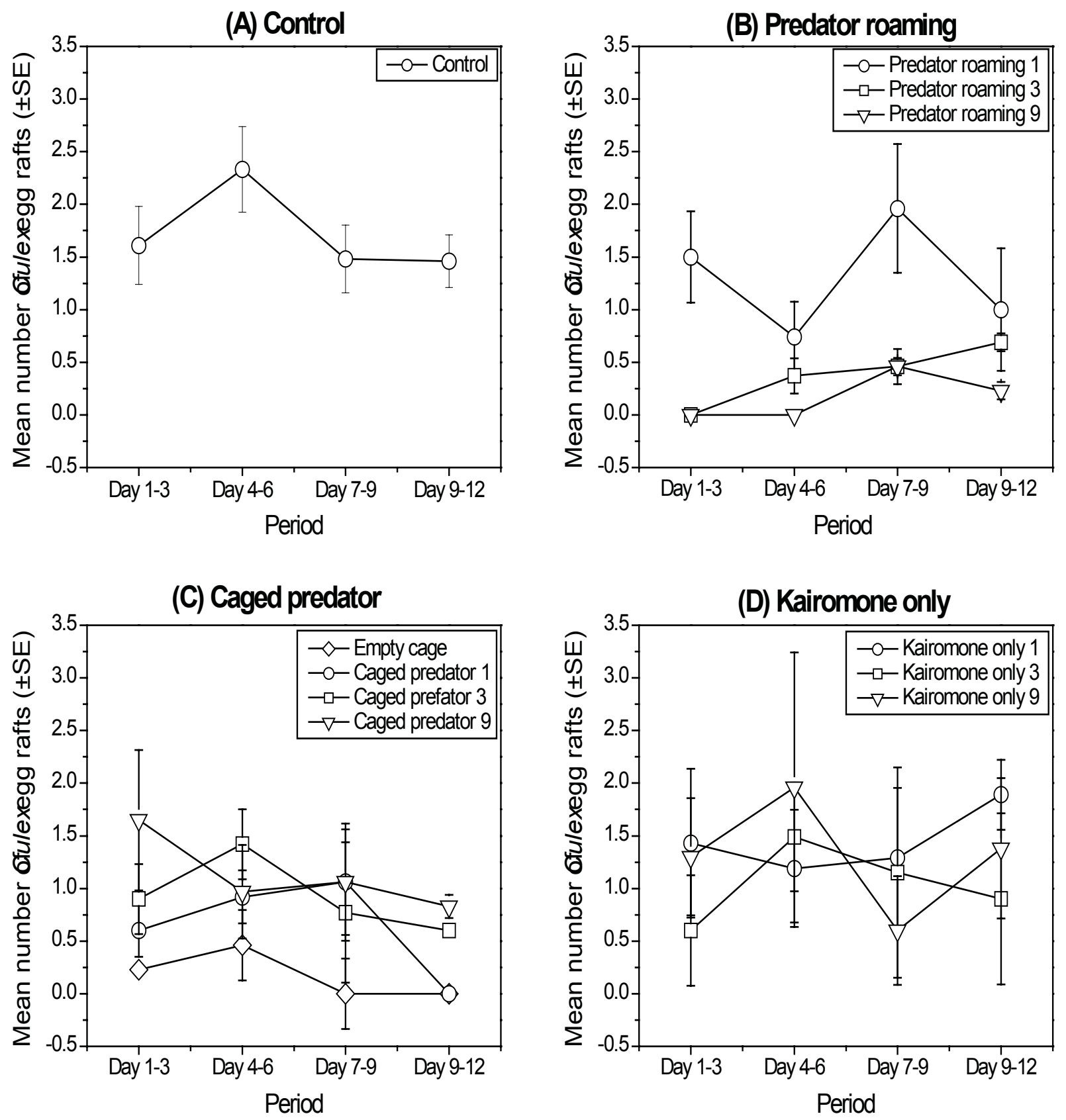
Table 2. Pearson correlation analysis results between temperature, wind speed, rainfall, humidity, and pressure with $C x$. pervigilans egg rafts after 12 days post-treatment based on two-year study periods. Significant values are in bold. ${ }^{*}$ indicated that the significant value is at 0.05 and ${ }^{* *}$ is at 0.01 . $\mathrm{df}=271$ for all factors.

\begin{tabular}{lcc}
\multicolumn{1}{c}{ Factor } & Pearson $\mathrm{r}$ & Significance \\
\hline Temperature & $0.159^{\star}$ & $\mathbf{0 . 0 1 2}$ \\
Wind speed & -0.104 & 0.098 \\
Rainfall & -0.084 & 0.182 \\
Humidity & $0.187^{\star \star}$ & $\mathbf{0 . 0 0 3}$ \\
Pressure & $-0.504^{\star \star}$ & $<\mathbf{0 . 0 0 1}$ \\
\hline
\end{tabular}

swimming A. sardea, Culiseta mosquitoes were repelled from ovipositing in pools, resulting in a significantly lower number of eggs than in control pools. However, we found no evidence that $C x$. pervigilans modifies its oviposition behavior in response to predators. We postulate that $C x$. pervigilans either ignored the presence of the predator or that the cues from Anisops predators were not sufficiently strong enough to provide an alarm to these mosquitoes.

The densities of predators that we used have elicited avoidance responses in Culex mosquitoes elsewhere. The densities of predators in our study were more than twice that used in the study by Eitam and Blaustein (2004), but we observed no significant response by mosquitoes to the predator or its kairomone. In regard to kairomones, other mosquitoes such as Culiseta longireolata can detect chemicals from Notonecta predators for periods of up to eight days after their removal from the pool (Blaustein et al. 2004) and at least two days for Culex species (Blaustein et al. 2005). It thus seems reasonable to expect that the mosquitoes would have shown a response to this predator in our experimental design but we failed to detect one. Nevertheless, we cannot rule out the possibility that the mosquito would have shown a response to the predator at higher predator densities.

Given the substantial effects of individual predators on $C x$. pervigilans populations, we would have expected this mosquito to have evolved an ability to detect the densities of the predator we used in the experiment. In laboratory experiments, we have observed that Anisops kill large numbers of $C x$. pervigilans (Fatma Zuharah, unpublished data). A single adult predator can kill an average of 10-82 Culex larvae per day based on prey and predator size and density (Nabaneeta et al. 2007). There was thus clearly no reason why $C x$. pervigilans should have ignored the presence of the Anisops predator. In the absence of any behavioral modification of oviposition, these lethal effects of Anisops seem likely to be the mechanism resulting from the near ly complete absence of mosquitoes co-occurring with this predator in our field studies (Fatma Zuharah, unpublished data).

We can only speculate, given the lethal effects of Anisops on mosquito populations, why an ability to detect predators has not evolved in this mosquito. It is possible that until recently, these species may not have naturally occurred together. Greig ${ }^{1}$ found that Anisops sp. in Canterbury, New Zealand, is likely to inhabit either permanent or semi-permanent water bodies but not temporary pools. However, $C x$. pervigilans is able to breed in a wide variety of water habitats. Culex larvae can easily be found in fresh and polluted waters, permanent and temporary ground pools, natural and artificial containers, and also slow moving streams (Belkin 1968, Dumbleton 1968, Holder et al. 1999). With the creation of water troughs by humans in the farming industry, Anisops predators have perhaps only recently started to share the same habitat with $C x$. pervigilans. Statistics New Zealand (2008) indicated that $76 \%$ of agricultural land was used for animal farming industries in 2002, with many thousands of existing water troughs as potential habitats for Cx. pervigilans, Anisops, and other aquatic insects. Culex pervigilans are now the most common species observed in water bodies such as animal troughs where Anisops also occur (Laird 1990). Because of the immense selection pressure exterted by Anisops on $C x$. pervigilans in this new habitat, the mosquito may develop an ability to detect this predator, but the evolution of such an ability would likely take a long time to develop.

Given the lack of response of $C x$. pervigilans to Anisops predators, we predicted that variation within and between years in mosquito oviposition behavior might be explained by environmental factors. Changes in temperature or precipitation may drive changes in mosquito density and populations (Canyon et al. 1998, Ritchie and Rochester 2001, Koenraadt et al. 2004, Hsu et al. 2008, Platonon et al. 2008). Similarly, our results also indicated that more egg rafts were oviposited by Culex mosquitoes when the temperatures were higher and the humidity and pressure were lower, as demonstrated in the 2007/2008 summer season. In our experiment, environmental variables clearly had a far greater influence on oviposition than did the presence of Anisops predators.

In summary, we found that $C x$. pervigilans did not alter their oviposition behavior in response to Anisops predators (or its kairomone traces), the presence of different densities of predators, or environmental factors. This is the first published study to demonstrate that $C x$. pervigilans do not alter their oviposition behavior according to the presence of a voracious predator. The complexity of possible abilities to detect predator presence still remains to be examined.

\section{Acknowledgments}

This research was supported by Victoria University of Wellington and Wan Fatma Zuharah by a grant from the Malaysian government for graduate work in New Zealand. We thank the VUW "Bug Club" for providing comments on a draft manuscript. We also thank Rewi Elliot for the

${ }^{1}$ Greig, S.H. 2008. Community assembly and food web interaction across ponds permanence gradients. Ph.D. thesis, University of Canterbury. 142 pp. 
sampling permit at Otari-Wilton's Bush and Nik Fadzly for assisting with experiments.

\section{REFERENCES CITED}

Angelon, K. and J. Petranka. 2002. Chemical predatory mosquitofish (Gambusia affinis) influence selection of oviposition site by Culex mosquito. J. Chem. Ecol. 28: 797- 806.

Belkin, J.N. 1968. Mosquito studies (Culicidae: Diptera). VII. The Culicidae of New Zealand. Contr. Am. Entomol. Inst. 3: 1-182.

Bentley, M.D. and J.F. Day. 1989. Chemical ecology and behavioral aspects of mosquito oviposition. Annu. Rev. Entomol. 34: 401-421.

Blaustein, L. 1998. Influence of predatory backswimmer, Notonecta maculata, on invertebrate community structure. Ecol. Entomol. 23: 246-252.

Blaustein, L., M. Kiflawi, A. Eitam, M. Mangel, and J. E. Cohen. 2004. Oviposition habitat selection in response to risk of predation in temporary pools: mode of detection and consistency across experimental venue. Oecologia 138: 300-305.

Blaustein, L., J. Blaustein, and J. Chase. 2005. Chemical detection of predator Notonecta irrorata by ovipositiong Culex mosquitoes. J. Vector Ecol. 30: 299-301.

Blaustein, L., B.P. Kotler, and D. Ward. 1995. Direct and indirect effects of the predatory backswimmer (Notonecta maculata) on community structure of desert temporary pools. Ecol. Entomol. 20: 311-318.

Bond, J.G., J.I. Arredondo-Jimenez, M.H. Rodriguez, H. Quiroz-Martinez, and T. Williams. 2005. Oviposition habitat selection for a predator refuge and food source in a mosquito. Ecol. Entomol. 30: 255-263.

Canyon, D.V., L.J. Hii, and R. Muller. 1998. Adaptation of Aedes aegypti (Diptera:Culicidae) oviposition behavior in response to humidity and diet. J. Insect Physiol. 45: 959-964.

Dumbleton, L.J. 1968. A synopsis of New Zealand mosquitoes (Diptera.Culicidae) and a key to their larvae. Tuatara 16: 167-179.

Eitam, A. and L. Blaustein. 2004. Oviposition habitat selection by mosquitoes in response to predator (Notonecta maculata) density. Physiol. Entomol. 29: 188- 191.

Eitam, A., L. Blaustein, and M. Marc. 2002. Effect of Anisops sardea (Hemiptera: Notonectidae) on oviposition habitat selection by mosquitoes and other dipterans and on community structure in artificial pools. Hydrobiologia 485: 183-189.

Graham, D. H. 1939. Mosquito life in the Auckland district. Trans. R. Soc. N.Z. Biol. Sci. 69: 210-244.

Holder, P., G. Brown, and M. Bullian. 1999. The mosquitoes of New Zealand and their animal disease significance. Surveillance 26: 12-15.

Hsu, S.M., A. M. F. Yen, and H. H. Chen. 2008. The impact of climate on Japanese encephalitis. Epidemiol. Infect. 136: 980-987.
Kiflawi, M., L. Blaustein, and M. Mangel. 2003a. Oviposition habitat selection by the mosquito Culiseta longiareolata in response to risk of predation and conspecific larval density. Ecol. Entomol. 28: 168-173.

Kiflawi, M., L. Blaustein, and M. Mangel. 2003b. Predationdependent oviposition habitat selection by the mosquito Culiseta longiareolata: a test of competing hypotheses. Ecol. Lett. 6: 35-40.

Koenraadt, C.J.M., A.K. Githeko, and W. Takken. 2004. The effects of rainfall and evapotranspiration on the temporal dynamics of Anopheles gambiae s.s. and Anopheles arabiensis in a Kenyan village. Acta Trop. 90: 141-153.

Laird, M. 1990. New Zealand's Northern mosquito survey, 1988-89. J. Am. Mosq. Contr. Assoc. 6: 287-299.

Laird, M. 1995. Background and findings of the 1993-94 New Zealand mosquito survey. N.Z. Entomol. 18: 7790.

Leisnham, P. T., P.J. Lester, D.P. Slaney, and P. Weinstein. 2006. Relationship between mosquito densities in artificial container habitats, land use and temperature in the Kapiti-Horowhenua region, New Zealand. N.Z. J. Marine Freshw. Res. 40: 285-297.

Maguire, T., J.A.R. Miles, and J. Casals. 1967. Whataroa virus, a group A arbovirus isolated in South Westland, New Zealand. Am. J. Trop. Med. Hyg. 16: 371-373.

Miles, J.A.R. 1973. The ecology of the Whataroa virus an alphavirus in South Westland, New Zealand. J. Hyg. 73: 701-713.

Nabaneeta S., A. Gautum, B. Animesh, and G.K. Saha. 2007. Comparative study of functional response of common hemipteran bugs of east Calcutta wetlands, India. Int. Rev. Hydrobiol. 92: 242-257.

Platonon, A.E., M.V.Fedorova, L.S. Karan, T.A. Shopenskava, O.V. Platonova, and V. I. Zhuravlev. 2008. Epidemiology of West Nile infection in Volgograd, Russia, in relation to climate change and mosquito (Diptera: Culicidae) bionomics. Parasitol. Res. 103: S45-S53.

Ritchie, S. and W. Rochester. 2001. Wind-blown mosquitoes and introduction of Japanese encephalitis into Australia. Emerg Infect. Dis. 7: 900-903.

Statistics New Zealand 2008. Measuring New Zealand's progress using a sustainable development approach: 2008. Topic 5: Land Use. Retrieved September $14^{\text {th }}$, 2009, from http://www.stats.govt.nz/Publications/ NationalAccounts/sustainable-development/land-use. aspx

Stav, G., L. Blaustein, and J. Margalith. 1999. Experimental evidence for predation risk sensitive oviposition by a mosquito, Culiseta longiareolata. Ecol. Entomol. 24: 202- 207.

Weinstein, P., M. Laird and G. Browne. 1997. Exotic and endemic mosquitoes in New Zealand as potential arbovirus vectors. Ministry of Health, Wellington, New Zealand.

Wisenden, B. D. 2000. Olfactory assessment of predation risk in the aquatic environment. Phil.Trans. R. Soc. Lond. B 355, 1205-1208. 


\section{ApPendiX D:}

Zuharah WF and Lester PJ (2010) The influence of aquatic predators on mosquito abundance in animal drinking troughs in New Zealand. Journal of Vector Ecology. 35(2): In Press 


\title{
The influence of aquatic predators on mosquito abundance in animal drinking troughs in New Zealand
}

\author{
Wan Fatma Zuharah ${ }^{1 凶}$ and Philip J. Lester ${ }^{2}$ \\ ${ }^{1}$ School of Biological Sciences, Universiti Sains Malaysia, 11800 Minden, Penang, Malaysia \\ ${ }^{2}$ School of Biological Sciences, Victoria University of Wellington, P.O. Box 600, Wellington 6140, New Zealand
}

Received 5 March 2010; Accepted 6 July 2010

\begin{abstract}
The occurrence and abundance of mosquito populations may be associated with the abundance of predators. We examined the relationship between aquatic predators and populations of mosquitoes in animal water troughs in Waikanae, New Zealand. We also investigated the effects of water volume and environmental factors (temperature, rainfall, wind speed, humidity, and pressure) in order to further understand factors influencing mosquito and predator populations. Logistic regression indicated that the presence or absence of mosquitoes was primarily affected by three factors: predator abundance, week of observation, and water volume. Pearson's correlation indicated that the presence of predators had a positive correlation with water volume $\left(\mathrm{r}^{2}=0.176, \mathrm{p}<0.05\right)$. Otherwise, the presence of mosquito larvae in water troughs was negatively correlated with water volume $\left(\mathrm{r}^{2}=-0.159, \mathrm{p}=0.022\right)$ and wind speed $\left(\mathrm{r}^{2}=0.142, \mathrm{p}=0.041\right)$. We established a translocation experiment in which predators or mosquitoes were moved between troughs in order to examine the prey survival rate after exposure to Anisops wakefieldi predators. The survival rate of mosquitoes was not significantly different, between $0-0.1 \%$, irrespective of the number of predators translocated (1-9) or the initial mosquito density (20-70 larvae). Our results suggested that $A$. wakefieldi predators may have the potential to be a promising biological control tool for the control of mosquito populations by altering mosquito population dynamics. Journal of Vector Ecology 35 (2): xxx-xxx. 2010.
\end{abstract}

Keyword Index: Environmental factors, mosquito population, predator, translocation, water trough, water volume.

\section{INTRODUCTION}

Artificial containers such as bottles, cans, tires, pots, and animal drinking troughs are major habitats for mosquito populations. However, aquatic predators also occur in many of these habitats, including animal drinking troughs, and have been suggested to influence the abundance of mosquitoes (Laird 1990). Mosquito species may share the same habitat with predators, with some predators appearing to have little influence on mosquito populations (Lundkvist et al. 2003). Different mosquito species may be affected differently by predators (Griswold and Lounibos 2006), with the differential consumption of various mosquito species by predators resulting in the coexistence of some mosquito species (Griswold and Lounibos 2005).

A variety of aquatic insects in the orders Coleoptera, Hemiptera, Odonata, and Diptera is known to attack and eat mosquito larvae. In general, most predators are polyphagous and consume a broad range of prey species (Shaalan et al. 2007). In New Zealand, the common mosquito predators seen in natural and anthropogenic water bodies are the notonectid backswimmer Anisops spp. (Hemiptera), diving beetles in the genus Rhantus (Coleoptera), and damselfly larvae (Odonata) (Graham 1939). Several studies have focused on notonectid predators because of their effectiveness in controlling mosquito populations (Scott and Murdoch 1983, Murdoch et al. 1984, Koivisto et al. 1997). Notonectid predators clearly have the potential to alter mosquito communities via direct or indirect effects (Gilbert and Burns 1999). The indirect effects of the presence of notonectid predators in water bodies can include a reduction in oviposition by adult mosquitoes (Chesson 1984, Blaustein et al. 1995), while direct effects occur primarily through predation.

New Zealand currently has only 16 mosquito species, with 12 indigenous species and four exotic species (Derraik 2004a, 2004b, Laird 1990, 1995). No outbreaks of mosquitoborne disease have been recorded. However, out of 12 indigenous mosquito species, Culex pervigilans and Culiseta tonnoiri have been identified as vectors of the avian arbovirus (Whataroa Virus) (Maguire et al. 1967). Culex pervigilans is New Zealand's most abundant and widespread species and has the potential to be a vector of human pathogens. Culex pervigilans is often found in artificial containers including animal drinking troughs (Graham 1929, 1939, Belkin 1968, Laird 1990, 1995). There are other species which are of much greater concern such as Aedes notoscriptus and Coquilletidia iracunda, with the former also being found in drinking water troughs in New Zealand (Laird 1995).

Environmental factors may affect the abundance of predator and mosquito populations. A backtrack simulation study of wind speeds sufficient for mosquito transport from Papua New Guinea to Australia was performed by Ritchie and Rochester (2001). Winds at 36 and $72 \mathrm{~km} / \mathrm{h}$ were capable of carrying mosquitoes from New Guinea to the Northern Peninsula of Australia. Slow velocity winds are also important as they allow female mosquitoes to place their eggs calmly without disturbance in water containers (Service 2000). Temperatures can also strongly influence predation rates. For example, Anderson et al. (2001) showed 
that tadpoles raised in warmer water experienced a higher probability of capture by notonectids predators than those reared in cooler conditions.

Our aim in this study was to examine the relationship and interactions between predators and mosquito populations in animal drinking troughs. We translocated predators between troughs in order to better understand their influence on mosquito populations. We also examined the effects of water volume and environmental factors on predator and mosquito populations.

\section{MATERIALS AND METHODS}

\section{Study site}

Our study was undertaken at Queen Elizabeth II Park, Waikanae, New Zealand (41"06'31.43 S, 175"13'12.91 E). This area contains a variety of habitats, including coastal and inland sand dunes as well as pastoral areas for animal farming. A total of 13 water troughs within an area of $4.8 \mathrm{~km}^{2}$ were sampled. Troughs ranging in volume from 0.32-0.84 $\mathrm{m}^{3}$ were sampled at weekly intervals. Sampling continued for two southern hemisphere summers from December to February of 2007/2008 and 2008/ 2009.

\section{The relationship between predator and mosquito populations}

During each sampling occasion, predators such as Anisops wakefieldi (backswimmers), Rhantus rhantus larvae (diving beetles), and Onychohydrus hookeri (water beetles) were visually observed and counted. Predators were inspected and identified in situ, as they were easily identified to genus level. To estimate mosquito densities we used a conventional dipping technique (Russell 1993, Service 1995). The water surface was stirred using a stick before the sample was taken. A total of ten liters of water was sampled by dipping at equal intervals around the water trough. The water samples were strained through $0.10 \mathrm{~mm}$ mesh and the filtered water was then returned to the trough. Mosquitoes collected in the strainer were placed separately in containers with $500 \mathrm{ml}$ of water and brought back to the laboratory for identification. If any predators were caught in the strainer, they were released back into the trough. Mosquito larvae were identified using a key by Snell (2005). The dipper and strainer were thoroughly rinsed with distilled water before sampling the next water trough.

The water volume for each trough was recorded. Water volume was used rather than water depth because there were different shapes of water troughs located in the field. Environmental data (temperature, wind speed, rainfall, pressure, and humidity) were provided by the New Zealand National Institute for Water and Atmospheric Research from Paraparaumu Aero Station, which is approximately $4.5 \mathrm{~km}$ from our study site.

We analyzed the data with logistic regression using $\mathrm{R}$ version 2.10.1 (Ihaka and Gentleman 1996). The presence and absence of mosquitoes served as the response variable. The predictor variables were predator, water volume, week of observation, temperature, rainfall, wind speed, and humidity. This logistic regression approach was used because prior work has suggested that the sole presence of predators or kairomones can influence mosquito communities by altering mosquito behaviors such as adult oviposition (Blaustein et al. 2004, Blaustein et al. 2005). We then used Pearson's correlation tests in SPSS 15.0 (2006) to examine the relationship between the environmental factors and water volume, and the abundance of predators and mosquito populations in water troughs. If, as in our experiments, the presence or absence of predators does not influence mosquito behaviors such as oviposition, an analysis of the influence of predator abundance is more appropriate.

\section{Predator translocation experiment}

In order to examine the effectiveness of the predator $A$. wakefieldi in altering mosquito populations, we transferred these predators among troughs. Anisops wakefieldi was used in this study because it was the most common predator species at our study site. We transferred between one and nine predators, and $3^{\text {rd }}$ instar $C x$. pervigilans mosquito larvae, in each water trough as follows; (A) zero predators (control) with 20,40, or 70 mosquito larvae, (B) one predator with 10,15 , or 20 mosquito larvae (C) three predators with 20,30 , or 40 mosquito larvae (D) nine predators with 30 , 50 , or 70 mosquito larvae. Experiments were replicated four times. Data were recorded two days after each transfer.

In order to test the effects of predator density and prey number on mosquito survival rates in the translocation experiments, we ran a two-way ANOVA in SPSS 15.0 (2006). The percentage of surviving prey served as the dependent variable, whereas type of treatment and initial number of prey offered were fixed factors. Survival rates were expressed as a percentage and were therefore transformed using arcsine square root prior to analysis to satisfy the assumptions of ANOVA.

\section{RESULTS}

\section{The relationship between predator and mosquito populations}

The only mosquito species that was observed utilizing animal drinking troughs during the entire study was Culex pervigilans. The three predator species observed in same habitat were Anisops wakefieldi (91.8\%), Rhantus rhantus larvae (6.6\%), and Onychohydrus hookeri (1.6\%). The total number of $C x$. pervigilans larvae collected in 2007/2008 was 3,293 , with only 715 individuals in 2008/2009 over the same sampling duration. The total number of predators was high in 2007/2008 with 916 individuals, but only 419 individuals were recorded in 2008/2009.

In 2007/2008 the highest numbers of predators (300) were observed after the first week of sampling during summer but densities declined closer to autumn (Figure 1A). In the same trough in the following year (2008/2009), the situation changed with a high abundance of mosquitoes. However, only two predators were observed for the entire study period (Figure 1A). In most troughs the pattern of 
(A) With predators

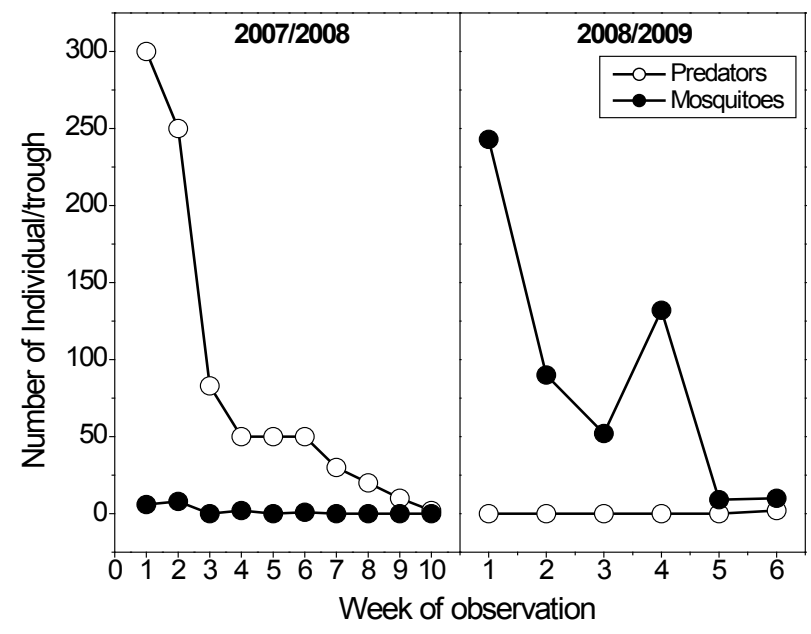

(B) No predator

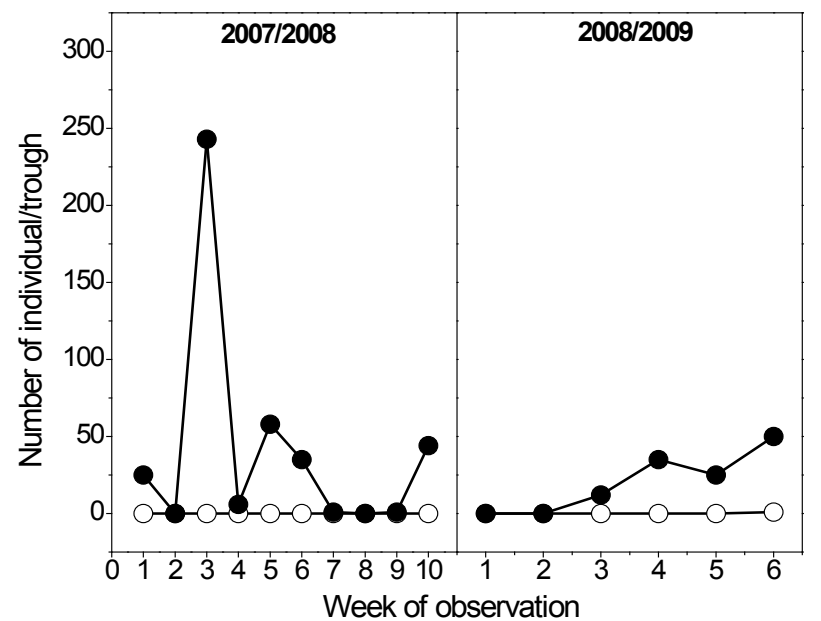

Figure 1. Examples of the relationship between predators and mosquitoes in water troughs at Queen Elizabeth II Park, Waikanae, New Zealand. Two of the 13 troughs examined in the study are shown, one trough with predators (A) and one without predators (B). population dynamics of mosquitoes and predators was similar to that shown in Figure 1B.

The model resulting from the logistic regression indicated that with each increase in the abundance of predators, the probability that mosquito populations existed also increased, but it is not statistically significant (Figure 2). For each increase in the abundance of predators, the odds of mosquitoes being present (vs absent) positively increased by a factor of 1.0059 . The probability of mosquito presence significantly decreased with increasing water volume and week of observation $(p<0.05$; Table 1$)$.

Predator abundance increased significantly with increasing water volume in both years of the study $\left(\mathrm{r}^{2}=0.176\right.$, $p=0.011$; Table 2 and Figure 3), but was not correlated with any other environmental variable nor the abundance of mosquitoes $(p \geq 0.232$ ). In comparison, mosquito abundance decreased significantly with increasing water volume $\left(\mathrm{r}^{2}=-0.159, p=0.022\right.$; Table 2$)$ and wind speed $\left(r^{2}=0.142, p=0.041\right)$ but was not correlated with any other environmental variable $(p \geq 0.220)$.

\section{Predator translocation experiment}

The translocated predators had a major effect on mosquito populations. The maximum number of mosquito prey left alive was one mosquito two days post-treatment. Even at the highest number of 70 prey, with the largest water volume of $0.72 \mathrm{~m}^{3}$, the predator successfully consumed all of the prey (Figure 3 ). The ANOVA showed that the mosquito larvae survival rate in treatments with predators was significantly lower than in the control treatment without predators $(\mathrm{F}=443.92, \mathrm{df}=3, p<0.001)$. There was no significant effect of initial mosquito number on mosquito survival rate $(\mathrm{F}=0.87, \mathrm{df}=6, p=0.524)$, and the interaction between treatments and mosquito abundance was also nonsignificant $(\mathrm{F}=0.53, \mathrm{df}=6, p=0.780)$. Post-hoc comparisons showed that treatments with predators (one, three, and nine predators) were not significantly different from each other $(p \geq 0.704)$ but had a significantly lower prey survival (Tukey, $p<0.005)$ than in the control treatment without

\begin{tabular}{ccccc}
\hline & Estimates & SE & z-value & p-value \\
\hline Intercept & 4.937 & 1.561 & 3.163 & $0.002^{\star *}$ \\
Predator & $7.217^{\mathrm{e}-03}$ & $6.343^{\mathrm{e}-03}$ & 1.138 & 0.255 \\
& & & & \\
Water Volume & $-2.194^{\mathrm{e}-06}$ & $1.114^{\mathrm{e}-06}$ & -1.969 & $0.049^{*}$ \\
& & & & \\
Water trough & $5.201^{\mathrm{e}-02}$ & $6.036^{\mathrm{e}-02}$ & 0.862 & 0.389 \\
Temperature & $1.196^{\mathrm{e}-01}$ & $7.143^{\mathrm{e}-02}$ & -1.675 & 0.094 \\
Wind speed & $3.939^{\mathrm{e}-02}$ & $2.376^{\mathrm{e}-02}$ & 1.658 & 0.097 \\
Rainfall & $2.658^{\mathrm{e}-02}$ & $2.062^{\mathrm{e}-02}$ & 1.289 & 0.197 \\
Humidity & $-1.477^{\mathrm{e}-02}$ & $9.551^{\mathrm{e}-03}$ & 1.289 & 0.197 \\
Week & $-1.976^{\mathrm{e}-01}$ & $5.084^{\mathrm{e}-02}$ & -3.887 & $<0.001^{* * *}$ \\
\hline
\end{tabular}

Table 1. Logistic regression analysis for the predictor variables included in the model that affect the presence or absence of mosquito populations in the water troughs. d.f. $=202\left({ }^{* * *}=p<0.001,{ }^{* *}=p<0.01,{ }^{\star}=p<0.05\right)$. 


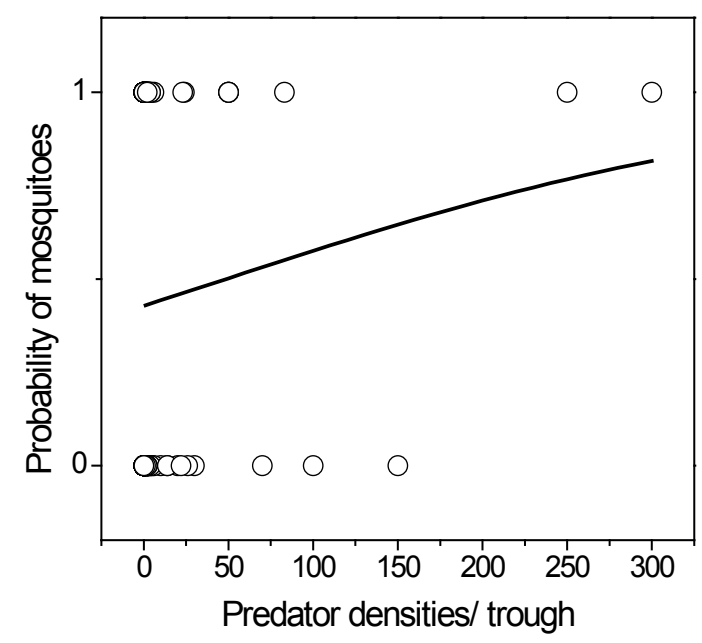

Figure 2. Logistic regression of the presence or absence of mosquitoes in association with predator abundance.

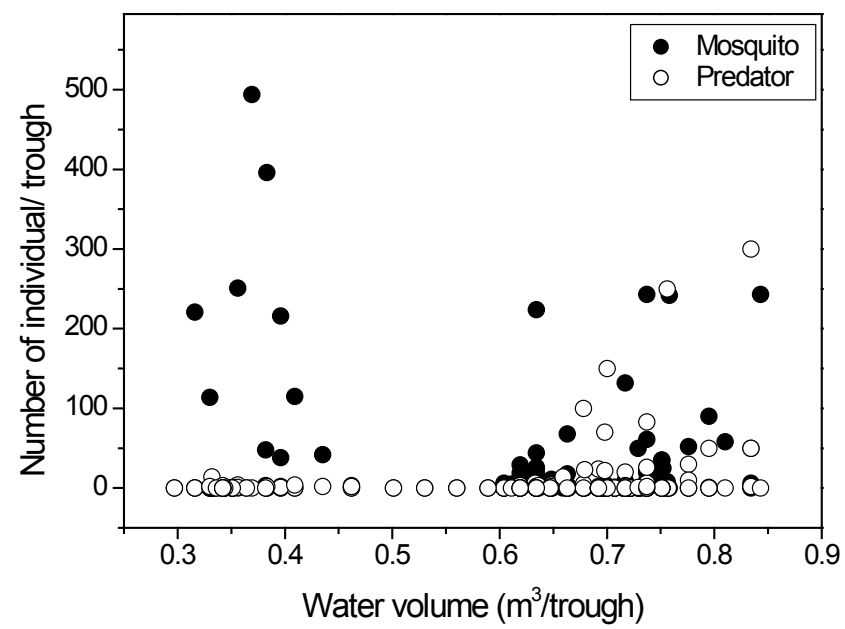

Figure 3. Abundance of mosquito larvae and predators recorded in animal drinking troughs compared to cumulative water volume.
(A) Control

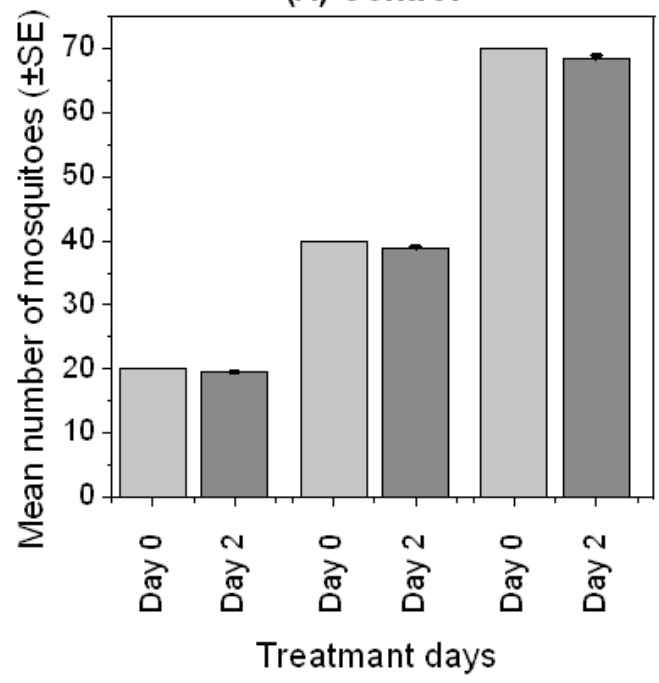

(C) 3 predators

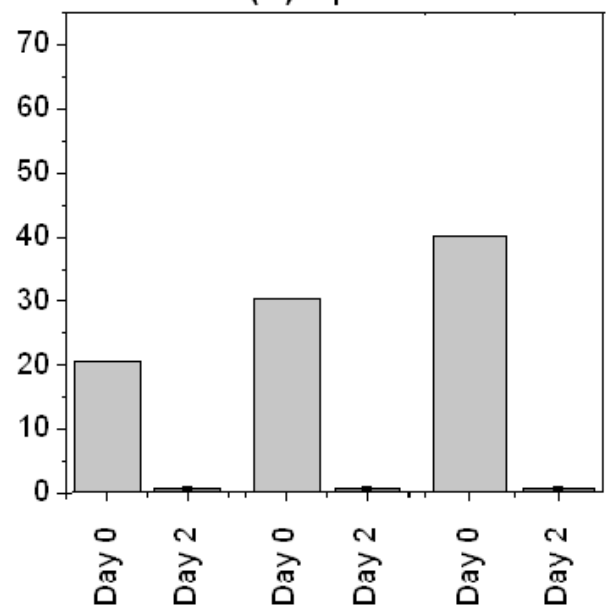

(B) 1 predator

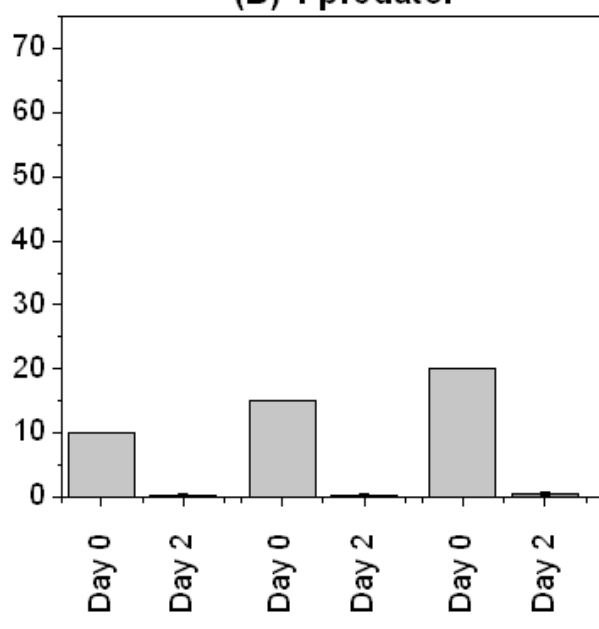

(D) 9 predators

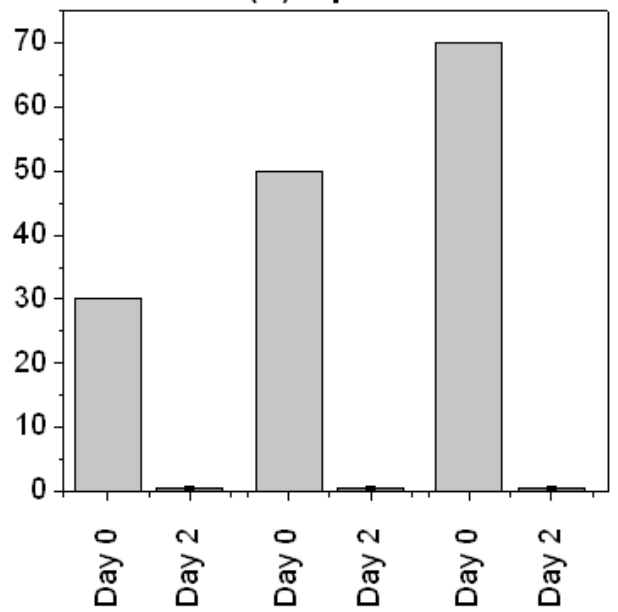

Figure 4. Results of the pre- (day 0) and post-treatment (day 2) experiment after mosquito prey were exposed to (A) control (with the absence of predators), (B) one free-roaming predator, (C) three free-roaming predators, and (D) nine free-roaming predators. 
Table 2. Results of Pearson correlation tests between Anisops wakefieldi or mosquito populations, and environmental factors (temperature, rainfall, wind speed, humidity, and pressure) or water volume. Data were collected from animal water troughs during the Southern Hemisphere summer (December to February 2007/2008 and 2008/2009) for two consecutive years. Significant values are in bold with $\mathrm{df}=207$. Data represent Pearson's 2-tailed correlation.

\begin{tabular}{lcc}
\hline & Predator & Mosquito \\
\hline Mosquito & $-0.052,0.454$ & \\
Water volume & $0.176, \mathbf{0 . 0 1 1}$ & $-0.159, \mathbf{0 . 0 2 2}$ \\
Temperature & $-0.020,0.773$ & $-0.085,0.220$ \\
Rainfall & $-0.041,0.558$ & $0.049,0.484$ \\
Wind speed & $-0.063,0.365$ & $0.142, \mathbf{0 . 0 4 1}$ \\
Humidity & $-0.023,0.741$ & $0.064,0.357$ \\
Pressure & $0.083,0.232$ & $0.022,0.748$ \\
\hline
\end{tabular}

predators. These results clearly demonstrate the ability of this predator to reduce the number of mosquitoes in water troughs within only two days. In the control treatments, where mosquito larvae were present in the water troughs without predators, the mortality rate of mosquitoes was less than $5 \%$.

\section{DISCUSSION}

The only mosquito species observed in this study was Cx. pervigilans. Culex pervigilans is the most common mosquito in New Zealand, utilizing many water containers and habitat types (Graham 1939, Belkin 1968, Laird 1990, 1995). It prefers organically rich water bodies (Graham 1939, Dumbleton 1968, Urbinatti 2001) but has wide tolerance for a variety of water qualities (Graham 1929, Derraik and Slaney 2004). The predators A. wakefieldi, R. rhantus, and $O$. hookeri are also widely distributed throughout the North Island of New Zealand (Brown 1943, Winterbourn et al. 2006). At our sampling site, A. wakefieldi was the most abundant predator observed; only $2 \%$ of all predators were $R$. rhantus and O. Hookeri. In our study, most of the water troughs utilized by predators had low densities of mosquitoes. Some of the water troughs that were utilized by large numbers of predators in 2007/2008 had few predators and large numbers of mosquitoes in 2008/2009. There are at least two hypotheses to explain these results. Firstly, predators may consume large numbers of mosquitoes and control their population numbers. Secondly, adult mosquitoes may have an ability to detect the presence of a predator and will not oviposit in troughs with predators.

To test the hypothesis that the predators consumed a large number of mosquitoes, we undertook a translocation experiment in which A. wakefieldi and mosquitoes were placed together in the same environment. Our translocation experiment showed that within two days, all mosquitoes were consumed by predators. Other laboratory studies confirm that a single A. wakefieldi predator in $500 \mathrm{ml}$ of water can kill about 18 individual mosquitoes within $24 \mathrm{~h}$ (Zuharah, unpublished data). In our study, it appears that even in large water volumes $A$. wakefieldi are voracious predators. Both adults and nymphs of $A$. wakefieldi prey upon mosquito larvae. This predator is believed to be most effective against $3^{\text {rd }}$ and $4^{\text {th }}$ instar larvae (Bay 1974, Lee 1967, Ellis and Borden 1970). Additionally, Anisops spp. prefers mosquito larvae over other prey when given a choice (Ellis and Borden 1970).

Our second hypothesis to explain the relationship between predators and mosquitoes was that adult mosquitoes may have the ability to detect the presence of a predator and consequently do not oviposit in troughs with predators. Predators may therefore regulate prey abundance without directly killing mosquitoes (Brown et al. 1997). Stav et al. (1999) suggested that the distribution and abundance of a mosquito species is dependent on their ability to selectively oviposit according to predator abundance. Other mosquitoes such as Culiseta longireolata can detect chemicals from Notonecta predators for periods of up to eight days after their removal from the pool (Blaustein et al. 2004) and this period is as low as two days for Culex species (Blaustein et al. 2005). It thus seems reasonable to expect that the mosquitoes would have shown a response to this predator. With increasing predator densities, the concentration of kairomones also increase and may result in reduced oviposition (Eitam and Blaustein 2004). A reduction in oviposition activities by mosquitoes may be expected with increasing numbers of predators, due to the ability of these prey species to detect the presence of a predator above a threshold density (Angelon and Petranka 2002) or a specific concentration of kairomones (Eitam and Blaustein 2004). In a separate experiment we examined the oviposition of $C x$. pervigilans in response to the presence of 
A. wakefieldi and kairomones. Unlike work elsewhere (e.g., Blaustein et al. 2004, Blaustein et al. 2005), we observed no response of mosquitoes to the presence of these predators (Zuharah and Lester, 2010).

Thus, it appears that the primary effects of predators are through predation rather than sub-lethal effects such as a change in oviposition behavior. However, our logistic data indicated a positive relationship between mosquito and predator densities, though this relationship was not significant $(p<0.10)$. Adult Anisops predators frequently disperse and may fly up to $1.6 \mathrm{~km}$ between habitats (Brier, unpublished data). It is possible that these predators periodically move between habitats and are more likely to stay longer in habitats with high numbers of mosquitoes. Further work is needed to confirm this hypothesis.

The abundance of mosquitoes was observed to be dramatically different between the two years of this study. None of the environmental factors we examined correlated with the abundance of predator and mosquito populations. Wind speed correlated only with mosquito abundance. Mosquitoes need 10-15 min to oviposit, therefore, slow velocity winds are important as they allow female mosquitoes to place their eggs without disturbance in water containers (Service 2000). The lack of any other relationship between mosquito abundance and predators with environmental variables may be a result of averaging. The environmental data analyzed are the average conditions over each weekly period of sampling, but within any one week there may have been conditions suitable for brief periods of oviposition or predator movement.

Water volume was highly correlated with predator and mosquito abundance in water troughs. Larger water troughs may be advantageous to A. wakefieldi colonies because they are less likely to dry out or overflow (Wilton 1968, Frank and Curtis 1977). A larger space offered by bigger water troughs can increase larval survivorship and reduce mortality risks such as cannibalism (Sota 1998, Sunahara et al. 2002). We also found that mosquito populations were negatively correlated with water volume. Female mosquitoes may oviposit in all types of habitats even if the water has evaporated. Browne (unpublished data) observed female mosquitoes ovipositing in full and nearly empty containers, suggesting that these mosquitoes are incapable of assessing water depth. Similarly $C x$. pervigilans appear incapable of assessing water depth (Derraik and Slaney 2004). The positive relationship between water volume and predators, and the negative relationship between depth and mosquitoes, is in accordance with the observations that predators influence mosquito populations.

Our results indicate that the predator, An. wakefieldi, can control $C x$. pervigilans densities even in relatively large volumes of water. However, the fluctuation in environmental changes from year-to-year, and even within a year, may indirectly affect the effectiveness of this predator in controlling mosquito populations.

\section{Acknowledgments}

This research was supported by Victoria University of Wellington and Wan Fatma Zuharah by a grant from the Malaysian government for graduate work in New Zealand. We thank Catherine Duthie for providing comments on a draft manuscript. We also thank Nikki LaMonica for the sampling permit at Queen Elizabeth Park II and Nik Fadzly for assisting with the experiments.

\section{REFERENCES CITED}

Anderson, M.T., J.M. Kiesecker, D.P. Chiver, and A. R. Blaustein. 2001. The direct and indirect effects of temperature on a predator-prey relationship. Can. J. Zool. 79: 1834- 1841.

Angelon, K. and J. Petranka. 2002. Chemical predatory mosquitofish (Gambusia affinis) influence selection of oviposition site by Culex mosquito. J. Chem. Ecol. 28: 797- 806.

Bay, E.C. 1974. Predator-prey relationship among aquatic insects. Annu. Rev. Entomol. 19: 441-453.

Belkin, J.N. 1968. Mosquito studies (Culicidae: Diptera). VII. The Culicidae of New Zealand. Cont. Am. Entomol. Inst. 3: 1-182.

Blaustein, L., J. Blaustein, and J. Chase. 2005. Chemical detection of predator Notonecta irrorata by ovipositiong Culex mosquitoes. J. Vector Ecol. 30: 299-301.

Blaustein, L., B.P. Kotler, and D. Ward. 1995. Direct and indirect effects of the predatory backswimmer (Notonecta maculata) on community structure of desert temporary pools. Ecol. Entomol. 20: 311-318.

Blaustein, L., M. Kiflawi, A. Eitam, M. Mangel, and J.E. Cohen. 2004. Oviposition habitat selection in response to risk of predation in temporary pools: Mode of detection and consistency across experimental venue. Oecologia. 138: 300-305.

Brown, E.S. 1943. A contribution towards an ecological survey of the aquatic water bugs of British Isles. T. Soc. Brit. Entomol. 8: 169-230.

Brown, G.E., D.P. Chivers, and R.J.F. Smith. 1997. Differential learning rates in chemical versus visual cues of a northern pike by fathead minnows in a natural habitat. Environ. Biol. Fishes. 49: 89-96.

Chesson, J. 1984. Effects of Notonectids (Hemiptera: Notonectidae) on mosquito (Diptera: Culicidae): Predation or selective oviposition?. Environ. Entomol. 13: 531- 538.

Derraik, J.G.B. 2004a. Exotic mosquitoes in New Zealand: A review of species intercepted their pathways and ports entry. Aust. N.Z. J. Publ. Hlth. 28: 422-443.

Derraik, J.G.B. 2004b. A survey of the mosquito (Diptera: Culicidae) fauna of the Auckland Zoological Park. N.Z. Entomol. 27: 51-55.

Derraik, J. G. B. and D. Slaney. 2004. Container aperture size and nutrient preferences of mosquitoes (Diptera: Culicidae) in the Auckland region, New Zealand. J. Vector Ecol. 30(1): 73- 82. 
Dumbleton, L. J. 1968. A synopsis of New Zealand mosquitoes (Diptera.Culicidae) and a key to their larvae. Tuatara. 16(3): 167-179.

Eitam, A. and L. Blaustein. 2004. Oviposition habitat selection by mosquitoes in response to predator (Notonecta maculata) density. Physiol. Entomol. 29: 188-191.

Ellis, R.A. and J.H. Borden. 1970. Predation by Notonecta undulate on larvae of yellow fever mosquito. Ann. Entomol. Soc. Am. 63: 963-973.

Frank, J.H. and G.A. Curtis. 1977. On the bionomics of bromeliad-inhabiting mosquitoes IV. Egg mortality of Wyeomyia vanduzeei caused by rainfall. Mosq. News 37: 239-245.

Gilbert, J.J., and C.W. Burns. 1999. Some observation on the diet of the backswimmer, Anisops wakefieldi (Hemiptera: Notonectidae). Hydrobiologia 412: 111118.

Graham, D.H. 1929. Mosquito of Auckland district. Trans. Proc. N.Z. Inst. 60: 205-244.

Graham, D.H. 1939. Mosquito life in the Auckland district. Trans. R. Soc. N.Z. Biol. Sci. 69: 210-244.

Griswold, M.W. and L.P. Lounibos. 2005. Does differential predation permit invasive and native mosquito larvae to coexist in Florida? Ecol. Entomol. 30: 122-127.

Griswold, M.W. and L.P. Lounibos. 2006. Predator identity and addictive effects in a treehole community. Ecology. 87: 987-995.

Ihaka, R. and R. Gentleman. 1996. R: A language for data analysis and graphics. J. Comput. Graph. Stat. 5: 299314.

Koivisto, S., M. Arnér, and N. Kautsky. 1997. Does cadmium pollution change trophic interactions in rockpool food webs?. Envir. Tox. Chem. 16: 1330- 1336.

Laird, M. 1990. New Zealand's Northern mosquito survey, 1988-89. J. Am. Mosq. Contr. Assoc. 6: 287-299.

Laird, M. 1995. Background and findings of the 1993-94 New Zealand mosquito survey. N.Z. Entomol. 18: 7790.

Lang, H.H. 1980. Surface-wave discrimination between prey and nonprey by the backswimmer Notonecta glauca L. (Hemiptera, Heteroptera). Behav. Ecol. Sociobiol. 6: 233-246.

Lee, F.C. 1967. Laboratory observations on certain mosquito predators. Mosq. News 27: 332-338.

Lundkvist, E., J. Landin, M. Jackson, and C. Svessons. 2003. Diving beetles (Dystiscidae) as predators of mosquito larvae (Culicidae) in field experiment and in laboratory tests of prey preferences. Bull. Entomol. Res. 93: 219226.

Maguire, T., J.A.R. Miles, and J. Casals.1967. Whataroa virus, a group of a arbovirus isolated in South Westland, New Zealand. Am. J. Trop. Med. Hyg. 16: 371-373.

Murdoch, W., M. A. Scott, and P. Ebsworth. 1984. Effects of general predator, Notonecta (Hemiptera) upon a freshwater community. J. Anim. Ecol. 53: 791- 808.
Ritchie, S. A. and W. Rochester. 2001. Wind-blown mosquitoes and introduction of Japanese encephalitis into Australia. Emerg. Infect. Dis. 5: 900-903.

Russell, R.C. 1993. Mosquito and mosquito-borne disease in southern Australia: A guide to the biology, relation to disease, surveillance, control and the identification of mosquitoes in southern Australia. University of Sydney.

Scott, M.A. and W.W. Murdoch. 1983. Selective predation by the backswimmer, Notonecta. Limnol. Oceonogr. 28: $352: 366$.

Service, M.W. 1995. Mosquito Ecology: Field Sampling Methods. London. Chapman and Hall. 988 pp.

Service, M.W. 2000. Medical Entomology for Students. Cambridge University Press, Cambridge, UK. 255 pp.

Shaalan, E.A., D.V. Canyon, R. Muller, M.W. Younes, H. Abdel-Wahab, and A.H. Mansour. 2007. A mosquito predator survey in Townsville, Australia, and an assessment of Diplonychus sp. and Anisops sp. predatorial capacity against Culex annulirostris mosquito immatures. J. Vector Ecol. 32: 16-21.

Snell, A. 2005. Identification keys to larval and adult female mosquitoes (Diptera: Culicidae) of New Zealand. NZ J. Zool. 32: 99-110.

Sota, T. 1998. Microhabitat size distribution affects local difference in community structure: Metazoan communities in treeholes. Res. Popul. Ecol. 40: 249255.

Stav, G., L. Blaustein, and J. Margalith. 1999. Experimental evidence for predation risk sensitive oviposition by mosquito Culiseta longiareolata. Ecol. Entomol. 24: 202-207.

Sunahara, T., K. Ishizaka, and M. Mogi. 2002. Habitat size: a factor determining the opportunity for encounters between mosquito larvae and aquatic predators. J. Vector Ecol. 27: 8-20.

Tompkins, D.M. and D.M. Gleeson. 2006. Relationship between avian malaria distribution and an exotic invasive mosquito in New Zealand. J. R. Soc. N.Z. 36: 51-62.

Townsend, C. and A.G. Hildrew. 1979. Resource partitioning by two freshwater invertebrate predators with contrasting foraging strategies. J. Anim. Ecol. 48: 909-920.

Urbinatti, P.R. 2001. Immature mosquitoes (Diptera: Culicidae) in a public city park. Rev. Sa冈de P囚blica. 35: 461-466.

Wilton, D.P. 1968. Oviposition site selection by the treehole mosquito, Aedes triseriatus. J. Med. Entomol. 5: 189-194.

Winterbourn, M.J., K.L.D. Gregson, and C.H. Dolphin. 2006. Guide to the Aquatic Insects of New Zealand. $4^{\text {th }}$ Edition. Bull. Entomol. Soc. N. Z. 108 pp.

Zuharah, W.F and P.J. Lester. 2010. Can adults of the New Zealand mosquito, Culex pervigilans (Bergorth) detect the presence of a key predator in larval habitat? J. Vector Ecol. 35: 100-105. 


\section{REFERENCES}

Allahyari H, Fard PA, Nozari J (2004) Effects of host on functional response of offspring in two populations of Trissolcus grandis on the sunn pest. J. Appl. Entomol. 128: 39-43.

Alto BW, Griswold MW, Lounibos LP (2005) Habitat complexity and sexdependent predation of mosquito larvae in containers. Oecologia. 146: 300-310.

Angelon K, Petranka J (2002) Chemical predatory mosquitofish (Gambusia affinis) influence selection of oviposition site by Culex mosquito. J. Chem. Ecol. 28: 797- 806.

Ball SL, Baker RL (1996) Predator- induced life history changes: Antipredator behavior costs or facultative life history shifts. Ecology. 77: 116-124.

Bank MJ, Thompson DJ (1987) Regulation of damselfly populations: The effects of larval density on survival, development rate and size in the field. Freshwater Biol. 17(2): 357-365.

Bar-zeev M (1957) The effects of extreme temperature on different stages of Aedes aegypti (L.). Bull. Entomol. Res. 48(3): 593- 599.

Bay EC (1974) Predator-prey relationship among aquatic insects. Annu. Rev. Entomol. 19: 441-453.

Bedhomme S, Agnew P, Sidobre C, Michalakis Y (2003) Sex specific reaction norms to intraspecific larval competition in the mosquito Aedes aegypti. J. Evolution. Biol. 16: 721-730.

Beier S, Bolley M, Traunpurger W (2004) Predator-prey interaction between Dugesia ganocephala and free-living nematodes. Freshwater Biol. 49: 77-86.

Beketov MA, Liess M (2007) Predation risk perception and food scarcity induce alterations of life-cycle traits of the mosquito Culex pipiens. Ecol. Entomol. 32: 405-410.

Belkin JN (1968) Mosquito studies (Culicidae: Diptera). VII. The Culicidae of New Zealand. Cont. Am. Entomol. Inst. 3(1): 1-182.

Bentley MD, Day JF (1989) Chemical ecology and behavioral aspects of mosquito oviposition. Annu. Rev. Entomol. 34: 401-421.

Bishop TD, Brown JA (1992) Threat-sensitive foraging by larval threespine sticklebacks (Gasterosteus aculeatus). Behav. Ecol. Sociobiol. 31: 133-138. 
Black AR, Dodson SI (1990) Demographic costs of Chaoborus induced phenotypic plasticity in Daphnia pulex. Oecologia. 83: 117-122.

Blackmore MS, Lord CC (2000) The Relationship between size and fecundity in Aedes albopictus. J. Vector Ecol. 25: 212-217.

Blaustein L (1998) Influence of predatory backswimmer, Notonecta maculata, on invertebrate community structure. Ecol. Entomol. 23: 246- 252.

Blaustein L, Blaustein J, Chase J (2005) Chemical detection of predator Notonecta irrorata by ovipositiong Culex mosquitoes. J. Vector Ecol. 30(2): 299-301.

Blaustein L, Chase JM (2007) Interactions between mosquito larvae and species that share the same trophic level. Annu. Rev. Entomol. 52: 489-507.

Blaustein L, Kiklawi M, Eitam A, Mangel M, Cohen JE (2004) Oviposition habitat selection in response to risk of predation in temporary pools: Mode of detection and consistency across experimental venue. Oecologia. 138: 300-305.

Blaustein L, Kotler BP, Ward D (1995) Direct and indirect effects of the predatory backswimmer (Notonecta maculata) on community structure of desert temporary pools. Ecol. Entomol. 20: 311-318.

Blossey B, Notzold R (1995) Evolution of increased competitive ability in invasive non indigenous plants: A hypothesis. J. Ecol. 83: 887-889.

Boersma M, Spaak P, de Meester L (1998) Predator-mediated plasticity in morphology, life history, and behaviour of Daphnia: The uncoupling of responses. Am. Nat. 152: 237-248.

Bond JG, Arredondo-Jimenez JI, Rodriguez MH, Quiroz-Martinez H, Williams $T$ (2005) Oviposition habitat selection for a predator refuge and food source in a mosquito. Ecol. Entomol. 30: 255-263.

Braune P, Rolff J (2001) Parasitism and sex in a damselfly: Does sex matter? P. Roy. Soc. London Series. B. 268: 1133-1137.

Briegel H (1990) Metabolic relationship between female body size, reserves and fecundity of Aedes aegypti. J. Insect Physiol. 36: 165-172.

Brier RA (1998) Matapopulation ecology of Notonecta in small ponds. Ph.D. thesis, University of Sheffield.

Brown ES (1943) A contribution towards an ecological survey of the aquatic water bugs of British Isles. T. Soc. Brit. Entomol. 8: 169-230. 
Brown GE, Chivers DP, Smith RJF (1997) Differential learning rates in chemical versus visual cues of a northern pike by fathead minnows in a natural habitat. Environ. Biol. Fishes. 49: 89-96.

Browne G (1994) The development of an IPM strategy of the control of Auckland mosquitoes. M.Sc. Thesis. University of Auckland.

Busvine JR (1971) A critical review of the technique for testing insecticides: Commonwealth Agricultural Bureaux, England.

Calow P (1973) The relationship between fecundity phenology and longevity: A systems approach. Am. Naturalist. 107: 559-574.

Canyon DV, Hii LJK, Muller R (1998) Adaption of Aedes aegypti (Diptera:Culicidae) oviposition behavior in response to humidity and diet. J. Insect Physiol. 45: 959-964.

Case CM, Crawley MJ (2000) Effect of interspecific competition and herbivory on the recruitment of an invasive alien plant: Conyza sumatrensis. Biol. Invasions. 2: 103-110.

Chesson J (1982) Estimation and analysis of para- sitoid search and attack parameters from field data. Environ. Entomol. 11: 531-537.

Chesson J (1983) The estimation and analysis of preference and its relationship to foraging models. Ecology. 64: 1297-1304.

Chesson J (1984) Effects of Notonectids (Hemiptera: Notonectidae) on mosquito (Diptera: Culicidae): Predation or selective oviposition? Environ. Entomol. 13: 531-538.

Chesson J (1989) The effect of alternative prey on the functional response of Notonecta hoffmani. Ecology. 70 (5): 1227-1235.

Chiver DP, Kiesecker JM, Marco A, DeVito J, Anderson MT, Blaustein AR (2001) Predator-induced life history changes in amphibians: Egg predations induce hatching. Oikos. 92: 135-142.

Cock MJW (1978) The assessment of preference. J. Anim. Ecol. 47: 805816.

Colautti RI, Ricciardi A, Grigorovich IA, Maclssac HJ (2004) Is the invasion success explained by the enemy release hypothesis?. Ecol. Lett. 7: 721-733.

Collins LE, Blackwell A (2000) The biology of Toxorhynchites mosquitoes and their potential as biocontrol agents. Biocontrol News and Information. 21: 105-116.

Cook A, Weinstein P, Woodward A (2002) The impact of exotic insects in New Zealand. In: Biological invasions: Economic and Enviromental; 
Costs of alien plant, animal, and microbe species: CRC Press: Baco Raton, USA.

Crowl TA, Covich AP (1990) Predator- induced life history shifts in a freshwater snail. Science. 247: 949-951.

Crump JA, Murdoch DR, Baker MG (2001) Emerging infectious diseases in an island Ecosystem: The New Zealand perspective. Emerg. Infect. Dis. 7: 767-772.

Darwin C (1859) On the Origin of Species by Means of Natural Selection. John Murray, London.

Derraik JGB (2004a) Exotic mosquitoes in New Zealand: A review of species intercepted, their pathways and ports of entry. Aust. NZ J. Publ. Heal. 28: 433- 444 .

Derraik JGB (2004b) A survey of the mosquito (Diptera: Culicidae) fauna of the Auckland Zoological Park. NZ Entomol. 27: 51-55.

Derraik JGB (2006) A scenario for invasion and dispersal of Aedes albopictus (Diptera: Culicidae) in New Zealand. J. Medic. Entomol. 43: 1-8.

Derraik JGB, Calisher CH (2003) Is New Zealand prepared to deal with arboviral diseases? Aust. NZ J. Publ. Heal. 28: 27-31.

Derraik JGB, Slaney D (2004) Container aperture size and nutrient preferences of mosquitoes (Diptera: Culicidae) in the Auckland region, New Zealand. J. Vector Ecol. 30(1): 73- 82.

Derraik JGB, Slaney D (2007) Anthropogenic environmental change, mosquito-borne disease and human health in New Zealand. EcoHealth. 4: 72-81.

Dodson SI (1988) Cyclomorphosis in Daphnia galeata mendotae Birge and Daphnia retrocurva forbes as a predator-induced response. Freshwater Biol. 19(1): 109- 114.

Dodson SI, Crowl TA, Perkarsky BL, Kats LB, Covich AP, Culp JM (1994) Nonvisual communication in fresh water benthos- an overview. J. N. Am. Benthol. Soc. 13: 268-282.

Dugovic C, Maccari S, Weibel L, Turek FW, Van Reeth O (1999) High corticosterone levels in prenatally stressed rats predicts persistent paradoxical sleep alterations. J. Neurosci. 19(19): 8656- 8664.

Dumbleton LJ (1968) A synopsis of New Zealand mosquitoes (Diptera: Culicidae) and a key to their larvae. Tuatara. 16(3): 167-179. 
Eitam A, Blaustein L (2004) Oviposition habitat selection by mosquitoes in response to predator (Notonecta maculata) density. Physiol. Entomol. 29: 188-191.

Eitam A, Blaustein L, Marc M (2002) Effect of Anisops sardea (Hemiptera: Notonectidae) on oviposition habitat selection by mosquitoes and other dipterans and on community structure in artificial pools. Hydrobiologia. 485: 183-189.

Ellis RA, Borden JH (1970) Predation by Notonecta undulate on larvae of yellow fever mosquito. Ann. Entomol. Soc. Am. 63: 963-973.

Elton CS (1958) The ecology of invasions by animals and plants. T. Methuen and Co., London.

Engel K, Tollrian R (2009) Inducible defenses as key adaptations for the successful invasion of Daphnia lumholtzi in North America? Proc. R. Soc. B. 276: 1865-1873.

Fay RW (1964) The biology and bionomics of Aedes aegypti in the laboratory. Mosq. News. 24: 300- 307.

Ferrari MCO, Chivers P (2008) Latent inhibition of predator recognition by embryonic amphibians. Biol. Lett. 5: 160-162.

Frank JH, Curtis GA (1977) On the bionomics of bromeliad-inhabiting mosquitoes IV. Egg mortality of Wyeomyia vanduzeei caused by rainfall. Mosq. News. 37: 239-245.

Gerritsen J, Strickler JR (1977) Encounter probabilities and community structure in zooplankton: A mathematical model. J. Fish. Res. Board. Can. 34: 73-82.

Gilbert HM, Hartman BJ (1996) Short report: A case of fibrosing mediastinitis caused by Wuchereria bancrofti. Am. J. Trop. Med. Hyg. 54(6): 596599.

Gilbert JJ, Burns CW (1999) Some observations on the diet of Backswimmer, Anisops wakefieldi (Hemiptera: Notonectidae). Hydrobiologia 412: 111-118.

Graham DH (1929) Mosquito of Auckland district. Trans. Proc. NZ Inst. 60: 205-224.

Graham DH (1939) Mosquito life in the Auckland district. Trans. R. Soc. N.Z. Biol. Sci. 69: 210-244.

Greig SH (2008) Community assembly and food web interaction across ponds permanence gradients. Ph.D. thesis, University of Canterbury. 
Griswold MW, Lounibos LP (2005) Does differential predation permit invasive and native mosquito larvae to coexist in Florida? Ecol. Entomol. 30: 122-127.

Griswold MW, Lounibos LP (2006) Predator identity and addictive effects in a treehole community. Ecology. 87(4): 987- 995.

Gyssels FGM, Stoks R (2005) Threat-sensitive responses to predator attacks in a Damselfly. Ethology. 111: 411-423.

Hagman M, Shine R (2006) Effects of invasive cane toads on Australian mosquitoes: Does the dark cloud have a silver lining?. Biol. Invasions. 9(4): 445- 452.

Hassell MP (1978) Sigmoid functional responses and population stability. Theor. Pop. Biol. 18: 75-98.

Hassell MP, Comins HN (1978) Sigmoid functional responses and population stability. Theor. Popul, Biol. 14: 62-67.

Hetchel LJ, Juliano SA (1997) Effects of a predator on prey metamorphosis: Plastic responses by prey or selective mortality. Ecology. 78: 838-851.

Havel JE (1987) Predator-induced defenses: A review. In: Kerfoot WC, Sih A (ed) Direct and indirect impacts on aquatic communities. University Press of New England, Hanover, New Hampshire. pp. 263-278.

Havel JE, Dodson SI (1984) Chaoborus predation on typical and spined morphs of Daphnia pulex: Behavioral observations. Limnol. Oceonogr. 29:487-494.

Havel JE, Dodson SI (1987) Reproductive costs of Chaoborus induced polymorphism in Daphnia pulex. Hydrobiologia. 150: 273-281.

Hazelrigg JE (1973) Investigations of the biology and predatory capacity of Notonecta unifasciata Guerin. Ph.D. thesis, University of California.

Helfman GS (1989) Threat-sensitive predator avoidance in damselfishtrumpetfish interactions. Behav. Ecol. Socialbiol. 24: 47-58.

Herper PG (1996) Fatal memory: Does it exist? What does it do? Acta. Pædiatr. Suppl. 416: 16-20.

Holder P, Brown G, and Bullians M (1999) The mosquitoes of New Zealand and their animals disease significance. Surveillance. 26: 12-15.

Holling CS (1959) The components of predation as revealed by a study of small-mammal predation of the European pine sawfly. Canad. Entomology. 91: 293-320. 
Holling CS (1965) The functional response of predators to prey density and its role in mimicry and population regulation. Mem. Entomol. Soc. Can. 45(3): 3-50.

Holt LD (1977) Predation, apparent competition, and the structure of prey communities. Theor. Popul. Biol. 12: 197- 229.

Houston Al, McNamara JM (1997) Patch choice and population size. Evol. Ecol. 11: 703-722.

Hsu SM, Yen AMF, Chen HH (2008) The impact of climate on Japanese encephalitis. Epidemiol. Infect. 136: 980-987.

Ihaka R, Gentleman R (1996) R: A language for data analysis and graphics. J. Compt. Graph. Stat. 5: 299-314.

li'chenko LI (1974) Age composition of a natural population of Culex pipiens L., blood digestion and the maturation of eggs of these mosquitoes in the vicinity of Novocherkassk (In Russian). Med. Parazitol (Mosk). 43: 14-21.

Jackson RR, Dollard SD, Li DQ, Finj N (2002) Interpopulation on variation in the risk-related dicisions of Portia labiata, an archeophagic jumping spider (Arenea saltidae), during predator sequences with spitting spiders. Anim. Cogn. 5: 215-223.

Johansson F, Wahlström E (2002) Induced morphological defense: Evidence from whole-lake manipulation experiments. Can. J. Zool. 80: 415-423.

Juliano SA (2001) Non-linear curve fitting: Predation and functional response curve In: Scheiner S, Gurevich J, editors. Design and analysis of ecological experiment. Oxford University Press, New York. Pp 178196.

Juliano SA, Reminger L (1992) The relationship between vulnerability to predation and behaviour of larval tree holes mosquitoes: Geographic and ontogenetic differences. Oikos. 63: 465-467.

Kats LB, Dill LM (1998) The scent of death: Chemosensory assessment of predation risk by prey animals. Ecoscience. 5: 361-394.

Kelly-Hope LA, Kay BH, Purdie DM (2001) The risk of Ross River and Barmah Forest virus disease in Queensland: Implication for New Zealand. Aust. NZ J. Publ. Heal. 26: 69-77.

Kesarajavu B, Damal K, Juliano SA (2006) Threat-sensitive behavioral responses to concebtrations of water-borne cues from predation. Ethology. 113: 199-206.

Kiflawi M, Blaustein L, Mangel M (2003a) Oviposition habitat selection by the mosquito Culiseta longiareolata in response to risk of predation and conspecific larval density. Ecol. Entomol. 28: 168-173. 
Kiflawi M, Blaustein L, Mangel M (2003b) Predation-dependent oviposition habitat selection by the mosquito Culiseta longiareolata: A test of competing hypotheses. Ecol. Lett. 6: 35-40.

Kindlmann P, Dixon AFG (2001) When and why top-down regulation fails in arthropod predator-prey systems. Basic Appl. Ecol. 2: 333-340.

Klowden MC (1993) Mating and nutritional state effect the reproduction of Aedes albopictus mosquitoes. J. Am. Mosq. Cont. Assoc. 9: 169 -173.

Koenraadt CJM, Githeko AK, Takken W (2004) The effects of rainfall and evapotranspiration on the temporal dynamics of Anopheles gambiae s.s. and Anopheles arabiensis in Kenyan village. Acta Trop. 90: 141153.

Koivisto S, Arnér M, Kautsky N (1997) Does cadmium pollution change trophic interactions in rockpool food webs?. Envir. Tox. Chem. 16: 1330-1336.

Koperski P (1997) Changes in feeding behavior of larvae of the damselfly Enallagma cyathigerum in response to stimuli from predators. Ecol. Entomol. 22: 167-175.

Kusch RC, Mirza RS, Chiver DP (2004) Making sense of predator scents: Investigating the sophistication of predator assessment abilities of fathead minnows. Behav. Ecol. Sociobiol. 55: 551-555.

Laforsch C, Beccara L, Tollrian R (2006) Inducible defense: The relevance of chemical alarm cues in Daphnia. Limnol. Oceanogr. 51(3): 1466-1472.

Laird M (1990) New Zealand's Northern mosquito survey 1988-89. J. Am. Mosq. Control Assoc. 6: 287-299.

Laird M (1995) Background and findings of the 1993-94 New Zealand mosquito survey. NZ Entomol. 18: 77-90.

Laird M, Calder L, Thorton RC (1994) Japanese Aedes albopictus among four mosquito species reaching New Zealand in used tyres. J. Am. Mosq. Cont. Assoc. 10: 14-23.

Lang HH (1980) Surface-wave discrimination between prey and non-prey by the backswimmer Notonecta glauca L. (Hemiptera, Heteroptera). Behav. Ecol. Sociobiol. 6(3): 233-246.

Laurila A, Kujasalo J, Ranta E (1997) Different antipredator behavior in two anuran tadpoles: effects of predator diet. Behav. Ecol. Sociobiol. 40: 329-336.

Laurila A, Kujasalo J, Ranta E (1998) Predator-induced changes in life history in two anuran tadpoles: Effects of predator diet. Oikos. 83: 307317. 
Lee DJ, Hick MM, Griffith M (1982) The Culicidae of Australian Regions. Australian Government Publishing Service, Canberra.

Lee FC (1967) Laboratory observations on certain mosquito predators. Mosq. News. 27: 332-338.

Leisnham PT, Lester PJ, Slaney DP, Weinstein P (2006) Relationship between mosquito densities in artificial container habitats, land use and temperature in the Kapiti-Horowhenua region, New Zealand. NZ J. Mar. Freshw. Res. 40: 285-297.

Lester PJ, Pree DJ, Thistlewood HMA, Trevisan LM, Harmsen R (1999) Pyrethroid encapsulation for the conservation of acarine predators and reduced spider mite (Acari: Tetranychidae) outbreaks in apple orchards. Environ. Entomol. 28: 72-80.

Lester PJ, Harmsen R (2002) Functional and numerical response do not always indicate the most effective predator for biological control: An analysis of two predators in a two-prey system. J. Appl. Ecol. 39: 455468.

Lester PJ, Pike AJ (2003) Container surface area and water depth influence the population dynamics of the mosquito Culex pervigilans (Diptera: Culicidae) and its associated predator in New Zealand. J. Vec. Ecol. 28(2): 267- 274.

Lester PJ, Yee KM, Yee S, Haywood J, Thistlewood HMA, Harmsen R (2005) Does altering patch number and connectivity change the predatory functional response type? Experiment and simulations in an acarine predator-prey system. Can. J. Zool. 83: 797-806.

Lima SL (1998) Non-lethal effects in the ecology of predator-prey interactions- what are the ecological effects of anti-predator decision making?. BioSci. 48: 25-34.

Lima SL, Dill LM (1990) Behavioral decisions made under the risk of predation: A review and prospectus. Can. J. Zool. 68: 619-640.

Lindsay MD, Broom AK, Wright AE (1993) Ross river virus isolation from mosquitoes in arid regions of Western Australia: Implication of vertical transmission as a means of persistence of the virus. Am. J. Trop. Med. Hyg. 49: 686-696.

Lounibos LP, Nishamura N, Escher RL (1993) Fitness of a treehole mosquito-influence of food type and predation. Oikos. 66: 114-118.

Lundkvist E, Landin J, Jackson M, Svessons C (2003) Diving beetles (Dystiscidae) as predators of mosquito larvae (Culicidae) in field experiment and in laboratory tests of prey preferences. Bull. Entomol. Res. 93: 219-226. 
Maguire T, Miles JAR, Casals J (1967) Whataroa virus, a group of a arbovirus isolated in South Westland, New Zealand. Am. J. Trop. Med. Hyg. 16: 371-373.

Manly BFJ (1974) Model for certain types of selection experiments. Biometrics. 30: 281-294.

Maron JL, Vilá, M (2001) When herbivores affect plant invasion? Evidence for the natural enemies and biotic resistance hypotheses. Oikos. 95: 361-373.

Massey B, Glesson DM, Slaney D, Tompkin DM (2007) PCR detection of Plasmodium and blood-meal identification in a native New Zealand mosquito. J. Vec. Ecol. 32(1): 154-156.

Mathis A, Ferrari MCO, Windel N, Messier F, Chivers DP (2008) Learning by embryos and the ghost of predation future. Proc. R. Soc. B. 275: 26032607.

Mathis A, Murray KL, Hickman CR (2003) Do experience and body size play a role in responses of larval ringed salamander, Ambystoma annulatum, to predator kairomones? Laboratory and field assays. Ethology. 109: 159-170.

Mclntosh AR, Peckarsky BL (2004) Are mayfly anti-predator responses to fish odour proportional to risk?. Arch. Hydrobiol. 160(2): 145-151.

Mclntosh AR, Peckarsky BL, Taylor BW (1999) Rapid size-specific changes in drift of Baetis bicaudatus (Ephemeroptera) caused the alterations in fish odour concentration. Oecologia. 118: 256-264.

Mclntosh AR, Peckarsky BL, Taylor BW (2000) The influence of predatory fish on mayfly drift: Extrapolating from experiments to nature. Freshwat. Biol. 47: 1497-1513.

McLean DM (1953) Transmission of Murray Valley enchephalitis virus by mosquitoes. Aust. J. Experimen. Biol. Med. Sc. 31: 481-490.

McPeek MA, Miller TE (1996) Evolutionary biology and community ecology. Ecology. 77: 1319-1320.

Mikolajewski DJ, Brodin T, Johansson F, Joop G (2005) Phenotypic plasticity gender specific life-history: Effects of food availability and predation. Oikos. 110: 91-100.

Miles JAR (1973) The ecology of the Whataroa virus an alphavirus in South Westland, New Zealand. J. Hyg. (Cambridge). 73: 701-713.

Mirza RS, Manthis A, Chiver DP (2006) Does temporal variation in predation risk influence the intensity of anti-predator responses? A test of the risk allocation hypothesis. Ethology. 112: 44-51. 
Moses JL, Sih A (1998) Effects of predation risk and food availability on the activity, habitat use, feeding behavior and mating behavior of a pond water strider, Gerris marginatus (Hemiptera). Ethology. 104: 661-669.

Murdoch WW (1973) The functional response of predators. J. App. Ecol. 10: 335-342.

Murdoch WW, Scott MA (1984) Stability and extinction of laboratory population of zooplankton preyed on the backswimmer Notonecta. Ecology. 65: 1231-1248.

Murdoch WW, Scott MA, Ebsworth P (1984) Effects of general predator, Notonecta (Hemiptera) upon a freshwater community. J. Anim. Ecol. 53: 791-808.

Murdoch WW (1969) Switching in general predators: Experiments on predator specificity and stability of prey populations. Ecol. Monogr. 4: 335-354.

Murdoch WW, Oaten A (1975) Predation and population stability. Adv. Ecol. Res. 9: 1-132.

Nabaneeta S, Gautum A, Animesh B, Saha GK (2007) Comperative study of functional response of common hemipteran bugs of east Calcutta wetlands, India. Int. Rev. Hydrobiol. 92: 242-257.

Nylin S, Gothard K (1998) Plasticity in life-history traits. Annu. Rev. Entomol. 43:169-173.

Paine RT (1969) The Pisaster regula interaction, prey patches, predator food preferences and intercidal community structure. Ecology. 50: 950-961.

Peacor SD, Werner EE (2000) Predator effects on an assemblage of consumers through induced changes in consumer foraging behavior. Ecology. 81: 1998-2010.

Pech RP, Sinclair ARE, Newsome AE, Catling PC (1992) Limits the predator regulation of rabbits in Australia: Evidence from predator-removal experiments. Oecologia. 89: 102-112.

Peckarsky BL (1982) Aquatic insect predator-prey relations. BioScience. 32 (4): 261-266.

Peckarsky BL, Cowan CA, Penton MA, Anderson CR (1993) Sublethal consequences of stream-dwelling predatory stoneflies on mayfly growth and fecundity. Ecology. 74: 1836-1846.

Perkarsky BL (1996) Alternative predator avoidance syndromes of streamdwelling mayfly larvae. Ethology. 77: 1888-1905.

Pervez A, Omkar (2005) Functional responses of coccinellid predators: An illustration of a logistic approach. J. Insects Sc. 5: 1-6. 
Petrusek A, Tollrian R, Schwenk K, Haas A, Laforsch C (2008) A "crown of thorns" is an inducible defense that protects Daphnia against an ancient predator. PNAS. 106(7): 2248-2252.

Platonon AE, Fedorova MV, Karan LS, Shopenskava TA, Platonova OV, Zhuravlev VI (2008) Epidemiology of West Nile infection in Volgograd, Russia, in relation to climate change and mosquito (Diptera: Culicidae) bionomics. Parasitol. Res. 103: S45-S53.

Reynolds JG, Geddes MC (1984) Functional response analysis of size selective predation by the notonectid predator Anisops deanei (Brooks) and Daphnia thomsoni (Sars). Aus. J. Mar. Freshw. Res. 35(6): 725- 733.

Ritchie S, Rochester W (2001) Wind-blown mosquitoes and introduction of Japanese encephalitis into Australia. Emerg. Infect. 7: 900-903.

Rochette R, Dill LM, Himmelman JH (1997) A field test of threat sensitivity in a marine gastropod. Anim. Behav. 54: 1053-1062.

Rogers DJ (1972) Random search and insect population models. J. Anim. Ecol. 41: 369-383.

Russell BM, Wang J, Williams Y, Hearnden MN, Kay BH (2001) Laboratory evaluation of two native fishes from tropical North Queensland as biological control agents of subterranean Aedes aegypti. J. Am. Mosq. Cont. Assoc. 17 (2): 124-126.

Russell RC (1993) Mosquito and mosquito-borne disease in southern Australia: A guide to the biology, relation to disease, surveillance, control and the identification of mosquito in southern Australia. University of Sydney.

Russell RC (1995) Arbovirus and their vectors in Australia: An update on the ecology and epidemiology of some mosquito arboviruses. Rev. Med. Vet. Entomol. 83: 141-158.

Sagata K, Lester PJ (2009) Behavioral plasticity associated with propagule size, resources and the invasion success of the Argentine ants Linephitema humile. J. App. Ecol. 46: 19-27.

Schenk D, Bacher S (2002) Functional response of a generalist insect predator to one of its prey species in the field. J. Anim. Ecol. 71(3): 524-531.

Scott MA, Murdoch WW (1983) Selective predation by the backswimmer, Notonecta. Limnol. Oceonogr. 28: 352-366.

Service MW (1995) Mosquito Ecology: Field Sampling Methods. Chapman and Hall, London 
Service MW (1996) Medical Entomology for Students. Chapman and Hall, United Kingdom.

Service MW (2000) Medical Entomology for Student. Cambridge University Press, United Kingdom.

Service MW (2004) Medical Entomology for Students, 3rd edn. Chapman and Hall, United Kingdom.

Shaalan EA, Canyon DV, Muller R, Younes MWF, Abdul-Wahab H, Mansour A (2007) A mosquito survey in Townsille, Australia and an assessment of Diplonychus sp. and Anisops sp. predatorial capacity against Culex annulirostris mosquito immature. J. Vector Ecol. 32(1): 16-21.

Sih A (1980) Optimal behavior: Can foragers balance two conflicting demand?. Science. 210: 1041-1043.

Sih A (1986) Antipredator responses and the perception of danger by mosquito larvae. Ecology. 67: 434-444.

Sih A (1987) Predator and prey lifestyles: An evolutionary and ecological overview. In: Kerfoot WC, Sih A, editor. Predation: Direct and indirect impacts on aquatic communities. University Press of New England, England. pp. 203- 224.

Sih A, Moore RD (1993) Delayed hatching of salamander eggs in response to enhanced larval predation risk. Am. Nat .142: 947-960.

Smith ME, Belk MC (2001) Risk assessment in western mosquitofish (Gambusia affinis): Do multiple cues have addictive effects?. Behav. Ecol. Sociolbiol. 51: 101-107.

Snell A (2005) Identification keys to larval and adult female mosquitoes (Diptera: Culicidae) of New Zealand. NZ J. Zool. 32: 99-110.

Sol D, Timmermans S, Lefebvre L (2002) Behavioral flexibility and invasion success in birds. Anim. Behav. 63: 495-502.

Sota T (1998) Microhabitat size distribution affects local difference in community structure: Metazoan communities in treeholes. Res. Popul. Ecol. 40: 249- 255.

Spencer M, Blaustein L, Cohen JE (2002) Oviposition habitat selection by mosquitoes (Culiseta longireolata) and consequences for population size. Ecology. 83(3): 669-679.

Spurr EB, Sandlatt GR (2004) Risk assessment for the establishment of West Nile Virus in New Zealand. 31pp.

Statistic New Zealand (2008) Measuring New Zealand's progress using a sustainable development approach: 2008. Topic 5: Land Use. 
Retrieved September $\quad 14^{\text {th }}, \quad 2009, \quad$ from http://www.stats.govt.nz/Publications/NationalAccounts/sustainable$\underline{\text { development/land-use.aspx }}$

Stav G, Blaustein L, Margalith J (1999) Experimental evidence for predation risk sensitive oviposition by mosquito Culiseta longiareolata. Ecol. Entomol. 24: 202-207.

Stav G, Kotler BP, Blaustein L (2007) Direct and indirect effects of dragonfly (Anax imperator) nymphs on green toad (Bufo viridis) tadpoles. Hydrobiol. 579: 85-93.

Stibor H (1992) Predator induced life-history shifts in a fresh water cladoceran. Oecologia 92: 162-165.

Stream FA (1974) Size and competition in Connecticut Notonecta: In Beard R.L. (ed.) $25^{\text {th }}$ Anniversary Memoir, Connecticut Entomology Society, New Heaven. p 215-225

Sunahara T, Ishizaka K, Mogi M (2002) Habitat size: a factor determining the opportunity for encounters between mosquito larvae and aquatic predators. J. Vector Ecol. 27: 8-20.

Sweney TL, Barr R (1978) Sex ratio distortion by meiotic drive in a mosquito. Genetics. 88(3): 427- 446.

Taniguchi H, Nakano S, Tokeshi M (2003) Influences of habitat complexity on the diversity and abundance of epiphytic invertebrates on plants. Freshwater Biol. 48(4): 718-728.

Taniguchi H, Tokeshi M (2004) Effects of habitat complexity on benthic assemblages in a variable environment. Freshwater Biol. 49(9): 11641178.

Tollrian R (1995) Predator-induced morphological defenses: Costs, lifehistory shifts and maternal effects in Daphnia pulex. Ecology. 76: 1691-1705.

Tompkins DM, Gleeson DM (2006) Relationship between avian malaria distribution and an exotic invasive mosquito in New Zealand. J. R. Soc. NZ. 36(2): 51-62.

Townsend C, Hildrew AG (1979) Resource partitioning by two freshwater invertebrate predators with contrasting foraging strategies. J. Anim. Ecol. 48: 909-920.

Tschanz B, Bacher LF, Bacher S (2007) Functional responses: A question of alternative prey and predator density. Ecology. 88: 1300-1308.

Turner AM (2004) Non-lethal effects of predators on prey growth rates depend on prey density and nutrient additions. Oikos. 104: 561-569. 
Urbinatti PR (2001) Immature mosquitoes (Diptera: Culicidae) in a public city park. Rev. Saủde Pủblica. 35: 461-466.

Van Buskirk J (2000) The cost of an inducible defense in anuran larvae. Ecology. 81: 2813-2821.

van der Hurk AF, Nisbet DJ, Hall RA, Kay BH, McKenzie JS, Rithcie SA (2003) Vector competence of Australian mosquito (Diptera: Culicidae) for Japanese encephalitis virus. J. Med. Entomol. 40: 82-90.

Waldman B (1982) Quantitative and development analyses of the alarm reaction in the zebra danio Brachydanio rerio. Copeia. 1982: 1-9.

Walls M, Ketola M (1989) Effects of predator-induced spines on individual fitness in Daphnia pulex. Limnol. Oceanogr. 34: 390-396.

Watson TM, Kay BH (1998) Vector competence of Aedes notoscriptus (Diptera: Culicidae) for Ross River virus in Queensland, Australia. J. Med. Entomol. 35: 104-106.

Weinstein P, Laird M, Browne G (1997) Exotic and endemic mosquitoes in New Zealand as potential arbovirus vectors. Ministry of Health, Wellington, New Zealand.

Weinstein P, Laird M, Browne G (2007) Mosquito in New Zealand as potential Arbovirus vectors. Ministry of Health, New Zealand. pp16. ISBN 0-478-09498-1.

Weissman-Strum A, Kindler SH (1963) Hatching of Aedes aegypti (L.) eggs, a two- stages mechanism. J. Ins. Physiol. 9: 839-847.

Werner EE (1991) Nonlethal effects of a predator on competitive interactions between two anurans larvae. Ecology. 72(5): 1709-1720.

Werner EE, Anholt BA (1996) Predator-induced behavioral indirect effects: Consequences to competitive interaction in anuran larvae. Ecology. 77: 157-169.

Williams CR, Ritchie SA, Whelan PI (2005) Potential distribution of the Asian disease vector Culex gelidus Theobald (Diptera: Culicidae) in Australia and New Zealand: A prediction based on climate suitability. Aust. J. Entomol. 44: 425-430.

Wilton DP (1968) Oviposition site selection by the tree-hole mosquito, Aedes triseriatus. J. Med. Entomol. 5: 189-194.

Winterbourn MJ, Gregson KLD, Dolphin CH (2006) Guide to the aquatic insects of New Zealand. $4^{\text {th }}$ Edition. Bulletin of the Entomological Society of New Zealand. 108p.

Wisenden BD (2000) Olfactory assessment of predation risk in the aquatic environment. Phil. Trans. R. Soc. Lond. B355: 1205-1208. 
Wooster D, Sih A (1995) A review of the drift and activity responses of stream prey to predator presence. Oikos. 73: 3-8.

World Health Organization (1996) Report of the WHO informal consultation on the evaluation and testing of insecticides. CTD/WHOPES/IC/96.1. WHO. Geneva: Switzerland. 66 p.

Young EC (1970) Seasonal changes in populations of Coroxidae and Notonectidae (Hemiptera: Heteroptera) in New Zealand. Trans. R. Soc. N. Z. Biol. Sci. 12: 113-130.

Zuharah WF, Lester PJ (2010) Can adults of the New Zealand mosquito Culex pervigilans (Bergorth) detects the presence of a key predator in larval habitat? J. Vector Ecol. 36(1): 100-105.

Zuharah WF, Lester PJ (2010) The influence of aquatic predator on mosquito abundance in animal drinking troughs in New Zealand. J. Vector Ecol. 36(2): In Press A (accepted on 10 May 2010).

Zuharah WF, Lester PJ (2010) Are exotic invaders less susceptible to native predators? A test using native and exotic mosquito species in New Zealand. Pop. Ecol. In Press B (accepted on 10 July 2010) 